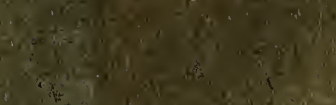

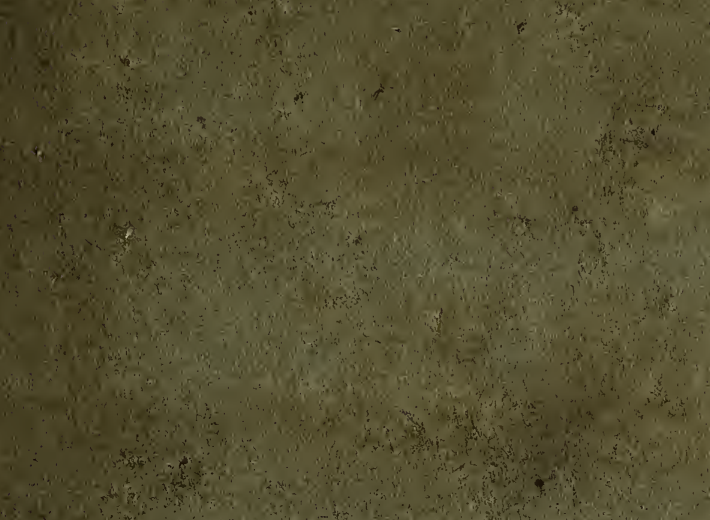

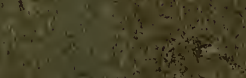
(2.

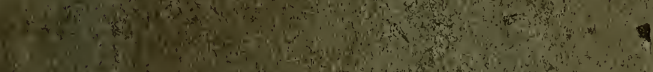

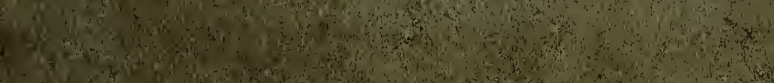

$x^{2}$

(1)

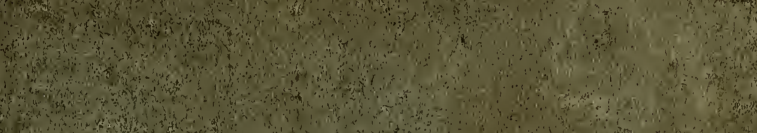

Het

Q

(f)

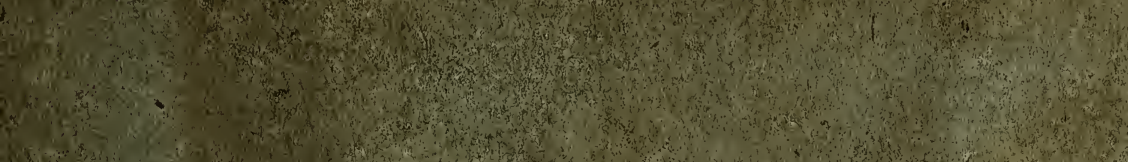

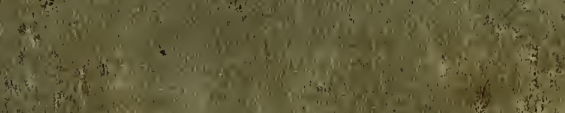

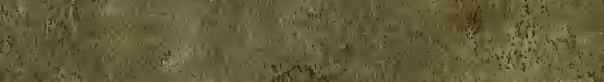
$\frac{1}{2}$

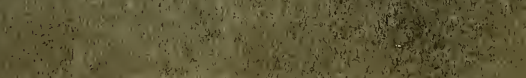
we?

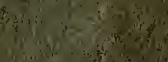
45

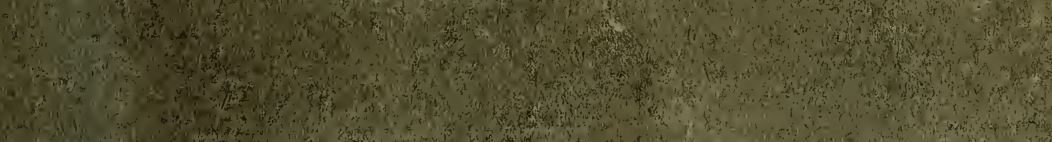
93 $w^{4}-y^{2} y^{2}$
(1)
$y^{2}$

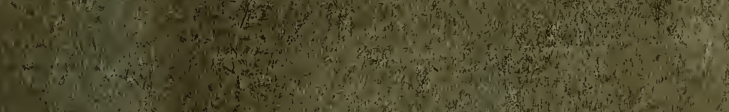

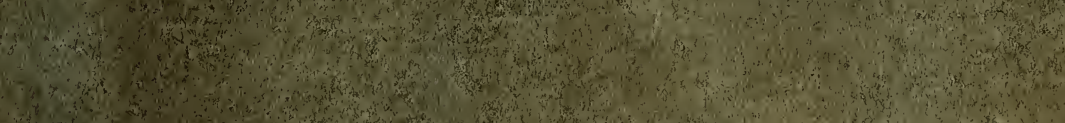

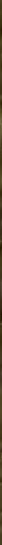


* 25458

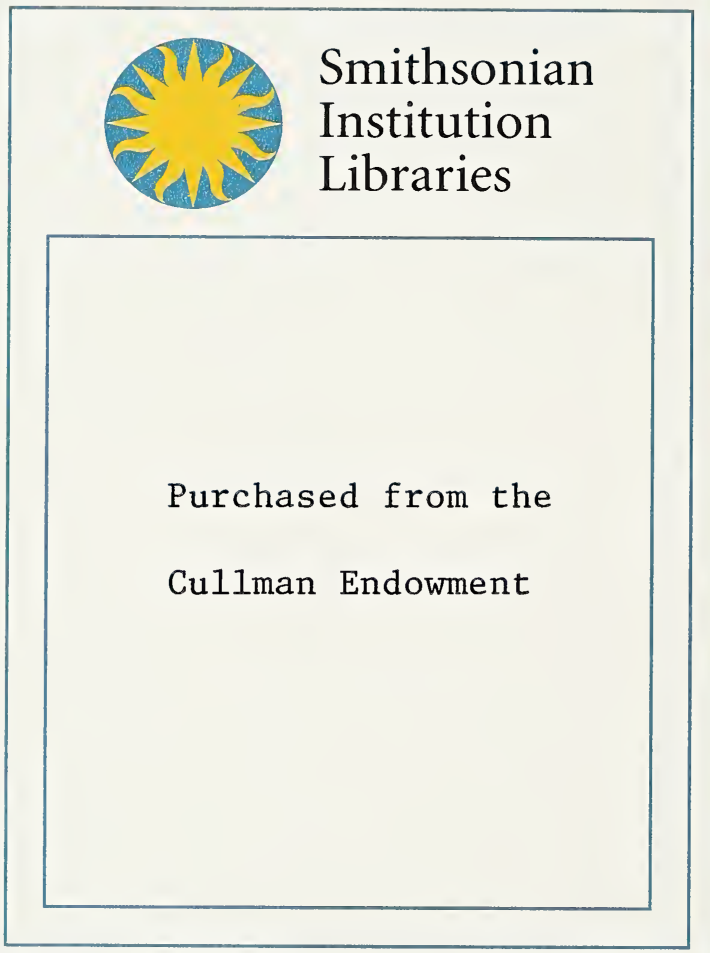





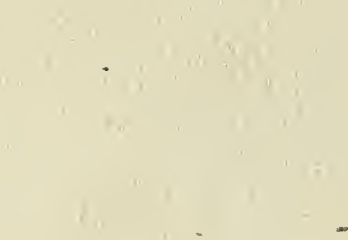

. 


\section{IN FRONTEM LIBRI.}

NOrica dumgremio tellins conchylia fundit

I Saxea, qua qroondam teft a fuere maris:

Dumglebas inter medicas, marmorg met allumque

Et lapidum formas monft ra marina jacent:

His fiupuit vifis pelago Nepiunus in alto ;

1 Sic, ait, 6 tellus caerula regna ienet?

Tellus, quam dudum prodens Deus ab/cidit undis Et fibi res proprias juffit babere fuas?

Tum venit in mentem merfifemel orbis imago,

Quum gravis Oceano mift a nat aret bumus.

Tunc, ubi placatum terris mare funera liqvit.

Multa fimul tumulis obrut a concha fuit.

Qve vero, o. Numen! (pergit) tot fecula durant?

Sedula qua rurfum collig it if a manus?

Dific bomo noffe Deum /unmism, qui talia preft at,

Et Collectori lingra animogre fare!

Interprete

Johanne Ginielmo Bajero, P.P.

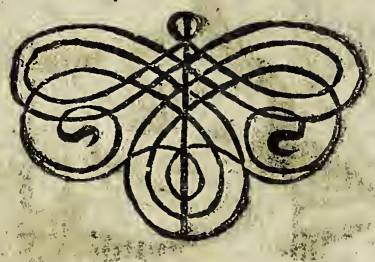

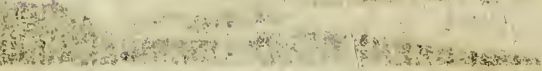




\section{JOH. JACOBI BAJERI,} PHILOS. ET MED. D. HVJVSQVE IN ACAD. ALTDORF. PROF. PVBL.

ILLVSTR. REIP. NORIMB. PHYSICI

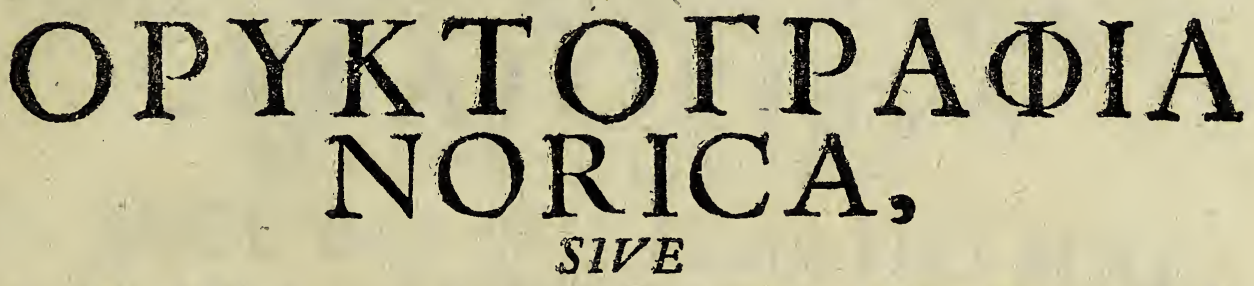

RERVM FOSSILIVM ET

AD MINERALE REGNVM PERTINENTIVM, IN

TERRITORIO NORIMBERGENSI EJVSQVE VICINIA OBSERVATARVM.

SVCCINCTA

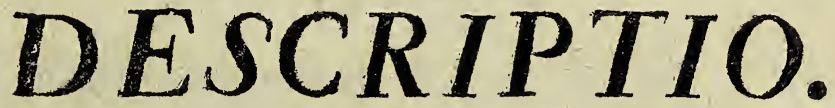

CVM ICONIBVS LAPIDVM FIGVRATORVM FERE DVCENTIS.

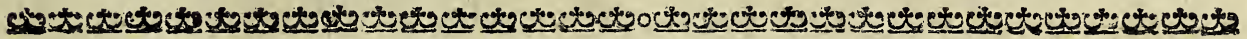

$$
\text { XORIMBERGA, }
$$

IMPENSIS WOLFGANGI MICHAHELLIS, BIBLIOPOL AN NO MDCCIIX. 
. VRGUA IgODAL .HOL

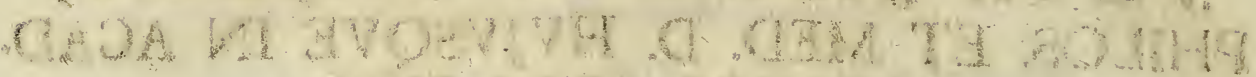

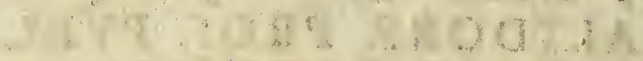

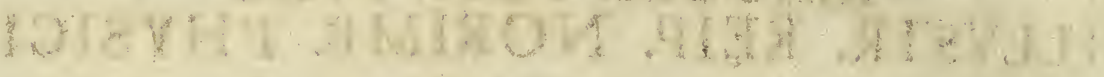

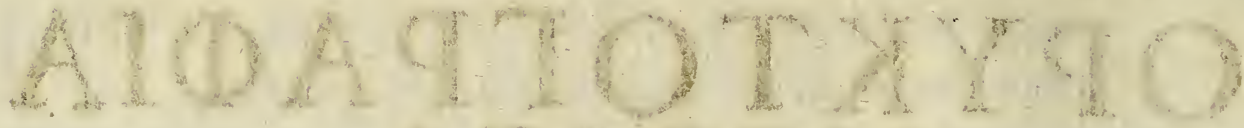

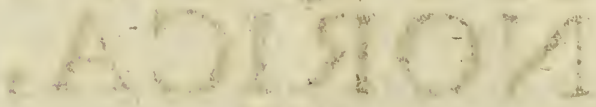

$$
\begin{aligned}
& \text { if }
\end{aligned}
$$

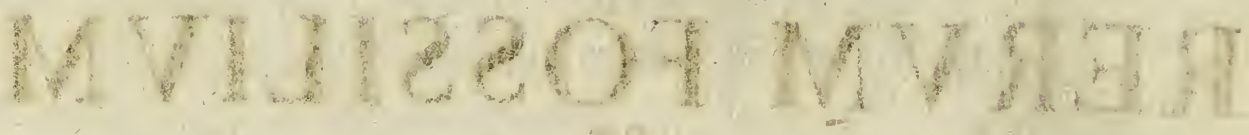

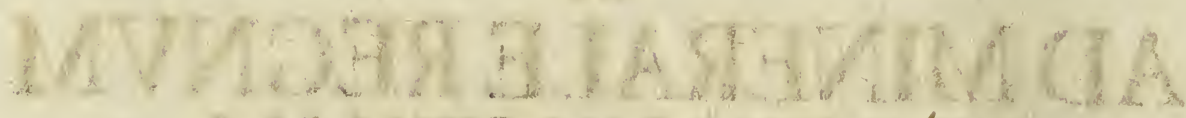

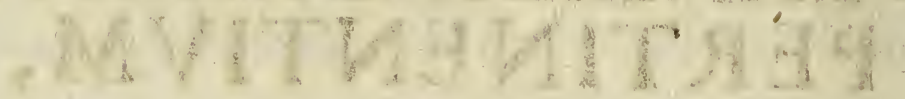

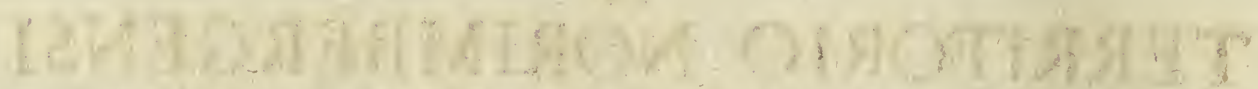

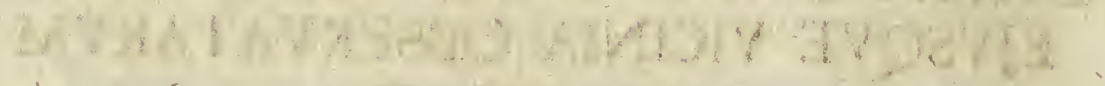

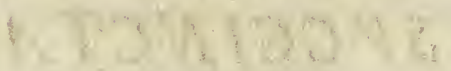

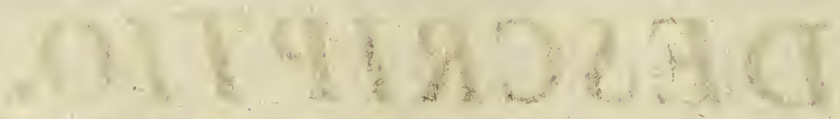

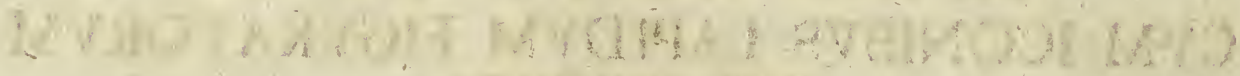

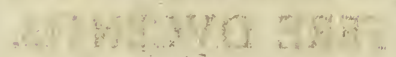

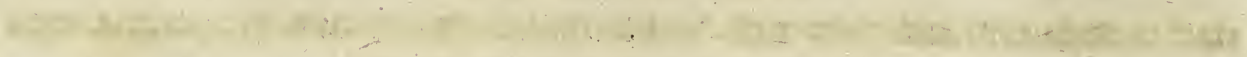

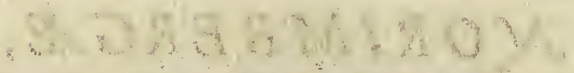

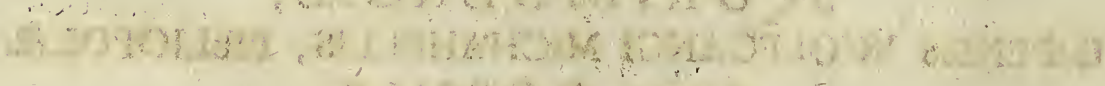

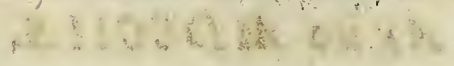


$108 \times$ ILLVSTRIBVS, GENEROSISSIMIS SCNHRE do PRVDENTISSIMIS

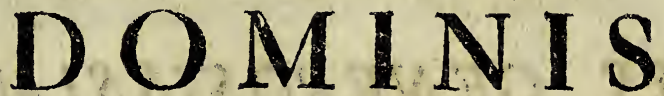

ACADEMIE ALTDORFFINE

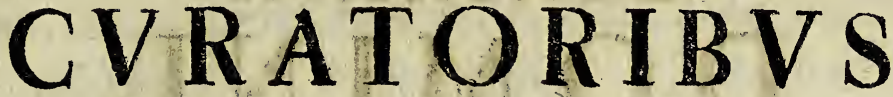
SPLENDIDISSIMIS,

DN. JACOBO WILIBALDO HALLERO

ab Hallertein,

Inclytæ Reip. Norimberg. Septemviro, Ecclefiarum Ephoro \& Proto-Scholarchæ,

DN. CHRISTOPHORO FV̈RERO ab Haymendorff, in Wolkersdorff,

DN. GVSTAVO GEORGIO TEZELIO à Kirchfittenbach, in Vorra \& Artelshofen,

DN. CHRISTOPHORO ANDREA TVCHERO

à simmelsdorff \&W Winterftein,

EJVSDEM EMINENTISSIM E REIP. SENATORIBVS CONSVIA. RIBVSET SCHOLARCHIS

DOMINIS meis jugi obfervantia demiffe colendis,

VITAM ET FELICITATEM! 


\section{1. \\ ILLVSTRES, GENEROSISSIMI AC PRV- DENTISSIMI

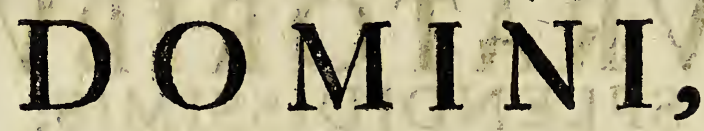 \\ DC ECENATES jugi obfervantis demifle colendi.}

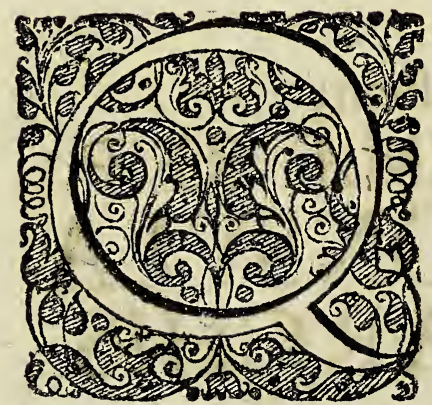

Vinqvennium fere eft, ex qvo, fingulari VEST RA fublevatus gratia, in hoc amoeniffimum Academix umbraculum, pothabita Ratisponæ opima Praxi Medica, fecesfi: cumqve per id tempus (qvod DEI Veftrumqve, DOMINI ac MECENATES, beneficium eft) optatisfima

tran- 
tranqvillitate ftudia mea fruerentur, aqvum effe duxi, non minus otii mei, qvam negotii VOBIS reddere rationem. Atqve hujus quidem indices VOBIS, Mufarum noftrarum Prafidibus, ftato tempore exhibemus, iftius autem qualescunqve fructus prefens opella fiftit. Quando enim ftatim à meo ad hoc munus acceffu deprehendi, fatorum benignitate eas me incolere terras, in qvas rerum foffilium copias, alibi latisfime fparfas, velut in compendium redegerit natura, id egi, ut horas à publici officii curis vacuas, qvasque fanitatis caufa motioni corporis dare folemus, perquirendxe huic regioni \& vicinitati impenderem. Excitare me potuit ad hoc opus fufcipiendum, preter infitam in ifta ftudia propenfionem, laudatisfimum exemplum Antecefforum meorum, pott fata qvoqve mihi venerandorum, qvi Flor a Altdorffina: collectas delicias maximo Philiatrorum commodo pofteritati confecrarunt. Qvare \& me juventuti Academicx, cui ducendx fum deltinatus, rem gratam atqve utilem preftiturum putavi, fi poft cognitam luftratamqve viridantis telluris fuperficiem, ad interiora qvoqve fpectanda viam ipfis preirem, fi cupidis fcientix animis oftenderem, coli folique noftri clementiam veluti qvoddam mufeum, variis naturæ donis refertum, \& abs omnibus gratis ufurpandum, undigve circa nos inftruxiffe. Hoc fine igitur libellum iftum, qvem VOBIS, PATRONI MAXIMI, fubmiffe offero, confcripfi, hoc fine eundem 
dem publici juris feci, nullus dubitans, qvin \& Vos pro fumma xqvitate Veftra, \& in hanc Vniverfitatem fudio. rum benigna voluntate, conatus faltem meos probaturi fitis, nec damnaturi iftam audaciam, qwæ ILLVSTRI A NOMINA VESTRA paginis his juffit prefcribere. Ita Deus Vos fervet, fanctumqve ac Iplendidum Ordinem Veftrum, qvem Vnius in Coelum abitus nuper imminuit, Alterius mox aufpicata cooptatio fupplevit, integritate valetudinis, felicitate regiminis, meritorum perenni gloria augeat $\&$ amplificet!

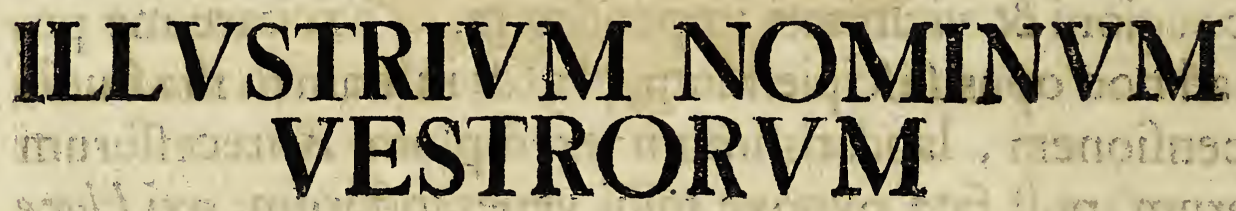

cultor Ecliens devotifimus

JOH. JACOBVS BAJERVS.

PREFA. 


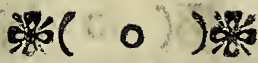
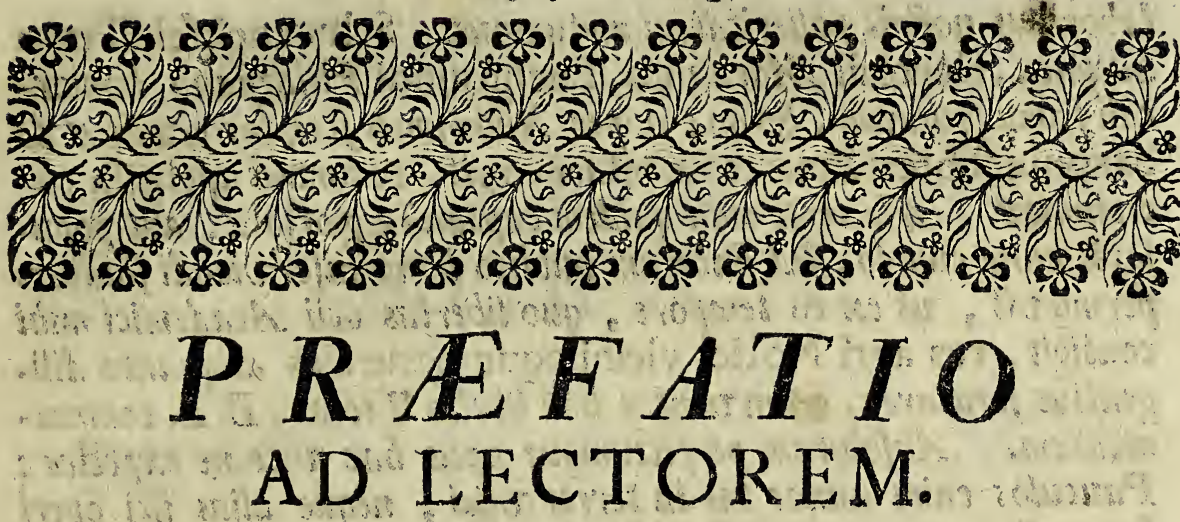

Uo majori fludio ea naturalis biflorie pars, que - Foffilia tradat, apud exteras nationes bodie ex4 - 1 colitur, eo magis dolendum eft, Germanorum - 15oftrorum bic deficere indufriam. Habuimus (1) dum, Gefnerum, Kentmannum, Fabricium, Encelium, Viros egregios, fua laude non defraudandos: At noftro evo paucos invenias, illorum prementes veftigia, plevisque funtuum five metu, five penuria deterritis, vel etiam cir$c a$ Lapidum figuratorum originem vulgi perfuafione occupati, meros bos effe nature lufus, feria inquifitione indignos. Clariffimus inter Anglos Eduard. Luidius, munificentia Procerum nixus, alacriter conquirere potvit Patria fue curiofos lapides, de. fcriptosque typis mandare: Dodiffimus Scheuchzerus Tigarini Mag:fratus ampliffimi autoritatem in condenda Helvetie naturali biftoria ducem babet: Noftris autem in regionbus rarior eft illa Magnatum gratia. Neque tamen crediderim, nos sdeo omni negledi officii culpa vacare, aut naturalem Germaniæ hiforiam minus feliciter proceffuram, dummodo Medicorum aut Pbilofophorum quirque in fuo, quem incolit angulò, debitam curam, E vel atium faltem, ei impendat. Non etiam eft, curingratamb $x x$, babo. 


\section{然( 0 ) $)$ 影}

labonus noftris pofteritatem metuamus. Schwenckfeldii enim Silefiaca, Hertodi Moravica, Lachmundi Hildefiana, immortali fama frutuntur, Éque nuper Anonymus scriptor eruditus de Saxonia fubterranea commentari copit, communi applaufu excipiuntur. Me certe non quidem captande gloriole, aut popu. laris aure cupido, fed fincerum publico bono inferviendi fludium permovit, ut ex eo tempore, quo libertas otii Academici mibi contigit, res agri Norici viciniæque naturales aliquanto diligentius fcrutarer, Es inventas boc libello Tecum, B. L. communicarem. Abjolutum perfedtumque opus bac vice ne expedes : Pauculos enim annos bis in terris vixi, neque alias ifti operi boras dicare potui, nifi fubcifivas, of a publico munere vacuas. Accedit, quod fine duce me in boc pelagus immiferim, quodque ante me plures (uti eos vel fortuna ${ }^{\circ}$ cafus, vel querendi indufria juvit) numerofa foffilium noftratium pecimina exporta. verint, quse fi in me incidifent, pleniorem reddere banc opellam potuiffent. Forte erit, ut laudatus D. Scheuchzerus, Altdorffine noftre quondam Civis, in bis fudiis or Arte Medica indefeffus, è colledis the fauris plura bic pratermiffa expromat in pu-

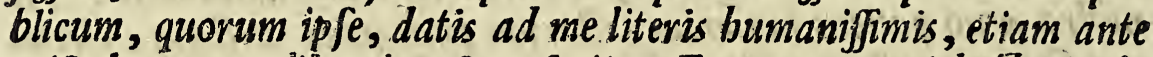
vifa bac mea, liberalem pem fecit. Ego vero, qui badenus ह5 fumtus non exiguos, Eoperam non omnino null am in bec curio. $\int a$ contuli, in pofterum quoque ea ulterius profequi, $f i$ vitam viresque largietur Deus, pergam. Adeo enim, dum bec frribo, nova fubinde fe offerunt notatu digna, ut fupplementum neque parvum neque contemnendum aliquando polliceri queass.

Vale interim, Es hec paucula boni confule. 


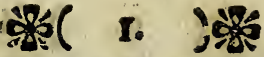

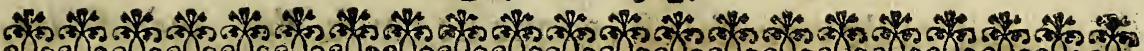

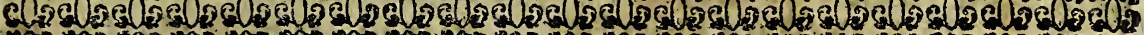
H. c.

\section{ORYGTOGRAPHIA NORICA $C_{A P} P T$ T.}

\section{DE SITV ET NATVRA AGRI} NORIC Grion antio

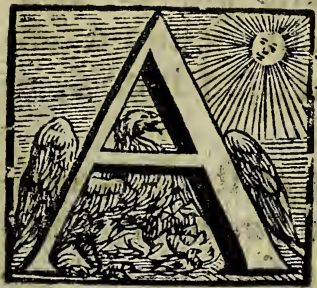

Ntiqua Noricorum Regio Danubium inter \& Alnum fluvios montemque Cetium fuiffe fertur $(q)$, quibus illi fedibus, crudelitate Hunnorum depulfi, ultra Danubium concefferunt (b), eumque Germanic tractum occuparunt, qui hodienum ab isdem oas Norogă appellatur. De finibus equidem recentioris hujus Norici disfentiunt Chorographi, fine dubio tamen caput ipfius ac pracipuam partem confituit, vel folo nominis indicio, $N o=$ rimberca eminentiflima, cum fas terricorio.

Hic itaque mihi NORICVS ille AGER eft, cujus not: tu digna varia, ad Regnum minerale pertinentia, recenfere animum induxi, quamvis \& vicinarum ditionum, prafertim Palatinatus fuperioris curio fa quadam hinc inde fim exhibitu. rus, à potiori interim denominationem faciens.

Caterum latitudinem hujus regionis, \& elevationsm Polz effe inter grad. XLIX. \& L.ex Geographicis conftat. Ipfum vero folum gleba natura ac fertilitate perquam diverfum deprehenditur. Qui proxime ambit Norimbergam ager planus qui A dem?

(a) Vid. B.Cbrifoph. Cellar. Notit.Orb, antiqu. Lib.II. cap.VII. p. 536.

(b) Conful. præ cæteris B, D. D. Wagenfeil. de Civit, Norimb. Cap. II: 


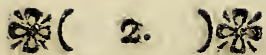

dem, fed valde arenofus eft, eaque de caufa Phil: Andrin. Olden. burgerus (c) rectiflime perhibet, cuniculos bic nullo effectu gaudere, neutiquam animalcula leporini generis hoc nomino venientia, fed militares telluris excavationes (DaB Miniren) intelligens, genus oppugnationis: fubterraneum, quod jam olim Flavio Vegetio (d) tefte cuniculum vocayunt, à leporibus, grá cavernas fub terris fodiznt. Iales autem cuniculos effectu carere neceffum eft, dum non coharet inter fe fabulum, fed cava per medium fui facta, deorfum \& à lateribus promte irruendo, iterum replet, aut faltem inditus pulvis pyrius non tanta vi, ut in gleba pingui, fundove lapidofo, poteft operari, cum potius arenz incumbertes accenfo pulveri facilem egreffum, citra infignem collocatorum in vicinia ædificiorum aut hominum jacturam, concedant: fed hæc ws ch macóda.

Campos utcunque arenofos, in fe macros ac fteriles, agricolas \& hortulani adeo didicerunt colere ac facundare, diligenter paitinando, arando, ftercorando, ut frugum variz generis, præefertim olerum délicatorum largo quotannis proventu, non modo Civitati ampliflimæ, verum \& diftantibus ab ea urbibus \& locis pluribus fufficiant; ne quid feorfin de bortis dicam cultijfimis, omnique amoeno Fiora of Ponsone apparatza abundantibus.

Kemotior ab Urbe tractus, maxime orientem, meridiem ac feptentrioncm verfus, fylva, veter is Hercynia portio, paffim tamen pagis \& oppidis interpolata, longe lateque diffeminata exiftit. Qua autem Paldoinatui fuperiori jungitur ager Noricus, apparet montofin \& lapidofus admodum, ita, ut plus fape lapidum quam glebæ in arvis confpiciatur, ipfeque fegetes e lapidibus pullulare videantur. Imminent hine inde vallibus prevupta rupes, \& faxorum moles, afpectu fatis horridæ, \& fubitaneam minitantes ruinam.

Neque

(c) Thefaur rer. publ. part. IV. p. I328.

(d) de Re milit, Lib.IV. cap. 24.

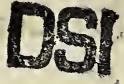




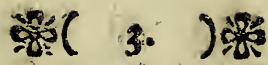

Neque vero defunt pingraia pafcur \& gleba purionis arvis, tum alibi vifenda, tum circa Hersbruccum inprimis ; ficuti pratorum bonitate \& lapuli cultura excellit Alidorffum noRtuma. Sed plura, de Agri Noricu diverfftate, non addo, cum ne prolata quidem ad inftitutum meum tantopere attineant.

\section{GAPVT II. \\ DE AQVIS, PR ASSER PM MEDI- GAMENTOSIS, MINERALIBVS ET CVRIOSIS.}

VT aliis vite adminiculis, fic aquis neceffariis Norico noftro benigniflime profpexit Deus: Quamvis enim regionem hanc, utpote mediterraneam, nullus alluat Ocea nus, nullaque interfluant è grandioribus navigabilia fumina, unde commerciis in Urbe, olim quidem quam nunc fructuofioribus, commodaretur; nihilominus aquarum ubivis abunde eft.

Præeter enim tres amnes, qui tnaximam territorii Norimbergenfs partem includunt, Regnefum puta, Nigrum \& $S_{c h y p}$ a bacum, a Septentrione promanans alveo tortuofo Pegnefus, inter lætiffimas ripas ad occafium deflectens, medium quafi Noricum ipfamque urbem dividit, multiplici quidem accolarum commodo, haud levi tamen etiam quotannis fere damno, quod inferre folet facilis ejus exundatio.

Plures alios amnes atque rivos, hinc inde fcaturientes ac fefe diffundentes, variis pircibus affluentes, enumerare fuperfedeo, perinde ut ftagna, quorum paffin ingens eft multitudo. Præ cæeteris autem confficuum ac celebre extat iftud, à meridie orientem verfus Vrbi propinquum, quod vulgo ber Tut(t)eteid) / rectius Duket-teich nuncupatur, cum $\grave{e}$ duodecim quondam $p i f c i n i s$ in unum conflatis ori- 


\section{然( 4.) 就}

ginem duxiffe populari opinione feratut $\mathrm{Vaftam} \&$ ampliflimam hanc, uberrimamque pifcinam, quam optimo jure lacum dixeris, inter alios amniculos Der Fifábach) cogno. minatus influit ac penetrat, Norimbergam ipfam poftea tranfiens.

Perperam quidem à multis attributa modo dicto rivo,

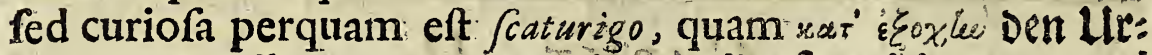
fprung appellant, occurrens in medio fere itinere, quod Altdorffio ad pagum Leimburg \& montem Mauritianum ducit. Ibi amplus \& alizgrot orgyas profanáns terre fubulore biatus aquam ex imo eructat, ea quidem copia, qua modico intervallo tribus molendinis fucceflive agendis fufficiat. Has aquas non effe alias, conftanter affeverant ruricolæe, quam illas quæe in monte. Weifferibrunnenfi, haud procul diffito, fcaturiunt, hinc paulifjer continuato fupra terram curfu iterum difparent, \& quafi abforbentur, ex hiatu de. mum ifto rurfús prodituræ.

Porro Fontium aque dulcis tanta fuppetit copia, ut in Vrbe fola numerentur CXXXFII. qui funt publici, quamplurimis autem privatorum ædibus proprii fui fontes inexiftant. Publicos inter, falubritat is laude, jam pridem eminuit ille, qui prope macelli pontem confpicuus, oer Lang= feimer-פinunnen appellatur. De hoc in contrarium beatus Cafp. Hoffmannus nofter (a) ita fripfit : Puteus cft Norimberge, Der Langtommer l ad quem magnus eft conous fus mi/erorum opificum: at ille medicat us eft, arrodit erim manus \& pedes lotricum, cum diutius penfeverant. Quemadmodum vero asfertum pofterius nulla hodie experientia confirmatur, fic prius, quod nempe medicatus: fit ille puteus, pariter vacillat, dum nihil peculiare five boni, five mali obfervare licet, proter infignem aque puritatem \& faporis fuavitatem, qua fontibus aliis ipfam præftare lubenter concefferim.

Jure:

(a) Paralipom.Medicam. Officin. cap. ulto 


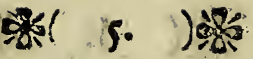

Jure autem meritoque aquis medicatis accenfetur BAL. NEVM, quod vocant FER INVM (ons 23 ilobad) intra: Vrbis mœnia fitum, verfus orientem, velut in fronte illius infulæ, quam Pegnefus, geminato poft ingreifum fuum alveo luxurians complectitur, vulgo die Schủtt appellatam. Puteus eft fatis amplus nec parum profundus, è quadratis faxis compolitus, quam ex dimidia circiter parte, paulo ultra juftam hominis alcitudinem afcendens aqua replet, non altius accrefcere folita, nec multum decrefcere, tametfi magna fubinde copia hauriatur. Tres ipfi fortes aut origines fubtus effe feruntur, qua falutarem ly mpham in commune receptaculum corrivant. Inde vero illa per antliam affabre confructam elevatur, deducenda per canales in proximum ædificium, \& infundenda prægrandibus ahe: nis, ut calefieri \& ufum balnei præftare poffit.

Non æque certo conftat de antźquitate bujus balnei, po: pularis tamen eft traditio, jam ante unum \& fesqui feculum id floruiffe. Floret faltem hodienum; omni neceffaria commoditate infruictum, \& frequentatur quotannis, Vere præfertim adulto, tum declinante in autumnum zeftate, à perfonis varia conditionis ac dignitatis, interdum etiam extraneis, læfam diverfimode valetudinem fuam provido illius ufu recuperantibus:

Conducere inprimis deprehenditur ex infarctu $\&$ ob. fructione vifcerum abdominis laborantibus, bypochondriacis, cacbecticis, \&c. Seorfim fexus fequior is complura incommoda tollere exploratum eft, menffirm puta difficultates, flicorem al. bum, ipfamque fterilitatem. Porro articulorum dehilitatem, tremorem, paralypin of contracturam potenter amoliri experientia docuit, cut is denique faditatibus variis mederi. $\mathrm{Ne}$. que folum lotionibus ac femicupios impenditur latex ifte falutaris, verum \& potari ad aliquot uncias: confuevit à balneantibus, antequam labrum ingrediuntur, haud fruftra perfiafi, 


\section{\%( 6.) 粕}

obftructiones fic facilius expediri, alvum quoque officii fui memorem fervari, cujus alias retentio tam moleftus quam frequens balinei effectus eft.

Caterum aquam hanc revera effe minevalem, five particulis quibusdam attivis mineralium imprægnatam, non modo laudate virtutes argunt, verum \& Japor indicat, fi quidem deguftata fubdulce \& fubadfringens quippiam manifefte fapit. Idem quoque pillidus confirmat color quem acquirit ubi paulifper in aëre libero ftetit, tametfi è puteo recenter hauita fatis clara \& fere pellucida appareat. ACcedit intenfa flavedo, qua ron tantum parietes putei é canales incrufantur, fed \& linteaminabalineantium adeo profunde tinguntur, ut difficillime, quovis etiam eluendi artificio adhi. bito, hinc purgari queant.

Jam de ingredientibus iftis aquam noftram particulis non una innotuit medentium opinio. Fob. Pharamundus Rhumelices (b) \& Foh. Scultetus (c) Norimbergenfis olim Phylicus, multique alii hujus \& fuperioris feculi Arte Medica praltantes Viri, ochram ferream five terram martialem accufant, falinis jubtilibus piculis in gremio terra reclufam atque exaltatam. Fors. Hikias Cardilucius autem (d) fententiam illam rejicit, nibilque prorfus martiale balneo ineffe contendit, experimentis quibusdam à fe inftitutis confidens, unde potius arbitratur, fulpbüe (nefcio quo) unizerfali vu. bro mineralis regri nondum specificato, of falis gemme tantillo imprægnatam exiftere balinei lympham, dioplici adeo naturali charactere vel fignatura notatam, folari nempe rubra, os lunari candida.

Me quod attinet, lubentius fubfriberem priori fenten. tiæ, quam huic Cardiluciance opinioni, cujus etiam fundamentum \& rationes parum firmas in proclivi effet firmiori-

(b) Nymphograph. A. 1632. edita. (c) Nuarrbergifdbeg $\mathfrak{Z}$ etfifod

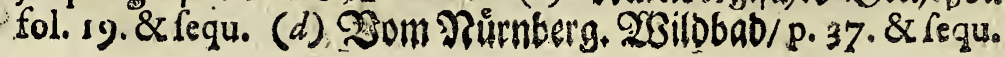




\section{落( 7.$)$}

bus argumentis deftruere, nifi crederem, Virum Excellentiffimum, Dn. D. Fob Paulum IWurffbainium, Affinem \& Col; legam meum plur. colendum, qui accurationem Ealne i Noyima bergenfis (mulcum defideratam) hiforiam pridem meditatus eft, id quoque non neglecturum. Quare ego plura in hanc rem proferre fuperfedeo, id faltrm annectens, haud videri, quod Scultetus exiftimavit, characterem martialem aquis illis imsprimi, per fcorias \& recrementa, que à ferraris officinis, ibi locorum quondam fortaffe extantibus fepulta remanfe. rint; quafi vero non conftaret, Norimbergenfe territorium paffim abundare venis ferri, unde laudata tinctura commodius deduceretur quam à fcoriis, quarum exiftentia \& fuffi. cientia libere nimis hic fupponitur?

Præter memoratum balnei ferini puteum, confimilis natura aquarum veftigia \& alibi fe prodiderunt. Ita cum ante femifeculum circiter in eadem infula, trecentis quafi a balneo pasShisus diftante loco, in gratiam officinæ tinctorix puteus foderetur, aqua illius pariter ochre ferrea particeps ideoque ad ufum quafitum inepta fuit deprehenfa, Sculteto (e) narrante. Quin hodieque in altera Vrbis extremitate, occafum verfus, non procul ab egreffu Pegnef, fonticulus perennat, lapides \& obria quoque fimili colere imbuens quo aqua balnei ut credibile fit ejusdem venæ effe propaginem. Neque hoc tacendum, quod anno fuperioris feculi XLVI. fama increbuerit novi font is foterii, in pago 3nbelshoff (fere dimidium milliare ab utbe, qua ortum ea (pectat, remoto) fcaturientis, cujus lympham itiatom quodammodo affinem balneo ferino judicarunt fagaciores $(f)$ fimul animadvertentes, hujusdem genii aquas hinc inde, præfertim ad amplam iftam, fupra indigitatem pifcinam (Den Duretteuct)) è terra rubiginofa prorumpere.

In

(e) l. c. fol. s. (f) Vid.Nymph. Nor. p. I 11. 


\section{慗( 8.) 就}

In Palatinatu fuperiori, DCC. circiter paflibus $a b$ oppido Reumarctt/ ad vicini montis radices, balneum reperitur ferinum quoque cognominatum. Hoc, multo quidem prius jam ufitatum, anno demum MDXCVIII. opufculo vernacula lingua edito celebravit Foh. Chunr. Rbumelizes, Neogarenfium t.t. Phyficus, qui occafione obfervationis in Fab. Langiz Epifolis ( $g$ ) contentæ (ubi mulier hydropica ex Novo foro, fingulari defiderio impulfa hauriendi frigidam fcaturientem, forte fortuna perveniffe ad fontem, cum aqua arenam fimul ebullientem, inde bibiffe \& convaluiffe narratur) coepit iftam aquam inquirere, deprehenfam probare \& approbare, autor etiam effe Neogarenfibus, ut puteum munire, \& prope ipfum ædificare domuin curarent, quæ adhuc fuperent, aliquibus hypocaufis atque cameris inftruta, quamvis ruinam fere minitans. Præfto funt balineum adminiftrantes, quod hodienum, verno cumprimis tempore invifitur a nonnullis utriusque fexus hominibus, tam fanis quam varie languentibus, fiquidem plures averruncare poffe morbos creditur.

Et fane fi Rbumelius confulatur, is balneum hoc fubtilifimas portiones, \& quintam veluti effentiam fulphivis, nitri; aluminis, ferri \& bituminis continere perhibet; coloris, fuo tempore, aquam fuiffe ex albo gryfei, cum quadam perfpicuitate, fuperficiem ornante fubtili pellicula, vivaciflimis quibusque coloribus radiante, faporem extitiffe acidulum \& fubaditringentem, odorem ferme fulphureùm, aut qualis eft accenfi pulveris pyrii. Ex quibus principiis Autor deducit vires fanandiulcera antiqua, fcabiem ferinam, dolores ac rbeimatifmos articulorum, contracturas, paralyes, cachexiam, nepbritidem, obftructiones hypocbondrionum of uteri, fterilitatem, \&c.

Verum enim vero noftra atate vix quicquam laudati cos loris, odoris atque faporis amplius perfentifcitur, ut non folum mihi,

(g) Lib. II. epift. XII. 


\section{犊( 9.) 夥}

mihi, fatis attende nuper deguftanti, a qua faltem fimplex ap. paruerit, fed etiam curiofius olim explorans Vir moskwiv à-

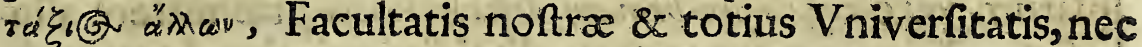
non Collegii Med. Norimberg. Senior venerabilis, D. D. Fac. Pancr. Bruno, fingulare rihil potuerit detegere. Quid, quod ipfius balnei effectus, poft hominum memoriam obfervat, tales plerunque fuerunt, quos ab omnis aqua dulcis balnei continuato (cum regimine) ufu facile expectaveris. Nolo interea vocare in dubium aut falfi arguere $R$ bumeliz experimenta \&avtopfiam, licet ipfi non fuffragentur modernabalnei Neagorenfis phanomena. Fieri enim potert, ac re vera fæpius folet, quod fontes medicati, aliquandiu fatis laudabiles, fuccelfu temporis degenerent, deficientibus fenfim, qua prius admifcebantur, mineralium activis particulis, ef fluente poitmoduin latice ab alia quavis communi aqua pa. rum vel nihil discrepante.

In pago (Stuppad) / haud procul ab arce Sulrbati Illuftriff. Comit. de IVolfftein perantiqua fede, fons elt, ACIDVLAM faturiens DILV TIOREM: Hanc, etfi non seque, ut alias magis faturatas acidulas, potu efficacem noverim, pro balneo tamen aperiente ac roborante utiliter adhiberi póffe non citra rationem fifpicor.

Aquis in Norico nojtro memorabilibus par eft annumerare LAPIDESCENTES, feu PETRIFICANTES vulgo dictas: Harum veftigia comparent inter pagum utrumque Rieden/ ubi ex monte in vallem delabentes rivuli concretionibus lapideo-porofis luxuriant. Sed multo elegantius fpecimen occurrit ultra pagtum, ab ortu vicinum, 5 angenbauten/ dum itidem in montis cactumine, tribus diftinctis faturiginibus profiliens aqua limpidifima \& perquam frigida, mufcum, ligna, lapides, \& quavis alveo præcipiti obvia, cortice inveftit to. phaceo, quod natura phanomenon alibi fufius declarabitur. 


\section{野( 10. )}

Coronidis loco nonnihil addam de AQVIS SYBTER RANEIS, quas crypts quadam Norice fpectandds offerunt. Ipfarum vero cryptarum brevem defariptionem præmittere allibefcit. Prima, eaque notior, dimidiam circiter leucam diftat ab oppido $\mathfrak{Z}$ eloen/ditionis Noribergenfis, \& communi-

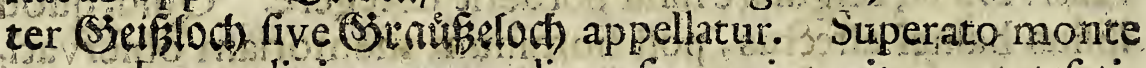
non adeo acclivi, per medium faxum introitus patet fatis amplus, mox tamen definens in rotundum foramen, altius collocaturn, ad quod, ope trunci arborei (qui acclinatus eft) ramofi, licer afcendere. Penetrato hoc foramine viator in cavernam venit, aliquot paffus longam latamque, verfus. coelum quidem apertam, \& hinc luminofam, à lateribus vero undique prolixa faxorum mole claufam. Ineft tamen iterum meatus, nempe oftum ipfius cryptze ad orientem protenfe. In hanc igitur erecto corpore datur ingredi, \& linea quafi recta plusquam centum greffus facere Latitudo alicubi eft major triginta pedibus, alicubi multo minor. Altitueo fumma cubitos XII. fuperat, propendentibus hiulcis lapidum fornicibushorribilis. Perpetua hic nox eft, actenebra denfiffima, non nifi facibus accenfis frangenda: Harum autem minifterio perluftrari poteft internus angulofe fpelince ambitus, nifi quod plara è lateribus hinc inde fe diffundant avia, propter anguftias fundumque paludofum acceffu difficillima, fiquidem nemo eft, qui cunctgs illius crpte anfraftus fe perretaffe, \& finem reperiffe gloriri queat.

Caterum in medio fere fpelao geminum continetur aque dulc is o limpide ftagnum, quorum majus adeo exitit amplum, ut fuo loco totam fere latitudinem crypte, nec minimam longitudinis partem occupet Profunditas alicubi deprehenfa plusquam pedalis, non computato largifimo fundi fabulo, fplendente, ex quo nonnulli nefcio quid nobilioris metalli conficere aliquando fruftra laborarunt. Hoc inpri. 


\section{\%(10.) )}

inprimis notabile, quod fagna if nullum, quovis anni tempore, oblerventur vel decrementum pati vel accrementum, tametfi frequentes è faxolis concamerationibus gutta paflim defluant: Quare vero fimillimum eft, fubinde tantum aquæ ex fignnis in vapores abire, quantum per dictas deftillationes rurfus accedit, fervata fic femper proportione. Occurrit equidem in via, quæ Hersbrucco Veldam ducit, prope hoc oppidum, rivulus e radice montis oppofiti cum impetu prorumpens, quem à laudatis fagnis originem trahere vulgus exiftimat, fed nulla probabilitate, nedum certitudine, mihi faltem hactenus perfpecta.

Interim aque ifte fubtervane a, utut vere ftagnantes, funt potu fatis delicatæ \& innoxiæ, vel folo ruricolarum conftanti teftimonio, qui opus facientes in agris vicinis, æftate præfertim fervida, hinc fitientes, ad illam cryptam advolare folent, mira fuavitate laticis, gratoque frigore allecti.

Quæ ulterius reperiuntur in hoc pelao digna notatu; e. g. Lac lune, Terra figillanda, Staladzites, \&c. ea in fequentibus fuo quodque loco proponam. Id folum obiter moneo, multos effe, qui pro exbaufia metallifodina (eine nusgefúfbrte Suno = (Sirube) habeant iftam peluncam; quod tamen minime videbitur ei, qui ipfam pariter ac fodinas quasdam metallicas viderit, $\&$ inter fe accuratius contulerit.

Altera crypta, cujus mentionem hic facere decrevi, fita eft non procul à pago Snucrfeim / qui ad Palatinatum Solisbacenfem pertinet, \& quatuor leucas circiter Altdorffio abeft. Ibi in plano montis vertice, inter agros, foramen, eminus haud confpiciendum, pracipiti ad paffus aliquot defcenfu viatorem dimittit in cryptam, cimmeriis quoque perfufam tenebris. Mox ab ingreffu cavendum eft, ne quis deflectat ab angufto tramite, \& in vaftum à latere præcipitium delabatur. Paulifper autem continuato per altam iftam femitam itinere, fatisque illuftrata per tadas crypta, 


\section{(2.) )}

major utrinque defcendendi facultas fefe offert, ad centum usque paffus, admodum declivi femper \& falebrofo fundo. Pendent deorfum, plus minus alte conftituta, faxorum laquearia, jacentibus hinc inde fragmentis prægrandibus, olim delapfis.

Stagna quidem hic nulla, cum interim largis aque limpide fillicidiis parietes \& pavimenta madeant, fuccrefcente pasfim ftalactite \& Lacte Lune, alibi commemorandis. Cæterum Crypta $\mathrm{h} æ c \mathrm{ab}$ accolis Dnß $\mathfrak{S B S i n d}$ loch nuncupatur, quafi effet Eolica, ventumque fpiraret, quod tamen nec ipfe hastenus, utut aliquoties coram adfuerim, potui obfervare, nec $\mathrm{ab}$ aliis fide dignis refcifcere.

Plures, quæ circa nos inveniuntur, $\beta$ eluncas nunc non recenfebo, fed paucis revertar ad aquas fubterraneas. Harum originem quidam à vaporibus ex profundo terræ fublimatis deducunt, alii contra è roris, pluviæ, nivis, per corticem terræ diffipatis, iterumque condenfatis moleculis proficifci contendunt; nec forte perperam, quamvis ejusmodi controverfias fagacioribus dirimendas lubens relinquam.

\section{CAPVT $I I l$. \\ DE TERRIS, QVARVM SINGV. LARIS VSVS EST, PARTIM APVD MECHANICOS, PARTIM MEDICOS.}

DRimarius in elencho Terrarum locus A RGILL ft folet tribui; quæ eft gleba ponderofa, pinguis veluti \& unEtuofa, tenax \& ductilis, quamdiu humida exiftit, ficcata vero duritiem acquirens, nec facile dehifcens. Hujus bene multas fpecies fuppeditat Noricum noftrum. Figulina optima , tam rubra quam alba, foditur prope pagum vicinum 


\section{瀵( 13.) 㴽}

Altdorffio, SISincfelfaio / in fylva, unde Norimbergam quoque pervehitur, infervitura figulis, non æque conceffa extraneis. Occurrunt aliquando in profundioribus fodinis argille hujus farata purpurea, flava, cinerea, nigricantia, quin etiam glebe eleganter variegata, colorumque diverforum venulis inter fe confufis pictæe eruuntur. Nec dubium eft, unam \& alteram illius terre differentiam, rite praparatam, vulgaribus $\int 2$. gillatis in Medicina commode fubftitui poffe, quatenus, præter colorem congruum, -ipfe fapor etiam haud alienus confimilem promittere videtur effectum.

Alio in loco, ad eundem pagum, abfonditus quafi eft in agro cujusdam ruftici thefaurus, Argilla nempe alba $\& \sqrt{a}$. bulofa, quæ primo quidem intuitu nil peculiare præ fe fert, pro conficiendis autem ollis five catinis, qui is vitrum funditur, presfrantiffima deprehenditur, quamobrem è locis diverfis \& remotis fubinde veniunt, qui terram hanc defiderant, \& pro fingulis ejusdem plauftris feptem ad minimum florenos perfolvunt. Fallor, an hæc argilla eft ipfum Pliniz Tafconium. quod is (a) hoc modo defcribit: Catini funt ex tafconio; hec eft terira alba, fimilis argilla; neque enim alia afflatum, ignemque \& ardentem materiam tolerat. Ad minimum noftra illa proxime accedit ad terram Hafficam, ex qua parantur catill? five crucibuta, per Europam longe lateque, ob fuam in igne durabilitatem, celebrata.

Non exiguam quoque laudem promeruit Argilla cinereas Heroldsberger.jis, jam dudum memorata à Goh. Kentmanno (b) quod ex ipfa Norimberga cum terra arenofa faunt vafa liquationis, in quibus arichalcuim conficitur: Cui fane operi hodienum utiliter infervit, \& lateres inde coct; ad fornaces metallurgicas expetuntur, quod furnmam ignis fuforii violentiam multo diutius, quam vulgares lateres, fuftineant. Cæterum Gtorg. $B \cdot 3$ Agri-

(a) H. N. Lib.XXXIII. cap.IV. Eag. 4. lat. 2.

(b) Nomenclat, terum foffil. 
Agricola (c) ante CLXX. ferme annos, commendavit forna culas fictiles, quas Norimberga mittit, pro coquendis venis \& metallis; addens infuper, ex argilla effoffa ad arcem Rotebergum, que diffat à Norimberga circiter XII. M. paff. feri catinos, in quibus oricbalcum confcitur: Hos ex igne, una cum orichalco ejectos non rumpi, fed vitri candentis modo torqueri \& trahi. Num vero tales adhuc elaborentur $\&$ ufurpentur, comperire hactenus. non potui, perinde ut id, quod $V$ aler. Cordus (d) fuo tempore annotatum tradidit: Lateres Norimberge \& Augufte fieri ex luto \& abiegni ligni coobe, fimul dusctis \& cactis: exsuffas foobes re. linquere cavernulas, ideoque pumicibus varitate \& levitate fimiles effe bos lateres, ex quibus camini \& intefini parietes extruantur.

Quoniam de terris, apudartifices mechanicos ufftatis, agere coepi, ejusdem generis unam alteramque fpeciem fubjungam. BOLVS RVBRA, vulgari Bobemice parum cedens, eruitur ad pagum Trof(t)enteúth ( Petzenfteinio, oppido Norimbergenfi, propinquum ) ditionisBrandenbürgico-Baruthinæ, tanta quidem copia, ut onerandis fubinde plauftris fufficiat, \& vili admodum vendatur pretio. In eodem tractu, prope pagum Noricum, pefrenfifeiner- STúll nuncupatum, è profundo valde puteo TERRA, itidem copiofe, depromitur FLAVA feu LVTEA, qux, in furno prius ficcata, Norimbergam \& aliorfum devehitur, exiguo pariter divendenda pretio. Hane pro genuina ocbra veterum ut babeam, tanto minus ambigo, quanto magis ipfa veros ochra cbaracteres exprimit, colorem puta laudatum, faporem adfringentem, \& præcipue, quia igne ufta ruffefcit adinftar rubsica, quod quidem Diofcorides $(e)$ ochræ proprium effe docet. Utraque autem, tam lutea, quam rubra terra, ufum potiflimum præbet in adibus pingendis, tametfi \& inter medicamersta abforbentia \& Aiptica reponi omnino mereantur.

RVBRI-

(c) De nat. foffil. Lib.VII cap. 14. (d) Sylv. var. oblervat. p. 220.

(e) de Mat, Med. Lib. X. cap.CXII. 
RVIBRICA FABRILIS, bona nota, eft in agro quodam montis Weiffenbrunnenfis, unde eruta quando que aratro \& in confpectum producta fuit. Nullus autem dubito, quir, fi altius fodiendo quæreretur, longe adbuc nobilior \& pinguior fit comparitura : Ut fane mirum videatur, poffefforem agri nondum hactenus cepiffe experimentum, minime fumptuofum, quod tamen, ubi feliciter fuccefferit, neutiquam careret lucro. Valer. Cordus l.c. narrat, vubricam extare Norimberge, lapidis hematitiss modo -jplendentem in livido, cumo made fcito Talem, etfi hodie circa nos alicubi ordinarie inveniri nefciam, affervo tamen, fub arce Rotenbergica, nuinc defolata, repertam, præduram nempe, \& ex ruffo (revera ut hæmatites) cum fplendore nigricantem, quæque fortius affricta fanguineum colorem reddit. Minime vero exiftimandum eft, quafi rubrica foli ufui pictorio \& lineis ducendis dicata fit: Cum enim profapie fit martialis, \& metalli hujus delicato fulphure, particulis terreis immerfo abundet, ideo remedium confituit polychreftum, tam interne quam externe adhibendum, \& hæmatiti lapidi in plerisque furrogandum. Non lubet fingulas ejus dotes enumerare: Hoc faltem memini, pro comperto quosdam habere, celebrem iftum $D$. Lehmanni, Archiatri olim Saxonici, pulverem, quo ipfe in morbis compluribus miranda præftitiffe fertur, maximam partem è rubrica fabrili fuiffe conflatum. In externis autem affectibus variis, præfertim in Synovia fafenda, egregiam rubrisaefficasciam Clar. D: Emban. Karing $(f)$ deprædicat.

Sed alix nunc ad fe nos invitant terra medicata. Continet $\mathrm{Cr}_{\mathrm{r} p t a}$, in preccedenti capite memorata, Veldenfis TERRAM SIGILLANDAM, ex luteo-puniceam (liedt)= broum) - pinguem \& puriffimam, quam nemo facile peritorum afpexerit, qui non terræe cuivis optimæ æquiparandam judicaverit, inprimis fi è fapore fimul, ut par eft, bonitas ejus xefti-

(f) Regn. miner. Sect. IV. Rart, Ili. sap. III. 
æeftimetur. Quamobrem etiam factum, quod inde à centum fere annis, ad imitutionem terra figillate Strigonien/s, vocata in ufum optato cum fucceffu fuerit. Sumere placet Ca/p. Hoffmanni ( $g$ ) teftimonium: Hanc (ait ille) terram civis quidam Her/fruccenfis conquirere folet, mundare, \& in placentislas orbiculares, cum figno montizm, \& infcriptione, Terra Ggillata, conformare. Hac fraus non eft, conffat enim multiplici meo experimento, ut o aliorum, in pauperibus pracipue idem agere cum terra Silefaca, in febribus mali moris.

Non licuit mihi effe tam felici, ut vel unicum hujus terre paftillum, dicto modo fignatum cernerem, tametfi diligenter inquifiverim; ejus autem loco incidi in aliud /fgigllum, quod Tab. 1. fig. lo delineandum curavi. De autore quidem haud conftat, tempus vero præparationis apparet Ann. 1632. fuiffe; Expreffa in medio inffgrnia Civitatis Norimbergen/sis, teftantur ipfius in territorio effoffam effe hanc terram, cujus in commendationem fplendida aliquot Syrionyma leguntur adfripta, viz. Axungia Solis, Terra S. Pauli, Terra Adami, Mineralif(t) (Einforn; non quod omnium, hisce nominibus venientium rerum externam (ut ita loquar):referat formam, fed internam faltem, \& in effeetu ippisirefpondeat. Quamvis autem imperitiæ juxtá \& jactantia arguendus videatur autor infcriptionis, certum tamen eft, non ea folum, quæ Ca/p. Hoffmannus afferuit, verum \& cunEta, quæ ab unicornu foffli \& terra qualibet laudabili, ipfaque adeo Lemnia expectari poffunt, hanc noftram facile præftare.

Martialis effe, aut de ferro iparticipare vulgo creditur: Hoc autem fi concedatur, Sileffaca, noftrze concolor, quam Solis axungiam vocant, non talis, fed itidem martialis erit, quando inter utramque vix aliquid difcriminis occurrit. Quare, aut Silefaca, non eft Solaris, aut. noffra non martialis, ad quod

(g) Paralipom. Officinal, cap.XLV. p. m.66s. 


\section{17 )}

quod fatrendum eo magis inclino, quo minus, mediante uftione aliisve experimentis, præfentiam ferri licuit detegere. Minime alitem omnium arridet ea quorundam opinio, quod viciriolat a it Veldenjis terra. Hanc enim, quocunque modo tractaveris, ne umbram quidem vitrioli exhibere fenties.

LAC LVN\&, cujus proventu fola quondam Helvetia gloriabatur, Noricum quoque noftrum impertit, è crypta Kauerbeimeñf ac Veldenfi, quamvis ex hac paulo largius, ubi ad finiftram receffus, alte fornicatus, è fuperno hiatu fenfim fundit, \& parieti affigit materiam, piffo aut coagulato lacti. colore of confiftentia fimilem, qua tamen exficcata in glebam evadit levem, raram, friabilem, candidam, adinftar agarici, unde \& fungum petraum, five agaricum mineralem, fofflem, faxatilem \&c. nonnulli dixerunt. Saporis eft ex terreo-fubdul. cis, odoris vix ullius. In aqua promte liquefcit, ipfamque reddit lacteam. Effervefcere folet cum liquoribus acidis, eo vehementius, quo fortiores illi extiterint. Alcalicam hinc ejus naturam nemo non intelligit, quod infuper confirmatur experimento noftro, dum igne forti calcinatum $\mathrm{Lac}$ Lune probuit calcem ex cinereo nigricantem, fed valde acrem, \& quix affufam aquam dulcem manifefte reddidit lixiviofam, evolutis vi flammæ atomis alcali falis fixi; quamvis hoc maximam partem adeo tenaciter adhæreat calci, ut ipfa, licet aliquoties elotionem aquix perpeffa fuerit, nihilominus cum. fale ammoniaco trita, odorem urinofum penetrantem inde fufcitet.

Quæ fane phænomena unicuique, vel nondum confulta experientia, perfuadebunt, effe Lac Lune antacidum \& abforbens egregium, unde tot virtutes eximiæ particulares, ipfo ufi manifeftatæ haud difficulter derivantur. Præconem earum quafi primum egit ó záy Conr. Gesnerüs (b) à quo

com.

(b) de figur. lapid. cap. II. p. so. 


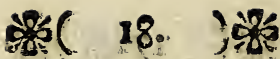

complures recentiorum, e. g. Anfelm, Boëtius de Boot (i) $79 b$, Carolus Rofenbergius (l); Olaus IKormius (m), Fob. Schraderus $(n)$ \&c. fua defcripferunt. Erit autem operæ pretium, Clar. D. Caroli Nicol. Langii, Lucernenfis, utpote noviffimi autoris, de ufu Lattis Lunc relationem (o) cæeteris locupletiorem hic inferere: Partium eft tenuium, facat fine mox/ $u$, abfirgit, acida imbibit acriacedulcorat ${ }_{2}$ plerisgue morbis ab is provenientibus medetur, \& non parvam Lac Luna inter \& Bolum Armenam depreben. di affinitatem, cujus potiones vires poffidet. Interne prodeft in fods G ructunidoro. a, grumis anguinis difolvendis, nec non in bemorrbagiis, alisgue fanguinis profluvits: fiftendis. In ardore urina, \& rem liquis ejus affectibus ab acrimonia \& aciditate ortis, Jpeciatim in ftranguria juvat, dolorem nepbriticum fedat, \& arenulas è renibus pellit, earumque generationem impedit. In colica, diarrbcea of dyfenteria prefertaneums eft remedium, quod nonnulli etiam in febribus malignis of pefizlentialibus cum fruttu exbibent. Demum lac mulierum lactantium copio/e anget, propinatum cum cryftallo proparata, fensine facniculi, alisque Recificis. Externe Lac Lune confert-ad acidum occultum ulcerumabfumendium, imprimis tibialium, que mive purificat, conglutinat \& ad cicatricem perducit. Multi illud, Loco nibili albi, callyris addunt ad exficcanda oculorum ulcera, eorumaque defuxiones acres inbibendas. Hactenus ille, quocum omnino conferri merentur, quæ Eman. Kanig ( $p$ ). Fob. Fac. Wagnerus (q) \& præcipue Excell. D. Fob. Fac. Scheuchzerus $(r)$ haud diffimilia fcriptis confignarunt.

Quod genefin Lactis Lime attinet, illam minime arbitror deducendam $a$ vaporibus metallicis, præfertim Lune few argen-

(i) de lap \& gemm hiftor. Lib. II cap. 229. ( $l$, Animadv. \& Exere. Med. XI (m) Mufei Lib. I. Sect. I. cap.IV. (n) Append ad Pharmacop. p. m. 897. (o) Idea Hift Nat. Lap. figur. Helvet. cap. III. (p) I. c. cap.II (q) Hif. Nat. Helvet. p. 34 I.

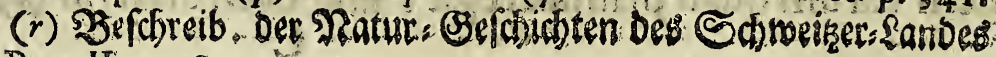
Part.II. p. 184. 


\section{粉( 19. ) 粰}

ti condenfatis, ut WWormius aliique autumarunt, fatis tamen confutati à laudato D. Scheucbzero. Sed longe probabilius ftatuitur, aquas (ficuti fub finem capitis antecedentis fuit oftenfum ) per corticem terræ abforptas, \& altius in compagem certi generis faxorum penetrantes, ablueve hinc inde \& jecum vebere tenerrimam lapidum jubftantiam, \& veluticremorem, hunc poftea rurfum è finu fuo dimittere, nacta occafione commoda in fubterraneis cryptis, quarum in parietibus corrivatæ aquarum guttæ, dicto lapidum cremore fcatentes, fenfim evaporando evanefcunt, relikta, quam fibi in tranfitu è faxis adfciverant, materia, in ipfum Lac Luna coalitura, ambientis præcipue aëris auxilio ficcanda.

Num cognitum habuerint prifci Medici Lac Luna, \& an Morocbtus aut Galactites eorundem fit? jam non vacat disquirere, quamvis multi neotericorum id fufpicentur. $\mathrm{Pa}_{\mathbf{7}}$ rum etiam intereffe puto, ad quamnam terrarum claj]em referas tur? ftante tamen propofita modo hypothefi, de ortu LaCtis Luine, iftud ad Margam five medullam faxorum pertinebit. Cæeterum mihi gratulor, quod, nemine præeunte, offenderim in hac regione curiofum illud foflile, \& apud nos extare, primus fortaffe nunc declaraverim, non defperans, quin \& alibi per Germaniam invertigari poffit, quemadmodum in Moravia \& Superiori Auftria Fob. Ferdin. Hertod (s) extra Earopam vero, in Infula Sumatra, Herm. Nicol. Grimm $(t)$ repertum teftantur. Seorfim quoque Cimbriam Lactis Lune feracem effe arguit Marga Saxatilis, ex infulis Ferö̈nfibus, quam defcripfit 1.c. Wormius, \& analogam penitus Helvetico Lacti Lune oftendit. Sed plura, in hanc rem, dubio procul legi poterunt in celeberr. Foh. Dan. Majoris peculiari tractatu de Las ¿te Lune, quem tamen hucusque nondum videre mihi contigit, etfi fedulo quæfiverim. Hoc interea poffum confir-

$$
C_{2} \text { mare, }
$$

(s) Tartaromaft. Morav. pag. 72. (t) Ephem. Germ. A. N. Co Dec. II. Ann. V. pag. 69. 


\section{整( 20. )}

mare, quod allegatus D. Langzus notavit; Lac Luna, nimirum', aêri magis (ac diutivs) expoffum, facillime iterum induere noturam lapidis: An vero genuina caufa hujus metamorphofeos fit nitrum aëreum, denuo admixtum, ut ille vult, ego quidem vix aufim decernere, contentus, quod è phænomeno ifto rationem didicerim, quare interdum Lac Lunc occurrat apperius \& lapidofius, non quod tale fit immaturum adhuc \& crudum, ceu Gefnerus credidit, fed quia nimis maturum \& veluti bis coctum eft.

Præter Lac Luna, alias etiam marge differentias Noricum noftrum exhibet, inprimis vero illam, quæ r DVLLA SAXORVM (Stein-Mincot) appellatur; paffimque obvia eft, inftar nuclei, glandulæ feu medullæ, de commiffuris \& cavitatibus petrarum eximenda, quando hæe à lapidicidis franguntur, cinexea plerumque aat albicans, non $x_{-}$ que ponderofa \& pingtis ut argilla, friabilis tamen. Hujusmodi confpicuas portiones elicui è rimis \& interftitiis faxi arenofi, in valle profunda prope pagum (Strunfperg/ ubi\& aliam ex amniculo collegi margam, nempe duriorem, rubricæ in modum, è eryfeo \&u violaceo variegatam, ponderofam, quæe lapidi nigro fifili affricta lineas ducit coloris fere carnei : Docuerunt autem experimenta, banc marge peciem ferro effe refertam, ideoque nobiliorem cenfendam. Alia rarfus mar-

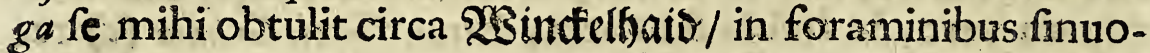
fis quorundam faxorum, tenera \& levis admodum, coloris aurez feu lutei, quam pariter martialem judico. E lapidicina montis Mauriciani margam quoque confecutus fum, fed impurio. rem, coloris.partim albicantis, partim lutei \& punicei. Cæterum. ufus Marge in Medicina \& virtutes, licet à variis deprædicentur varia, potifimum in abforbento \& leniter adffringendo confiftunt; quare inter ipfam \& terrea concreta alia exiguum ratione effectus intercedet difcrimen. 


\section{\%5. 2r. ) 㩆}

Marge perquam affiem testam, fifflem, aut è numerofis incumbentibus fibi laminis compofitam, colore glaucam feu ex corruleo incanam, faporis laudabilis, deprehendi ad radices montis, inter pagos Altdorffio propinquos, (Sirub \& S(t)inatzenbact). CRVSTOSA vero TERRA elegans, in lutifodinis noftris, \& inter arenas rivuli ad molam $\mathfrak{B}_{\mathrm{t}} \mathrm{etthat}$ reperitur, quam e uaraéms D. D. Maur. Hoffmannus nofter (u) lapidem vocat miniatum, ideo forfan, quia paulo eft durior, \& quarundam cruftarum colore minium mentitur. Ejus quandoque viginti poffunt numerari crufte, fibi invicem fuperinduct a, confimili modo, ut in lapide Bezoar apparet, centrum posfidente vel ejusdem confiftentiæ nucleo, vel pulvere non disparis natura \& coloris. Eft autem color, præter dictum miniatum, rariorem, vulgatior luteus aut ochreus, martialem arguens genium, qui clarius fe prodit uftione inftituta, hinc enim jucunde ruffefcit, \& rubrice aqualis evadit, cui propterea, quà pigmento, quà medicamento, fubftitui poffe illam terram non temere fpondeo.

Margacea porro gleba, pallidelutea, mihi obfervata eft in crypta Kauerheimenfi, fed quæ arenulis fcatet, lavando tamen, lege Artis, facile purganda. Et hrec quidem de TERRIS NORICIS in præfenti dicta fufficiant; plura fortaffe fuccurrent ac proferentur in pofterum, ego interim ad lapides recenfendos me conferam.

\section{CAPVT IV.}

DE LAPIDIBVS IN GENERE,

ET SPECIATIM IIS, QVI SVNT ámęQi, H. E. NVLLA CERTA FIGVRA CONSPICVI.

A Cturus de lapidibus Noricis, minime neceffarium puto, $A_{\text {generalem iftorum corporum notionem operofius evoivere: }}$ $\mathrm{C}_{3}$ Siqui-

(u) Florx Aitdortf. Vesic. Sylv, dub tinem lit, L。 


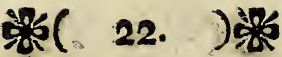

Siquidem plerisque mentibus jam fatis firmiter inhæret genericus ille conceptus de Lapides quod Jubffantia fit dura \& vigida, non ductilits, nec aqua nec.oleo folubilis, neg, igne liquabilis, \&cc. Cujusmodi conditiones quodammodo diffinctum reddere queunt lapidum genus, à reliquorum foffilium claffibus. Prolixas divifones lapidum, paffim ab Autoribus traditas; pariter haud moror, quippe qui neutiquam univerfalem, fed noftratium faltem lapidum bifforiam concinnare decrevi. Efto igitur idonea, pro inftituti ratione, fequens dispofitio:

I. APIDES NORICI figura certa

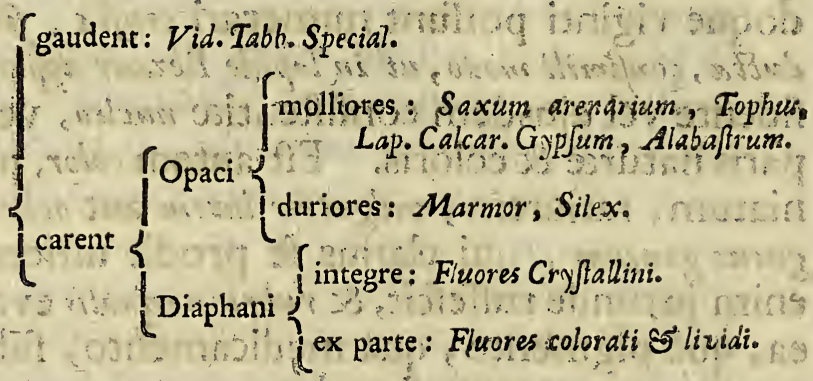

Inter lapides, figura certa carentes, opacos, molliores, recepto apud Phyficos more, primum collocavi SAXVM ARENARIVM: Eft autem character ipfius, quod afperum exiftat, nec poliri perfecte queat, affrictum ftrideat, \& in particulas duras, rigidas, ARENAM nempe foleat comminui; ut adeo ex hoc lapide refoluto Arena, ex hac autem concreta ipfe lapis oriatur. Vulgo dividunt arenam, in litoralem \& foffciam, ceu Vitruvius (a) jam fecit. De illa, quam mare pariter, ac fluviatiles aquæe tantum non omnes, alveis fuis continent ac vehunt, plus minus puram \& æqualem, non attinet dicere. Fofficiam autem, quæ fcilicet, extra aquam, è locis variis eruitur, habemus omnino variam: fed juvat, praftantiores faltem recenfere differentias. Iræ cæeteris notabile eft $\int a-$

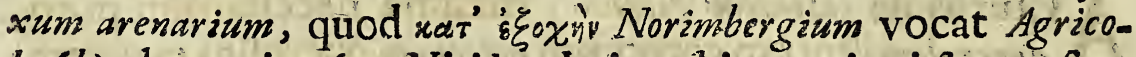
la (b); hoc enim (ut Viri laudati verbis, veritati fat confen-

taneis

(a) de Architect. Lib.II. cap.IV. (b) de Nat, follil, Lib.VII. cap.XIV. 


\section{* 23: ) 楼}

taneis utar-) in lapidicinis molle eft, quocirca, quamprimum fue erit extractum, figurandums eft. Etenim, ubi aliqua temporis intervallo id aër combit, mirum in modum duratur: $\mathbf{E}$ tali propterea faxo Norimbergæe fplendida pleraque ædificia funt extructa, quorum nonnulla per unum alterumique jam feculum fteterunt, integris adhic \& firmiffimis lapidibus. I pám vero lapicidinam (quod Vitruviz, pro lapidicina, eft vocabulum) tribus circiter paffuum millibus ab Vrbe diflitam, carmine heroico fufius defcripfit Helias Eobanus Hefjus (c). Ad oppidum W endelftein, laudabile quoque, tenuius tamen ac deticatius eft arenarium fascum, non modo ædificiis aptum, fed etiam lip ides præbens molares excellent iffimos, qui longe lateque diverfas in regiones devehuntur; idem infuper fabricandis ftatuis, monument is ac cippis, \& fculpendis epitaphiis, fi quod aliud, accommodatiflimum.

Peculiaris faxiarenariz fpecies, qua friabilion molliorque exiftit \& manet, depromiture cacumine montis Weiffenbrunnenfis. Adeo jam excavatus ifte locus eft continuis arenæ extractionibus, ut eyptam referat capaci/fmam, cujus: ruma profpexit foffor am fagacitas, irelictis hinc inde validis $\&$ fornicatis fulcris, quorum ope fütinetur incumbens vaftilima moles : Curiofum fane fpectaculum, nec tamen fine horrore, propter amplitudinem ac tenebras denfiflimas contemplandum. Habet autem ar na illa varias quafi venas, albi, flavefcentis, rubri coloris, etf nullo bonitatis difcrimine, fiquidem promifcue pura eft, terraque aut pulveris alienr expers, minutis conftans granulis, fed aqualibus, \& qua, oculo armato confiderata, pellucidas obtufasque cryftallos repræfentant. U/um affert hac arena finguIarem ad polienda opera metallica, praferizor orichalcea, quem in finem mechanioi Norimbergenfes illam avide expetunt: Taceo, quod pharmacevticis ac C bimicis laboribus eadem apprime conducat.

Aliud
(c) de Urive Norimb. cap. XI. 


\section{粕( 240 )}

Aliud porro faxum arenarium paflim circa nos reperitur albicans, craffaus \& fabulofum, deque argillaceo pulvere multum participans, unde priori longe eft inferius, ad purganda tamen utenflia \& edium tabulata communiter recipitur. Frequentiflimum autem eft faxim glareofum, quo nomine appello rnaflam è parvis filicibus alisque lapillis $\&$ arena, interfuro naturali quodam cæmento feu glutine compactam, plus minus friabilem, cujus folidærupes \& fragmenta hinc inde confpiciuntur, nullius quidem præeftantis ufus, quorum tamen concretionis ratio indagari meretur.

TOPHVS five PORVS (tametf fortaffe antiquitus, aliud quippiam fignificaverit) hodie lapidem denotat, multis foraminibus aut poris pervium, binc apperum, minus ponderofium, mollem vero ac friabilem, colonis utplunimum albicant is aut cinerei. Hujus frufta variæe magnitudinis, tum alibi paflim in agris, tum præcipue ad radices udofas quorundam circa nos montium inveniuntur, unde fufpicari licet, quod ex aquis, materia margacea impragnatis, per montes illos decurrentibus coagulentur \& coalefcant. Sane enim Tophum ea cumprimis loca largiflime exhibent, queis aquas petrificantes fcaturire, Cap.II. retulia Caterum vix ulli eft hic lapis ufui, præterquam, quod exornandis eremitoriis \& fpelæis artificialibus (zum (3totten- 2 Sert) inferviat, quem ob finem frepius Norimbergam \& aliorfum defertur : Poterit tamen etiam, fine dubio, caly inde fieri haud reprobanda.

Quod verofeorfim audit CALCARIVM SAXVM, non ejusdem eft generis: Datar enim valde durum, fed molle ufitatius, quale exMauritiano monte albicans \& copiofifimum defumitur, proximoque ad montem loco uritur in calcem, Norimbergæ ac vicinia ipfus defideratam, Virtutes calcis vive Medicas longum foret hic enarrare, imo \& fupervacuum, quoniam à compluribus Chimicis fcriptoribus illa 


\section{犊( 25: )}

jam fatis funt decantatæ, potiflimum ad fal, uftione explis citum, alcali acerrimuin referenda; quod, licet oculis nequeat ea forma fifti, qua plantarum falia, ceu recte monuit Olaus Dorrichius (d), effectu tamen, tum antacido, tum cauftico, $\&$ in pfilothris maximè, fit fatis confpicuum:

Affine faxo calcario habitum imper fuit GYPSVM, quod etiam hon eft ejusdem facieiacbonitatis. Optimum; in his terris mihi vifum, Winshemienje, candidum o argente pler doris, in fila divifibile, propemodum vut Amiantus, quod occafionem pràbuit, ut ipfi non folum, fed etiam alumini plymoro, pluribus in pharmacopoliis, turpi errore, fubnitueretur. Nuncupant autem vulgo Sinken-ftein / hanc gy/f Apecjem, qua propé Jenam quoque, dulcem patriam meam abundat, dudum ibi obfervata à G. Agricola (e), Uritur autem hic lapis facilius multo quam calcarium faxum, in pulverem hinc abièns tenerrimum \& plane niveum, ex quo, rite fubacto s formantur pontéas ftatuæ \& alia plaftarum curiofá opera, quin etrananotiffimo hodie artificio nuvismorum rariovum accurata ectypa inde concinnantiur, ut horum adeo intuitu Gypfum æeftimare deceat, fi vel maxime in ufum Medicum non cederet, de quo tamen Autores pharmacevtici varia differuerunt.

* Go Ut Gypfum calcarip faxo, fic ALABASTRVM gypfo cognatum merito cenfetur. Quamvis enim inter Marmoris Bpecies Alabaftrumi referri foleat, rectius tamen judicante Anf. Bositioide Roont $(f)$ ab illis, fi non figura externa \& politura, faltem duritie diftinguitur, imoll ins quippe èft: Nimis autem molsp itariut fealpello feindipollit, etfi vulgo Alubafftri nomine appelletur, potius gypi reputat /peciem citatus Autor, \& pro Alabaftrite incoito habet, ut contra hunc, paulo duriorem , pró imperféto marmore. Diverfis equidem

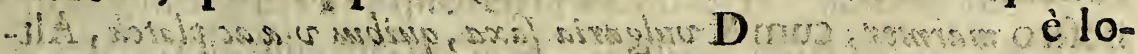

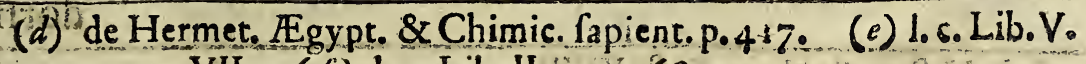
cap.VII. $(f)$ 1. c. Lib. Il. cap. 268 . 


\section{丞( 26.) 夥}

el Iocis Norimbergam accerfitur Alabaftum, fed nullum hovi proximius Winshemienf, quodimediocris eft duritiei, purum $\&$ candidum, nec tamen venis coloratis deftitutum. InMedicina raro adhibetur, \& nonnifi externe, unica hodie ufitata compofitione ungrenti illabaftrini, adverfus capitis dolorem prafcribendio Ordinatie autern converticur hic lapis ad vafula of alia toseumata munditie ac fplendido can dore oculis blandientia; Porro budicra inde fiunt \& crepundia : Uritur etiam in calcem tenerrimam, fimiliter ut gypfum, unde hujus cum illo affinitas magis elucefcit. Curiofum annectere placet phænomenon, ab Illuftr. Kab. Boyle ( $g$ ) accuratius obfervatum; quod nernpe pulvis Alabaftri aut Gyp $f 2$ Rarifi. enfes, wneo ferreove lebeti, prius percalefacto inditus, gradatim aucto igne, incipiat liquoris bullientis modo undulare, effervefcere, magnamque vaporum copiam fpargere, tametfi nec ante, neç inter, nec poft ebullitionein iftam pul vis Alabaitri humidus revera fuerit quod certe experimentum, fobrie applicatum, theorize fuiditatis corporum havd exiguam affundit licemon

Ex eaden claffe, lapidum ápóe $\varphi$ con, aut figura certa carentiim, qui vexé daisiones funt, primum locum occupet MARMOR, cujus ampliflima vena nuperis demum annis in territorio Norimbergenfi detedta fuit prope Graferbergam oppidum. Colonis eft cinerei', fape tamen venulis of maculit, albiçantibus pariter ac nigricantibus haud invenufte diftindtum... Duriries eximia, indeque aptitudo ad pal ituram reçipiendam fin-

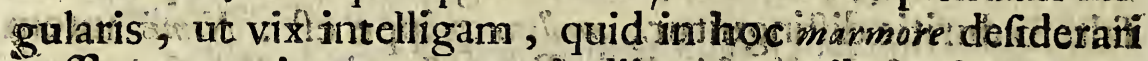
poflet, quo minus communi calis marmoribus ufui impen datur, nifi quod audiverim, obftare quasdam circa præparationem difficultates, fortaffe tamen in pofterum removendas. Interim certum hoc eft lateres paffim in Norico noftro marmos; Cum \& vulgaria faxa, quibus via ac platex, Altdorffii

(g) Hiftor Aluiditat. Sect XVIII. 


\section{粉 $27.7 \%$}

dorffii præertim Aernuntur, maimorea plerumque fint naturæ. Seorfim Hersbruccenje faxum, è valtifima latomia vicini montis depromptum, ad marmar quodammodo accedit, fed minus durabile, figuidem, vicifitudini tempeftatum aliquandiu expofitum, diffilire folet ac rumpi. Conftantio ris autem longe marmoris habeo glebas, albicantes, in fuperiori Palatinatu, verfus Ambergan colledtas, adeo duras, ut limæ impetum \& aciem eludant, ipfoque hoc nomine, tum quia ex iisdem ignis percuflione elicitur, ad filicum familiam referri mereantur.

Sed veri ac indubitati SILICES (quod faxi genus eft duriflimum, aut marmore faltem durius, ad fealpturam \& adificia in eptum ) varia penes nos hinc inde occurrunt Jpecies, colore potiffimum difcrepantes: Sunt enim albi, flavefcentes, rubentes, fufci, nigniçintes \&cc. Vulgaris autem alias flex, qui cornu externa facie repræentat, ideoque \$ocnftein vocatur, hic terrarum eft paulo rarior; neque vero deficit verficolor, ut agre liceat omnes indicare differentias, in eo nihilominus convenientes, tanquam in charactere fuo, quod fingulæ fortiori adinvicem aut chaly bis allifu ignem prompte fufcitent, unde Germanicum nomen Seuerfein $/$ \& quia fpeciatim bombardis pro eodem fcopo applicantur, flin tenftein / originem traxit. Caterum tritifima eft flicis illa fpecies, quæ fluviatilis audit, quoniam in alveis \& litoribus glareofis fuminum maxime abundat, fed reliquis filicibus cedit duritie. Varii eft coloris, præfertur vero candidus; igne tam calcinari quam fundi poten, quapropter valde dubito, an filex hic pyrimachus fit veterum, ut Boëtio, Wormio, aliisque videtur. Noftrates hunc lapidem roeínen Riefels ftein nuncupant, \& Medici utuntur ipfo tam externe ad dentifricia, quam interne contra nephritidem, calculum, \&c. refolvendo prius in liquorem, à Chimicis tradita diverfimode enchirefi, quo fpectat etiam famofe illius tincture nepbri- 
tice Ameliong it præparatio Antequam filices dimitto, licebit obiter monere, interdum \& apud nos cum illis confundi lapides nobiliores, ficuti Chriffoph. Encelius (b) urbem Mifniæe, ubi pretiofo fa pide jpadiceo utebantur prófilice, ad ignem excutiendum, fe noffe teftatur, jufto cum epiphonemate: o Jañeft Simplicitas Germañorum!

LAPIDES DIAPHANI rariores quidem funt in noftro climate, nec tamen prorfis iisdem deftituimur. Poffum oftendere filices, quorum finubus: inhærent:plendentes adeo cryft $t l_{i}$, ut cum Bohemicis adamantibus fácile certarent, fi fplendori ac duritiei congrua accederet magnitudo; funt enim hæ cryftalli perquam exiles, ac difficulter eximendæe integræ, cum interim acie fua vitum promtiffime. fcalpant, \& lineas in ipfo ducant fatis profundas.

Genuizano vero CRYSTALLVM poffideo, in Monte Pinifero Franconie Superioris repertam, dummodo fas eft ipfam accenfere hoc loco Noricis fo/flibus. Id filiceret, pari jure huc. etiam referrem deprehenfum in eodem monte PSEVDOTOPAZIVM, qui apparet nil aliud effe, quam tinsta cryftal. lus, ex aureo colore parumper in nigredinem vergens, falva: tamen utplurimum perfpicuitate Fert preterea idem Mons Pinifer PSEVD-AMETHYSTVM, dilutioris violacei coloris : Sed talem multo elegantiorem, SMARAGDO viridi jucunde interpolatum, habeo, binis à Ratispona milliariBus, prope Domauftauff erutum, ibique in copia colligendum, de quo D: Fob. I elinexus (i) plura memorix prodidit. Locis autem Altdorffio vicinioribus paflim extant FEV ORES (flube) ita dicti, vel quod ex materia fluida coaguJati manifefto, videantur, vel quod igne facilius quam alii lapides fundi \& liquari foleant. Sunt vero lapides, qui nitore ac pellisciditate, plus minus perfecta, \& coloribus his illis ,

gemmas:

(b) de Re metall. Lib. III. cap. 7 I. ( $i$ in Dedicat. nova defcript. Balnei Abacenfis Ann. 1669 . edito. 


\section{sot 29. ) 86}

gemmas amulantur ; fed minor omninó durities, ut levi opera frangi \& comminui queant. Hoc infuper, animadvertente fatis accurate $C_{\text {. }}$ Gefnero (l) plerisque commune eft, quod figura plane incerta gaudeant, \& plures jimul inequaliter cobarentes \& conglomerati proveniant, chaivadum feu firumarum quadam

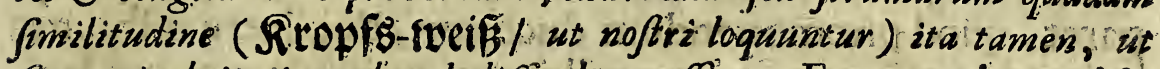
feparari ab invicem baud difficulter pofint. Frequentior nobis eft $e x$ candido pellucidus, numerofis per longitudinem fulcis atque ftriis afper, tranfverfim vero fractus politam fuperficiem exhibens inftar feculi. Alios flioves nactus fum, es candido vix leviter diaphanos, laminatim compofitos, in modum faxi metallici, quod Batum appellant: Alios porro magis obfcuros, \& quandoque lividos. Sed pulcherrimi, à me hucusque deprehenfi, Topazium imitantur colore quali melino : per medium autem confracti promifcue ex purpureo \& viridi refplendent. Quis us fus fit hujusmodi fluorum, vix attinet dicere, quia parcius circa nos proveniunt, quam ut magna cum iisdem liceat moliri. Alias commendantur ad vitra conficienda, \& /metallorum fufionem juvandam. At noftri fluores igne paulo intenfiori rediguntur in calcem albaim sypjo aperiorem, nondum mihi explorata ipfius: utilitate.

CAPVT $V$.

DE LAPIDIBVS EMMOPФOI $\Sigma$, SEV FIGVRA CERTA GAVDENTIBVS, IN GENERE, ET SPECIATIM TALIBVS EX LVSV NAT VRE:

DOfteaquam in antecedenti capite lapides, Norico noftro indigenas, figura certu. deffitutos, recenfui, lubet nunc ad

$D_{3} \quad$ alte.

(l) Lib. citat. p. 26. ao. 


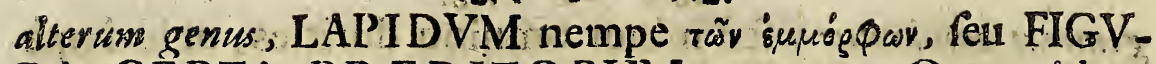
RA CERTA PRADITORVM pergere : Qua quidem phrafi defignatos cupio lapides, certorum, fub alizs natura regnis comprebenforum, corporum \$peciem \& externam formam, aut exacte, aur faltem minus coudte reprefentantes. Ubi ftatim apparet, quod præmonendum ducebam, difplicere mihi, nec imitandos effe mores nonnullorum curiofulorum qui lapidem quemvis, angulofum \& fabrum, è fio ingenio fingunt has illas exprimere mirandas rerum imagines, à nemine licet agnofcendas, nifi qui confimili phantafize per-

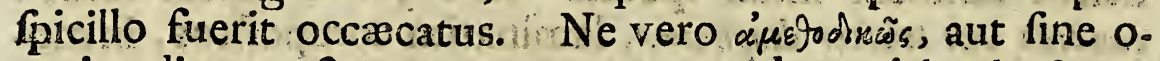
mni ordine proferam, quos exponere decrevi lapides figurafos eorum partitionem fequenti tabula, w's śv ouvó $\psi$ er tradere juvabit.

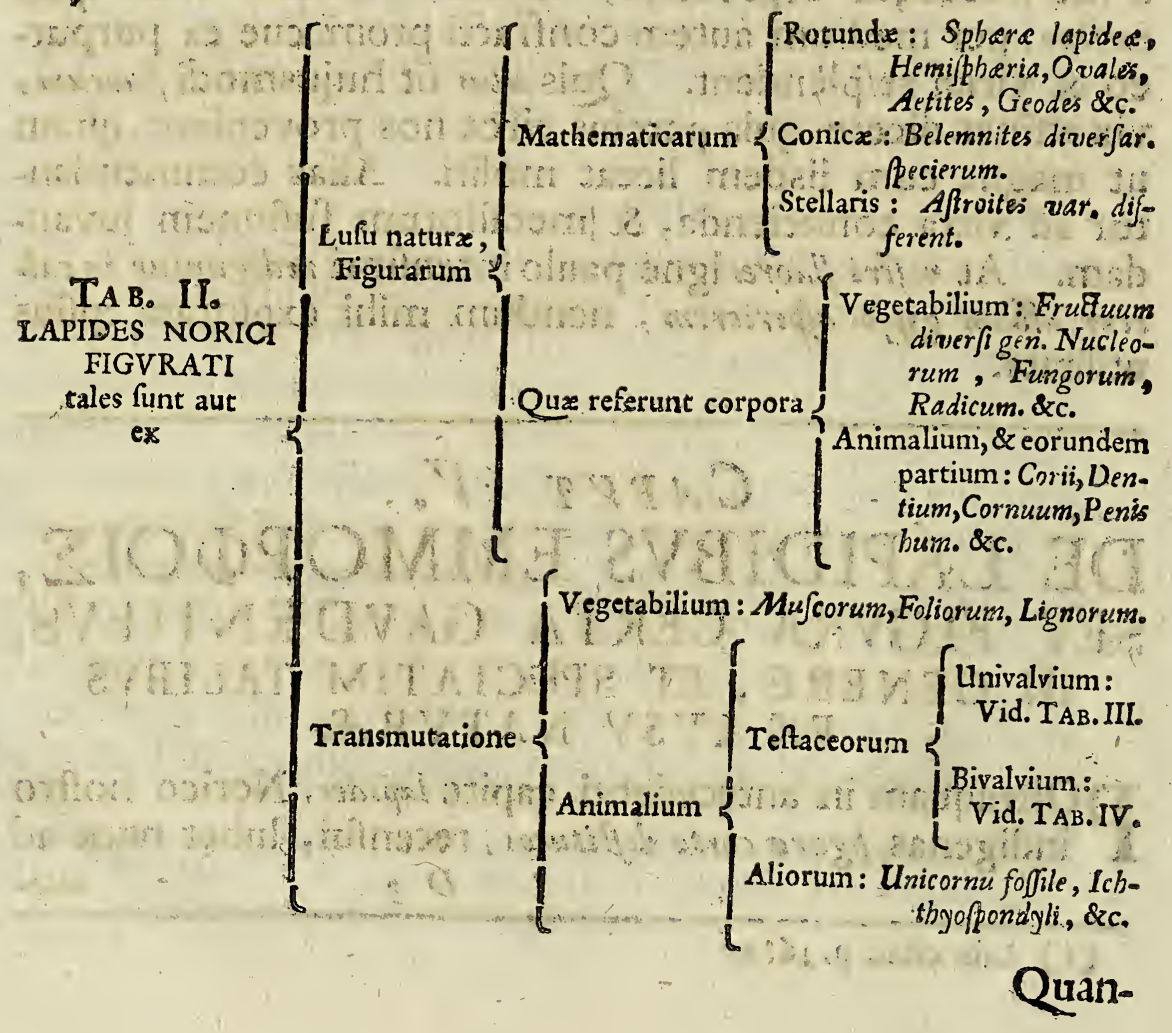


- 14 Quando lufum natureappello, indeque figuratos quosdam lapides oriri ftatuo, neutiquan exiftimandum eft; quafi cum vulgofuperftitiofo mihi concipiam Agens aliquods à Deo diftinctum, in hoc univerfo, præfertim globo terraquee creaturas corporeas dirigens atque modificans, interdum etiam in iisdem otiofelladens, \& abfurda velitimonftraque frepius producens, quale quid feorfim circa lapidum: efformationem cernere liceret : Verum $\mathrm{l}$ hoc folum intendo, ut liberum mihi fit, vocabulo lufus nature, idem, quod. alii folent, profiteri, nempe ignorantiam genuine originis \&. saufs (hoc quidem loco) figurarum in quibusdam lapidibus: Hunc igitur in cenfum veniant omnes ii lapides, qui vel fui generis figuram oftendunt, vel etiamli aliorum corporum formas imitantur, minus tamen perfecte id præftant, fed aut mole \& extenfione, aut notis characterifticis aliis deficiunt; ita, ut è rebus, queis utcunque affimilantur, ortum traxisfe nullatenus probari queat.

Non me fugit, fategiffe plures, phanomenorum iftorum rationem reddere, \& caufas declarare: Quod fi vero fingulorum argumenta ponderentur accuratias, præter autdaces fuppofitiones, conjecturas \& inductiones, patebit effe nihil Q aare fupervacuum arbitror, ejusmódi fallacibus commentis detinere Lectorem veritatis cupidum. Nulli autem invidebo, quin potius fincere gratulabor, fi quis aliquando rem acu tetigenit, atque zis diah fe inveniffe, non tam ipfe crediderit, quam mihi \& aliis demonftraverit. Meuin intereacerit, figuratas lapiden, incerte priginis, circa nos obfervatos, ordine in Tabula definito expro mere.

In claffe lapidum, figurd mat bematica ga dintizm, primo, nec immerito collocavi ROTVNDOS. Horum autem vara fíécimina, disparis magnitudinis, duritiei, coloris, \&c. producere poffem, etfi forte non tanta copia, qua Hieron. Cardse. 


\section{米( 32. )}

Cardanus (a) Cubam, Noviz orbis infulam, lapidibus exacte pharicis abundare narravit. Elegans pra cæteris mihi eft suha rula, è centro prægrandis Nautilitæ feu Cornu Ammonis,

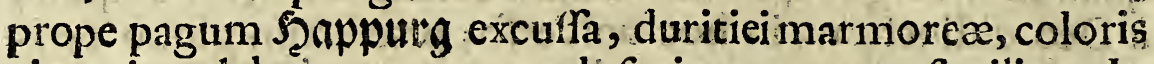
cinerei, globulo puerorum luforio perquam fimilis. In monte Weiffenbrumnenfi faxum arenario-ferrugineum $g l o$ : bos haud raro continet fubratundos, interdum pugni magni tudine, fapius longe minores, \& glandilus bombarde immit tendes aquales. Superficiem gerunt in rubigine fplendentem, leves funt ac friabiles, è luto \& arena indurati. Hemijplid ria porro lapidea, non ejusdem moduli, fe obtulerunt ; fed unum maxime perfectum, albicanti marmori colore \& con: fiftentia accedens, fub Arce devaftata $D_{\text {trafenfel }}$ a me repertum. Taceolapides ovales, is in rotundo compreffos, qualium non pauca exemplaria affervo, magnitudine, colore \& aliis momentis ab invicem discrepantia.

Lapidibus rotundis, è naturæe lufia, aut minus manifefta caufa profectis, AETITES ( $2 i$ orefteiti) meretur annumerari, quoniam plerunque globofus apparet, nomen for titus ab aquila, quod in ipfius nido præftantior unice quærendus olim ferebatur. Proprium huic lapidi eft, cavitate intis gaudere, vel prorfus inani; vel lapillum (quem callimam vocant) vel are: nam, vel terram, \&c includente: Hinc pecies ipfius oriuntur varie, nominibus variis venientes. Noftra in regione fequentes mihi occurrerunt hactenus : I) Inanis, vel quafi talis, mollior, fufci coloris , in cavitate fua nil continens, quod ipfo lapide concuffo libere moveretur ac foritum ederet; cujusmodi Aetitem Franc. Cupioni (b) ridicula non minus quam barbara phrafi, lapidem aquilinum appellat tacitum, non crotulantem. 2) Ferrugineus, aper ac durus, arend fubtili profunde lutea, trium fere drachmarum pondere pregnans. 3) Terre

(a) de Subtilit. Lib.VII.p. m. $257^{\circ}$ (b) Supplement. LI. ad Hort. Cathol. Panormit. p. 5I. 


\section{橉( 35. ) 船}

3) Terra Cruftofe (Cap.III. p. 21. jam defcriptæ) affinis, duritie faltem diftinctus, \& iisdem in locis repertus, varioris texture terram includens, unde GEODES vulgo audit. Peculiarem ejus notavi differentiam, quæ haud inepte cellulo. fus Geodes diceretur, fiquidem non fimplici cavitate, fed variis finubus aut cellulis eft inftrućtus, terræque laudatæ grumulis refertus. 4) Geodes, figura oblonga, utrinque acuminata, pecieffercoris canini, quem Boëtizis (c) recenfuit, jam olim quoque à Beató D. D. Maur. Hoffmanno noftro obfervatum, circa cryptam profundæ vallis, fæpius allegatæ Grunfpergenfis (in Der Teuffeliz-(S)ruben):: Eft vero Geodes hic albicans, è pluribus cruftis aggregatus, quafi argilla effet indurata. Cæterum vires Aetiti aflignantur quidem mirifice à multis autoribus, quorum teftimonia, ut \& notatu digna plurima hiftoriam hujus lapidis concernentia itudiofe congeffit Academix Nat. Curior. primus optimeque meritus Præfes, D. Foh. Laur. Baufchius '(d). Sed tamen acutiffimus D. Paulus Ammannus (e) plerasque Aetiti ad/criptas virzutes, quod fcilicet brachio alligatus abortum præcaveat, inferioribus contra partibus admotus foetum $\&$ fecundinas pellat, venena infuper ac fures prodat, amorem denique conciliet, \&c. nullo niti fundamento, fed meras effe fuperftitiones, lepidis, pro more fuo, argumentisedocuit, tandem concludens, obtinere potius aetitem terra fgillate vires, in morbis malignis, \& venenis.affumtis, \&c. quo in judicio \& nos acquiefcimus.

Figure autem Matbematica LAPIDES porro funt CONICI; quo in genere omnem penes nos abfolvit paginam BELEMNITES, cum fuis fpeciebus ac differentiis. Perplacet compendiofa Clar. D. D. F. F. Wagneri $(f)$ defcriptio belemnita, generatim confiderati, quod fit lapis oblongus; ex amE plo

(c) 1. c. cap. 201. (d) Schediasm. de Aetite. (e) Manuduct. ad mat. Med. p. 18. (f) 1. c. p. 305. 


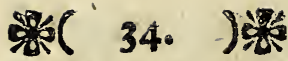

plit radice in obtufum definens apicem, inftar fagitte, colore communiter cinereo, vel ferreo, nonnunquam maculis ferreis armatus, di. giti magnitudine, radios è centro diffundens; fricutus, contu/us, calcinatus cornuca bovis ufta redolens, \&Ec. Cui defcriptioni, pro neceffario fupplemento inprimis annectere decet, quod $\mathrm{Agri-}$ cola \& Boëtius $(g)$ jam notarunt: Omnibus nimirum bolemnitis à natura ineffe quaridam quaje rimam, qua fit, ut facilius in longitudinem diffindantur, fed eam inpellucidis quam reliquis mugis effe confpicuam, ut fic è duabus partibus equalibus veluti conglutinati appareant. Mulcis de cætero nominibus fignantur hi lapides, prout vel ad figuram, vel ad originem eorum habitus - lim refpectus fuit. Et à figura quidem, quæ cuspidem teli aut Jagitta ( $\beta$ ś $\varepsilon u$ uv Græcis vocatæ) exprimit, Belemnites dicitur ; cui vocabulo Germanicum S(t)ok-ftein refpondet. Ex urina Lyncis quoniam aliquibus perfuafum erat generari, Lyncurius aut lapis Lyncis appellatur. Alii contra lapidem hunc, Cevaunii peciem, aut fulminis progeniem ftatuentes, hinc fulminarem nuncuparunt, quod nomen noftrates communiflime retinent, ac in vernacula lingua (Donnetfeil/ ober (Strab-ftein) efferunt. Quae vero ulterius ad hane onomatologiam pectant, erudite fatis evolvit Theologus quondam Dortrechtanus, Balthafar Lydies $(b)$ ad quem re: mitto Lestores, fi qui funt ejusmodi fubtilicatum cupidi. Neque etiam de Belemnit is in genere plura præfabor, quod hoc fine dubio egregie facturus eft Clarifr. D. D. Scheucbzerus, quando promiifam (i) fingularem, de iftis lapidibus, Differtationem evulgabit.

Ego nunc ad indicandas Belemnits differenizas, à me in: hac vicinia hucasque obfervatas, progredior ; \& primo quidem eas, qua funt ratione quantitatis; hac enim tam in longitudine, quam lat irsedine aut potius crafjitie multum variat.

(g) l.c. cap. 25.8. (b) Epiftol. Q xft. Foh. Bezuerovic. p. 161. \& fequ.

(i) Specim. Lithographi Helvet. p. 26. 


\section{祭( 35 . 就}

riat. Maxims belewnite raro deprehenduntur integri: $\mathrm{Ha}$ beo autem ingentia fragmenta, ex monte Heimburgenfi, quæ evidenter arguunt, lapidem ejusmodi, fi integer effet, octo unciis fore longiorem, cum interim fumma craffities in ansbitu quatuor uncias cum dimidia omnino expleat (conf. Tab.I. fig. 2. ) ut propterea hi belemnita noftri majores fint Britannicis maximis, à Clariff. Eduardo Luidio ( $l$ ) recenfitis. Dantur ex adverfo longe exiliores, imo exiliffimi, quales monfrare poffum, culmo mediocri adbuc graciliores. Quantitatis vero intermedia funt frequentiffimi, gradu tamen rurfus ab invicem haud parum difcrepantes, \& nunc fupremo, nunc infimo proximiores.

Porro autem Belemnite figura differsnt : Hanc, licet antea cum $W$ agnero ordinarie conicam pronunciaverim, faepe tamen cylindricam confpici fatendum eft, quod etiam permoviffe fufpicor Dn. Car: Nic. Langium, ut (m) feparatam belemnitarum clafeem conftitueret cylindroidaorum : Sed enimvero, conftans a'vzou'ses me docuit, omnes belemnitas. non conicos, aut in apicem plus minus acutum definentes, mutilatos aut detruncatos effe, neutiquam integros, à conicis fpecie diftinftos. Ipfe autem apex modo eft acutior, quali gaudens beirmnites appofite fatis oxyrrbynzobus audit Luidio; modo eft obtuffor, qui dum juftam fimul magnitudinem habet humani digiti, dactylus Ideus proprie vocatur, etfi hoc fynonymon omni promircue belemniti quidam tribuant.

Magis à figura communi abludunt belemnite, in medis ventricofiores, utrog autem extremo tenuiores, cujusmodi fpecimina Luidius (num. 1702. \& fequ.) nec non Scheucbzerus (num. 34.) dederunt, ari pifilllum nempe referentium: Quibus minimè poftponendus eft, à me (Tab.I. fig.7.) exhibitus, strimque perquam acuminatus, \& faxo cinereo inhærens, fufums

$$
E 2 \text { mulie. }
$$

(l) Lithophylac. Britann. ichnograph. p. 87. (m) I. c. Cap.VI. p.22 I. 


\section{夥( 36.$)$ 楾}

souliebrem (cine Spinbel) fiquid aliud, reprefentans. Hune lapidem, pluresque in Norico noftro repertos; Generof. Dn. Cbriftoph. Frider. Im Hoffius ab. Helimftadt, Patritius: Norimberg. \& Dicafterii infer. Affeffor, pro fuo in me favore conceffit delineandos, quam humanitatem gratus agnofcere, \& una Viri illitis optimi fingularem curiofitatem, in colligendis rarioribus, Naturæ \& Artis: operibus, , deprædicare ex merito, hac occafione debui.

Ad figure belemnitarum difcrimina hoc etiam pertinet; quando funt canaliculati, feu, ut Luidius loquitur, aqualiculo per mediam longitudinem infigniti :- Táles ', circa nos pasfim extantes ( Fig. 3. \& 4.) fiftuntur. Qui proxime his adftat (Fig. s.) depictus, id habet peculiare, quod minus quidem ample fit canaliculatus, tribus: autem evidentibus in apice ftriis five fulcis dotatus, quare ipfum kelemnitem trijulsum quis haud inepte appellaverit.

Non tam modis naturalibus, quam vitiis figure belemnitarum adfcribo, quod aliqui dentur nimium compreffie, quin: \& contriti appareant, præfertim circa bafin, ceu pluribus in: individius à me affervatis cernere licet, quafi crufta fuperior ac durior impetu quodam externo violenter olim contufa \& diffracta fuiffet, cedente interiori fubftantia, ipfique adhærentibus fragmentis cruftæ. Quibus è phænomenis id facile efficeretur, molles: aliquando, faltem quoad partem: intimiorem, extitiffe belemnitas: Accedit etiam, transverfim difruptos, hinc incurvos fape confpici, nihilominus iterum confolidatis, antea divulfis, portionibus; ; Utrum, vero eapropter, an aliam ob caufäm, cocblititis turbinatis mereantur annumerari, prout quidam contendint, jam non difputabo, neque tamen, contraxium mihi videri diffitebor. $\mathbf{C}_{\mathfrak{a}}$ terum vitiate in belemnit ts figura fpecimen quoque eft, erofa ast cariofa fuperficies, qua multi laborare folent, non fecus, ac fi à vermibus hoc malum ipfisiaccidiffet. 
Aliæ belemnitarum differentic a coloribus defumuntur.s E fufco nigricantes apud nos maxime abundant, in agris \& quibusdam rivulis Altdorffio propinquis, tam liberi, quam fuæ matrici, terræ fcilicet bituminofæ', fiffili, nigræ, aut confimili cruftofo lapidi infidentes. Valde nigrum vel atrums hujusmodi belemnitem Frider. Lachmund ( $n$ ) coraciam feu corvinum lapidem ( Pinbenftein) vocari perhibet; Teterrimi hic eft fatoris, fi durius tractetur aut frangatur. Qui colore ac pelluciditate fuccinum falernum æmulantur; quibusque Lyncuriorum aut Lyncis lapidum nomen frifte competit, oppido rari funt hic terrarum, imo exacte talis mihi nondum ullus fefé obtulit, cum interim è̀ latomia Hersbruccenfi, \&c agro prope 'SBindelfeio habeam aliquo faliem modo flavos ac pellucidos. Ad cinereum tendint plerumque grandiores illi, quos in monte Heimburgenfi extare fupra foripfi ; quin \& poffideo verficolores, aut è cinereo of fufco variegatos. Nec defunt candidi, quamvis raro per fe fubfiftant, fed aliorum, præfertim nigricantium in centro lateant, quemadimodum è fig: 6. ( Tab: I. ) videre eft. Minus hi ut cæeteri folent effe ftriati, fed moleculis inæqualibus, adinftar fluoris. fplendentibus: concreti. Talius fubftantiæ lapides quandoque: faxo cuidam impactos, fed plane informes deprehendi, facile comparandos ad Luidii (num. 1734.) lapillum, belemnio. te congenerem cryftallinum, informem.

Denique contentorum ratione differunt belemnita. Certo conftat, quod fagaciflimus D. Mart. Lifferus (o) afferuit: omnium integrorums bafin aliquousque foratam effer modo bac mo. do illa materia cavitiatem opplente. At quad fit etiam naturaliter in aliquibus materia quedam; tanguam propria lapidis medulla, ex ejus concrematione patefsit: Etenim Selenite inftar in albijfimam valent is. fimamque calcem, meduilla excepta, uftulatur; que tamen (medulla) E 3 etiam

(n) Opuxrogạ. Hildes, p. $25^{\circ}$ (o.) Hiftor. Animal.Angl.Tract.IV: p. 226. 


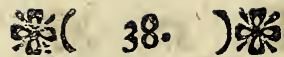

etiam poffquam ignem experta eft, nigricat, \& $\varepsilon$. Noftri belemnilic continere folent I) \& quidem communiflime, terrans Inteam, aliquando in lapidem duratam : 2) Pyritem, magis vel minus fplendentem, interdum fluore candido permix-

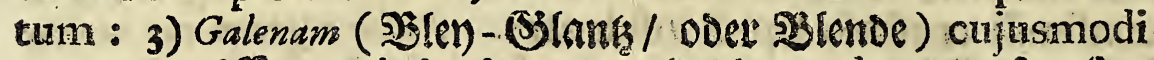
tamen rariffime obtingit : 4) Alveolum, de quo feorfim nonnihil hic placet attexere.

Eft igitur ALVEOLVS, co fenfu, quo in Lithologia phyfica modernorum accipitur, ex accurata Luidiz $(p)$ defcriptione, lapis, orbiculato capfule operculo fimilis, modice excavatus, marmoris infar politus, magnitudinis varic. i Nativus ipfires locus belemnitarum majorum calix eft: hijce enim fractis, geniculatum alveolum, fuffformen, cavitatem occupare fepius no. tatur, lamella maxima fupino concavo fupremum locum tenente, reliquisque ordinatim, pro belemnita forma diminutis. Patet exinde, cur hujus lapidis tractationem hunc in locum rejecerim. Quamvis enim alicubi, præfertim in Anglia, folitarius aut fequeftratus inveniatur alveolus, nobis tamen non nifi plures fimul juncti, \& concreti firmiter, in figuram conicam, hactenus comparuerunt, ita ut ab invicem divelli ægre queant, licet rimis aut lineis circularibus fatis aperte diftinguantur. Exemplo fint Fig. 8.9. \& 10. repræfentati, omnes è calicibus belemnitarum diffractis exemti, materia tamen diverfa conftantes: Nam gemini ifti, Fig. 8. expreffi, faxo fuis bafibus infixi, ad belemnitem candidum antea memo. ratum accedunt; duo fequentes autem è lapide duriore fubcinereo funt conflati, \& alteruim eorum ( Fig. 10.) à poftica parte cortex belemnitæ adhuc amplectitur. Ejusdem plane commatis eft D. Scheuchzeri longior, ex alveolis pluribus, invicems entrochi inftar junctis, columnula, in matrice belemnitica jacens, quam ( $q$ ) delineatam dedit, à fe olim inventam in ipfo Altdorffino agro noftro. Incidimus præterea in alveo-

(p) 1.6. p. 86.8287. (q) 1.6. pag.9. Fig. II. 
los pyritico- ferrugineos, rurfum alios magis molles ac friabiles zerreos. Quod vero Fig. II. fiftit, obelijci mar marei alveolaris Jpecimen, extra matricem fuam, prope pagum Fieidelis-Seofi repertum, ideo eft notabile, quod aliqua faltem in parte fui ambitus feparati appareant alveoli, in reliquis artiflime coaliti.

Sed ad belemnitem redeo, cujus quidem plures fuperesfent enumeranda differentice, quoniam vero levioris funt momenti, ipfis in præe enti non immorabor ; properandum enim eft : Qua etiam de caufa virtutes buic lapidi attributas non vacat expendere. Adeat, cui volupe ent, Autores haEtenus allegatos, inprimis vero perdoctam Baltbaf.Lydii jam laudatam epiftolam, ex qua non poffum quin paucula, fpeciminis loco, huc transferam : Inter alia ad pleuritidem vale.. re putatur, boc argumento, quod muscronem babet. $O$ acumen! Eodem argumento urunt buric lapidem, ad dolores dentium. Quis: non in bac Satyram? Prater promiffum, larga manu fero, 600 mnia converro. \&C.

Diu deliberavi, quonam STALACTITEM, five STALAGMITEM (liceat his vocabulis promifcue uti) reponerem? Vifum tandem fuit affociare lapidibus, ex natur \& lis $_{\text {is }}$, conicis, hinc belemniti fubjungere, etfi in Tabuba antecedenti lapidum figuratorum generali per incuriam fuerit omiffus. EA autem ftalaczites nihil aliud, quam lapis, è confluentibus ac deftillantibus aqua fubterranea guttis, ad cryptarum fornices \& parietes concretus, quando particulæ margaceoterrea, ac falino nitrofe (ut Phyfici plerique ftatuunt) e* aquarum amplexibus fenfim dimifre, ad invicem accamulantur, beneficio poftmodum aëris ambientis condenfantur, \& lapidis acquirunt foliditatem. Ordinarie figura gau. det oblonga, ex ampliore bafi gracilefcens, in modum ftirie', quamobrem \& lapidea firia (Germ. Tropf-ftein/ à fillando) nuncupatur. Caterum fæpius omnino accidit, hanc, quafe 


\section{然( 40.) 然}

conican falactitis figuram, per caufas plus minus manifeftas deturpari, \& in alienam deflectere formam, unde fit, ut in compluribus fpeluncis hoc lapideabundantibus varia effigientur corpora, miranda vifu : Quo nomine in Germania præ cæteris eminet Belunca Baumanni:( cujus, \& aliarum, in Hercyniæ fylvæ tractu Saxonico extantium, accuratam defcriptionem nuper dedit D. Georg. Henning Behrens ( $r$ ).

Nobis fupra memoratæ in cap. II. crypte, \& præter has

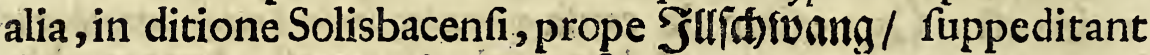
falagmitem, tam facieftiriarum, frequenter concavarum, quam fecus figuratum, candidum ac durum, interne (fi grandiora frufta fint) plendentem fluoris inftar. Quandoque fornices ac hiatus faxorum talismodi crufta obducti confpiciuntur. Eft in Veldenfi feorfim crypta elegans \& amplum quoddam, è fundo affurgens ut columna, rotundum fpecimen, quod quia limini alicujus receffus adftat, canem (Den Şund) veluti cuftodem vulgo dicunt. De Kauerheimenfi vero fpelunca, procul dubio intelligenda funt, quæ Dn. Goh. Henr. Senfrio/:Sereniff. Germania Neftoris, Ducis Solisbaco-Palatini Confliarius Camere (s) retulit, thon indigna, quæ hic infe-

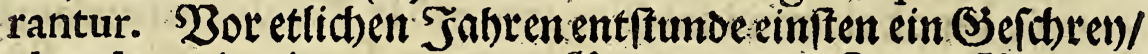
ob fwáren in einer/ an ben (Sirentsen Des Land =:(Śerichts

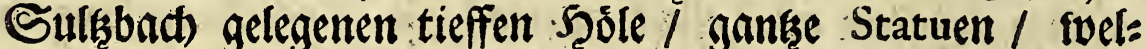
the die Natur aus dem zu Stein gervordenen $23 a f f e r$ / fvie

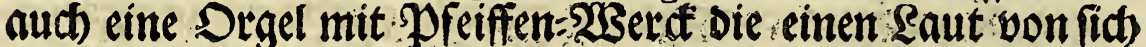
geben/formiret hatte/ / zu fefhen. Scietauf gefahahe ein 3u=

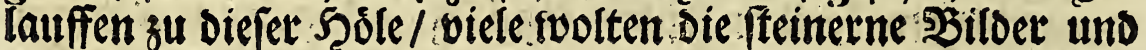
Orgel pehen. (Es befano fia aber auf eingenommenen 2 (u:

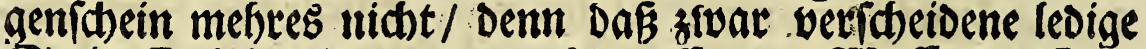
Stein=Stüfe bie nus Dem abtropffenden 23 affer entftan:

Den/

(r) Hercyn. Curiof. Cap. I. integro. (s) Medullo mirab. Nat。 Lib.II. cap.VII. S. 39 . 


\section{楼( 4 I. )}

Den/ ba funden; fie hattent zivar alletband felfame / abeet

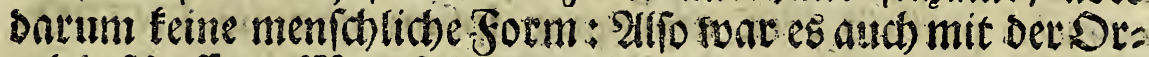
gel befdbaffen: Mian fabe eine eanzabl fodmater/ taum drey

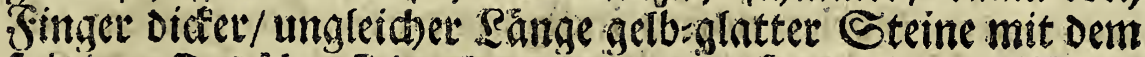

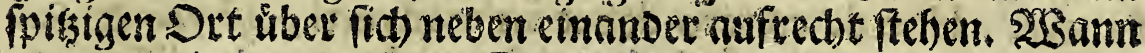
man an einten mit einem Stedfen ichluge/ gab er ein ziemlis

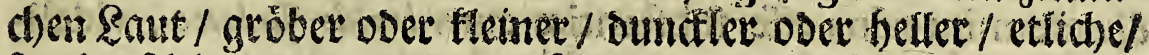
ro abgeisthlagen rworden / befand man im Retrn mit cinem

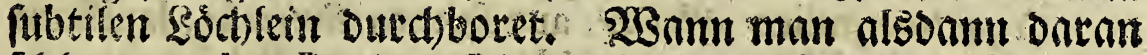

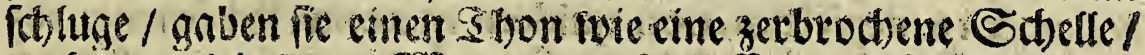

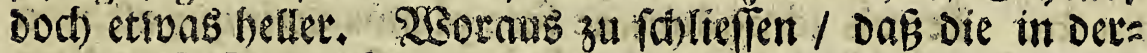

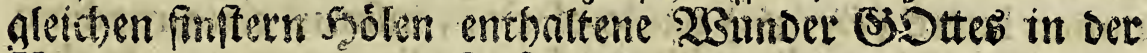

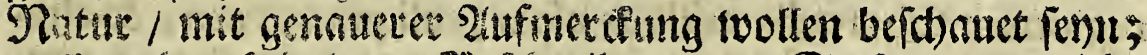

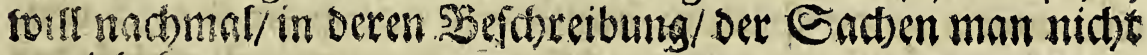
gut viel thun.

Ex genere lapidum, ob foure originis figura mathematica pres ditorum, juxta methodum in Tabula prefixam, delibandi nunc veniunt STELLARES, feu ASTERIE, vel ASTROI, $T$ T , ideo fic vocati, quod ftella imaginem, radiata, \& sapies pentagina figura reprafentant, prout è Tabule noftræ I. Fig. I2. 13. 14. elucefcit, quanquam minus perfecte refpondeant ipfis lapidibus. Neque funt, fateor, tam elegantes hi noftri, oppido licet rari, quam qui aliis in regionibus magna copia colliguntur. Attamen prior (Fig.12.) cum Afteria vera C. Gelneri $(t)$ quæ \& ab eodem Sphragis Afferos nominatur, fatis belle congruit, fed multo minor eft. Coherent autem, more entrochorum, in zsio quation ftelluda, acute angulatæ, difficulter fequeftrandæ. Parem numerum habet alterum exemplar (Fig. 13.) magis obtufurn \& ad rotunditatem compofitum: Hoc in agro pagi 2 sinctelfeio/illud in rivulo quodam Mufis noftris propinquo deprehenfum. Afteria Fig I4. licet folitarie \& libera delineata at, nunquam tamen mihi F hacte-

(t) l.c. pag. $37 \cdot a_{0}$ 


\section{\$2. 42.}

hactenus vifa, nifi in faxo grifeo, pluribus exilibus sion celatibs entrochis perfufo ; ut eapropter ipfum quoque ENTRO. CHVM live rotularem lapidem, tanquam peculiarem figuratorum ßpeciem, Norico noftro indigenam, feorfim poffem adfruere. Hoc de cætero debet animadverti, Afterias \& Entrochos, utut externa facie inter fe quodammodo differant, ejusdem interius effe fubftantiæ cum lapide fudaico, videli-cet felenitica laminatæe ac refplendentis.

Cognatum judico Aftroiti, aut faltem Entrocho, lapillum Fig. 15. \& I6. depitum, non quidem materix, fed formæ refpectu. Tenuis admodum, ac fere planus utrinque eft, uno tamen latere (Fig. 16.) paulo elatior, infimul circa mediam regionem tuberculis exilibus afper; reliquum vero, \& alterius lateris omne fpatium, innumeræ occupant ftrie, à centro ad peripheriam radiatim diffuse. Ex amniculi vicini (Dek (Sd)rant(zad)) fabulo depromtum accepi. Videtur autem effe idem penitus cum Luidii Porpite minori nummulari, five. complanate propemodum figure, quem num. Is I . ac delineatum Tab.III. exhibuit.

Propius ad fellares lapides ille fpectat, qui Fig. 17. fiftitur, ad Pegnefi \& Regnefi confluentes repertus, mihique benevole communicatus à Viro Nobiliff. D. D. Micb. Frid. Locbnego, inter Medicos Collegii Norimberg. Seniores, fama \& felicitate fingulari confpicuo; cui me, non hoc folum nomine, fed \& propter liberalem rariorum librorum commodationem, \& plura collegialis amicitia documenta, haud leviter obftrictum publice profiteor. Ipfe vero lapis, ASTROITES minoribus fellis merito dicendus, marmoreæ eft durisiei, non tubulofus, fed qui.fellularum fimulacra fuperficiei tantum infculpta gerit.

Stellaris figure lapidibus tandem accedat MODIOLVS STELLARIS, à Luidio (u) fic nuncupatus, approbante Scheuchzero.

(u) I. G. pag. $54 . \& 98$. 


\section{$\dddot{W}^{2}(43 \cdot)$ )}

zero cujus defcriptionem $(x)$, quandomagis accuratati concinnare nefcio, bona cum pace Clar. Autoris huc transferam: Conftat lapillus hic è felenitica materia, ficuti Afterie, Lapides Fudaici, alizg congeneres; figura refert criopianulam vel forem monopetalum campanc formem, eusng in in marginiend pentagonum expanfum; cavitatem explet laminaifiellaris; etias pertagona concava; bafis ima non eft acuminata, fed latiuf culaj circello punctato co. ronata, \& puncto centrali excavata. Minus autem appofite hunc lapidem vocari caryophyllum lapideum, idem Autor oftendit, comparatione inter utrumque inftituta, \&c. Ego, perinde ut Luidius in Anglia, unicum hucusque modioli iftius exemplar in his terris inveni, \& quidem in alto monte (ditionis Wolffteinenfis) Codlipfelbetg / ut herbarum felectiorum uberrimo proventu celebri, fic propter lapidum figuratorum varietatem aftimando. Caterum quod habeo fpecimen, Tab. I. Fig. 18. repræfentatum, fatis quidem genuinum eft, etfi non integre confpiciendum, inverfo enim fitu affixum cernitur confracti Nauîlite vel cornu Ammonis centro. ita, ut tres faltem apices cum ima bafi emineant, reliquis profundius immerfis. Hic tamen modioli mei ftatus tanto minus mihi difplicet, quanto infolentius forfan eft, hunc lapillum alis notatu dignis lapidibus, præe fertim Cornu Am monis adnatum reperiri, ut contra folitarium ac liberum occurrere frequentius, vel inde conjicio, quia talismodi complures modiolos, non ex Helvetia folum, fed \& Francofurto ad Mœnum obtinui, per amicum, qui ipfos in vicino huic Urbi loco collectos affeveravit. Num autem hic modiolus fit area ftelle cujusdan marine fofflis, ceu Luidius fufpicatur, id quidem ego tamdiu ponam in medio, donec fellam viderim, cujus modiolo exacte fimilis fit ille fofititis ; certe enim allegatas à L uidio icones, apud Fabium Colsmnam, Vlyf. Aldrovandum, Fab. Fonftonum, minus huc quadrare, quilibet, fine prajudicio inquirens fatebitur. $\quad F_{2} \quad$ Alteram

(x) l. c.pag. s! 


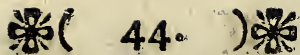

Alteram nunc aggredior clajfem lapidum, è nature lufu, vel zincerta de caufa figuratorum, nempe illorum, qui Vegetabilia $f$ Animalia, eorumg partes referunt. Ero autem in his exponendis paulo brevior, quod fculptæ plerorumque imagines, vel folax, fatis loquantur. Agmen ducat DENTRITES, five lapis,

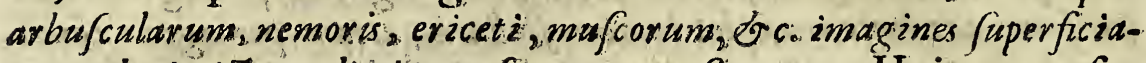
rie; veluti pictas, diminut forma reprefentans. Hujus non folum in Comitatu Pappenheimenfi, fed etiam Epifopatu: Eyftettenfi variæ infignes differentize pafim reperiuntur. Quin \& è lapidicina Herfpruccenfi egregia fatis habeo fpecimina. Unum vero, præ omuibus mihi charum, fortuito impetravi, cum in proxima Altdorffienfi agro lapidem cinereum \& rudem, facieque externa tale nihil promittentem, confringerem : In medio enim ucriusque fragmenti adum bratos fpectabam montes qusafis confitos fruticibies, tanta quidem pulchritudinis ac fubtilitatis, quæ nullo vel optimi artificis penicillo aut calo poffet exprimi Plura de Dentrite non addo, quoniam hoc genus lapidum Clarifr. D. D. Scheuchzerus, exalciata quadam epiftola $(y)$ curiofe admodum evolvit.

Sequantur nunc diverfarum in lapiditus fructuum fimula. cra: Quorum in ordine primum facio LAPIDEM JVDAICVM, cujus fynonyma antiqua \& nova, compluresque differentias enumerat Luidius ( $z$ :. Major isque vulgatior ac:

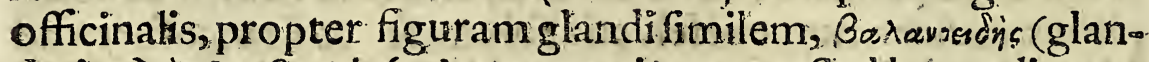
darius) à Diofroride (aa) cognominatur Sed hæc, aliæque fpecies, in hac regione mini nondum occurrerunt, præter illam, mediz modisli, Fig. 1y. T. ah. I. delìneatam, cujus unicum hoc exemplar in monte Gul(3bira/duriflimo faxo claufum inveni. Coincidit autem lapis ille meus cum radiolo cucu. mevina minori Luidia (num.I008.) \&melius fanerefert minum

tum:

(y) Vid. A pend. ad E hem. Germ A N.C Dec III Ann. V. \& VI. (z) I. c. p. 49 \& fequ. (ab) de Mat. Med. Lib. V. cap. $155^{\circ}$ 


\section{承( $\left.455^{\circ}\right)$}

tum cucumeris fructum (einen fleinent Fenchel-Siummerling) quam fculptor expreffit, neglecta tuberculorum afpredine, ftriis uberius intermixta. Cærterum lapides fudaicos marinovum echinorum effe radios petriffcatos, affirmat quidem Luidius, nec fine omni probabilitate, quantum ad ang ufficores five graciliores fipecies, fed quomodo cum ampliaribubs ipfisque glundaris conciliari queat hac hiypothefis, non intelligo; tantre enim craflitiei, cum brevitate conjunctæ, vadios ecbinorum me nullibi vidiffe recordor. Fortaffe tamen hæc, aliaque circa hiftoriam Lapid. fud notabilia \& obfcura dilucidabit laudatiflimus scheucbzerus, quod ut præftare, datamque (bb) fidem liberare velit, publico ipfum nomine obteftor.

Proxime ad lopidem Gudaicum forma externa accedit, defignatus Fig 20. lapillus, valde etiam durtus, fed difparis materiæ, \& fuperficieilævis, ob hanc vero, tum magnitudinem congruam, ¿ pediculi velut evulfi veftigium, magis quam ulIus Judaicus lapis, FRVCTVI OLEE (einter Oliven) SIMILIS; repertus: ad pagum Tieichels-hoff.

GRACILIOREM OLIVAM quodammodo Fig. 21. PRVNVM vero grandius, femi maturum, quoad colorem etiam exactifime, Fig 22.AMYGDALAM, Fig.23. CERASORVM OSSTCVLA, Fig. 24. \& 25. depicti lapides exprimunt; ommes collecti è terra glauca, fifili \& pyritofi, qualis eruitur Altdorffii, quando cellæ pro affêrvanda cerevifia fodiuntur aut amplificantur. Sunt vero hi lapides duri, ponderofi, ac fapius de pyrite participantes, colorem terræ matricis fux, aut alias lividum gerunt, frepe ruffefcunt, aliquando flavefcunt, interne præefertim. Mulio plura borum lapillorum, frue Itus \& nucleos ominino diverfos referentizum, Specimina pofferm producere, \& fingula convenientibus, licet novis appellare nominibus ; fed tempori parco \& chartæ, hoc faltem addens, confueviffe me id genus natura lufuum circo lapides, in ea$\mathrm{F}_{3}$ dem

(bb) Specim. Lithograph. Helvet, p. 26. 


\section{野( 46.) 噡}

dess matrice, tam varioresri, termino CAR POLITHI ALTDORFFINI (Gcuit)tfeit) per feria \& jocum indigitare. Huc vero etiam pertinet lapis, Fig. 29. SILIQVE PIPERIS INDICI, vel apfici, utcunq affimsilandus.

PYRVM MOSCHATELLINVM, aut aliud exiguum, Fig. $2 \gamma_{0}$ fiftitur in lapide, non folum apta magnitudine, fed 86 umbilico gaudente, vicem pediculi fuftinente fragmento conchita, quod loco fatis congruo ef impactum: GRANDIORIS vero PYRI effigiem xmulatur Fig. 28. exhibitus lapis; hic prope pagum (Eifmonnsberg / ille ad Reid)elö. boff inventus.

Mali Perfici majoris imitamentum, in lapide duro \& albicante, non procul ab Setrpetucf deprehenfo, oftendit Fig. 27. adeo quidem accurate, ut præter colorem nil videatur deeffe: Dignior fane hic nofter, qui PERSICITES vocaretur, quam Vlyfs. Aldrovando (cc) eodem nomine veniens, delineatus lapis, ut ex collatione figurarum cuilibet apparebit.

Propofiti Fig. 30. \& 3r. lapides, de monte Sd)lipfel= betg/ haud multum abludunt à FICOIDE Scheucbzeri $(d d)$ inprimis, quia minor nofter, perinde ut alter ipfius, circa umbilicum, aut centrale verticis foramen, numerofis ftigmatibus velut acu factis ent punitatus, quod neglexit chalcographus. Caterum an rectius ad ALCYONIA FOSSILIA, an ad FVNGITAS reducantur ifti lapides, alii disquirant.

Similitudinem quampiam Fungi pileati habet Fig.32. delineatus lapis, \& fequens Fig. 33. ad alcyonium propius accedit appericate \& porofitate eximia; offendi ad Neagorum, in monte Calvarix. Alcyonio huic foffli affinem facio lapidem Fig. 34. repræfentatum; quamvis enim altera extremitate, ubi rugofo cortice tegitur, radicis intortæ vultum gerat, parte tamen altera, qua latior eft ac decorticata, denfiffime

punda-

(cc) Mufai Metall.Lib.IV.p.50g. (dd) 1. c. pag. i7. 


\section{然( 47. ) 夥}

punctatur, porisque fcatet innumeris, licet iterum à fculptore pratermiffis.

Lapides, integrorum animalium corpora ex lufsu naturie fino gentes, quos recenfeam vix habeo; partes tamen animalium, \& buc Bectantium quarundum rerum imaginem qui mentiuntur, nonnullos in Tab.I. depictos enarrabo. Fig. 35 . Corio fufco quafi obductus cernitur lapis; numerof etenim areolæ, inæquali forma, magnitudine ac diftantia fua, CORII ANTYQVI SVPERFICIEM, in fruftula debifcentem, pulchre imitantur. Aliquot ejus fpecimina fe obtulerunt in vicino rivulo verfus molendinum (Sd) leiffimůbl.

PETASVNCVLVM, aut Pernam exiguam, è lutifodin. Altdorff. in minimo fiftit modulo Fig. 36 . cortice glabro, tanquam corio veftitam, infuper ampla portione offis prominula gaudentem: Sed neceffe eft, ut non attendat curiofus fpectator defectus ac diffimilia ratione coloris, magnitudinis, \&rc. fecus tota fere peribit fimilitudo.

Fig. 37. PAPILLAM MVLIEBREM, Fig.38. autem PENIS PVERILIS anteriorem partem, praputio denudatam, quadantenus adumbrat, invento utroque lapide inter fupra dictos carpolithos Altdorffinos.

Pedem bominis extremum, SANDALIO indatum, non ille pide refert Fig. 39. CALCEAMENTVM vero, duplici confpectu vel fitu, Fig. 40. \& 41. exhibetur, ubi fupremam fimbriam, aut alam (Die Enfchen) fragmentum belemnitæconftituit. Denique MVSTRICVLAM, feu formam calcei (einen (c)ul)-leiften) Fig. 42. defignat; quos lapides fingulos unde acquifiverim, non amplius fuccurrit.

Apicem cornu alicujus aduncum, variis ornatum ftriis atque ftigmatibus, haud obfcure exprimit Fig. 44. ut CERATITES facile mereretur dici: Sed fraus eft, nihilque aliud, quam Cornu Ammonis arcus, altera extremitate cafu quodam detritus \& acuminatior redditus. Qui Fig.45. fiftitur lapis, RON 


\section{范( 48.) )}

non caret fpecie DENTIS APRI; fatis enim incurvus, nec inconcinne angulatus eft, apicis vero acie deftituitur.

Sed exemplorum jam plus fatis, quæ doceant magnam; in regione noftra, varietatem lapidum figuratorum, ex lufu nature taluum, aut minus explorate originis. Poffet in immenfum augeri Catalogus, fi operæ videretur pretium: Habebit autem jam Lector curiofus in modo prolatis, quod admirari, ul: terius fcrutari, vel (fi magis hoc placet) ridere queat.

\section{CAPVT $V I$.}

\section{DE LAPIDIBVS EMMOPФOI SEV FIGVRATIS, EX QVORVNDAM VEGETABILIVM ET ANIMALIVM TRANSMVTATIONE.}

Vanquam fuperiori capite expofitos lapides, rebus aliis, vel animatis vel inanimatis quomodocunque figura fimiles, non ab iisdem profestos, fed ut materiam, ita formam fuam aliunde mutuatos, \& obfcuræ admodum originis effe perhibuerim; minime tamen defpero, quin modico temporis intervallo ingenia feliciora, continuatis obfervationibus, plures iftorum lapidum, e.g. belemnitas, entrochos, aferias, lapidesfudaicos, \&c. ad genus magis proprium fint redueturi, \& natales eorum, hactenus latentes, revelaturi. Interim bonam jam partem figuratorum lapidum, quos antiquitus plurimi, hodieque nonnulli, pro meris naturæ lufibus vendita. runt, modernorum fobrie magis philofophantium induftria rectius dijudicavit, \& ab iisdem rebus, queis aflimilantur, præter certum alicujus, quam perpeffæ fint, alterationis gradum, neutiquam differre, comprobavit.

Hujus itaque generis lapides, in Norico noftro hactenus obfervatos, recenfere nunc opportunum, \& factæ in Tabula 
difpofitioni confentaneum eft. Ubi quidem præmoneo, transmbatationis terminum à me non accipi eo fenfu, quo perfectam \& omnibus numeris abfolutam unius corporis in aliud, tam quoad materiam quam formam, denotat $\mu \varepsilon z u_{-}$ Bonvy: Sed talem hic intelligo moitationis modum, quo corpora quadam, e. g.vegetabilia ant animalia, de naturali ftatu fuo ita recefferunt, ut in aliquibus fais affectionibus, loco, extenfione, confiftentia, pondere, colore, \&re. alterata fint, relietis nihilominus quibusdam evidentibus, fi non materiæ, at faltem formæ priftinæ characteribus \& notis.

Sape etiam accidit, totam fere prioris corporis materiam evanefcere, ipfius autem formæ hæredem ex affe fieri heterogeneam poft accrefcentis lapidis fubftantiam: Qualem vicifitudinem laudatæ transmutationi cognatam ideo pronunciare non vereor, quia iftam formam nunquam recepiffet materia lapidefcens, nifi eidem præexiftens corpus occafionem dediffet. Exemplum ejus præbet luculentum MVSCVS PETRIFICATVS, vulgo fic dictus, de quo, præertim quantum ad natalem penes nos locum, jam fupra egi, Cap. II. pag. 9 . Hic ratione materie à topho parum vel nibil differt, formam autem mufci terreftris fequenti, ut opinior, modo induit. Quando aquiæ, particulis faxeo-margaceis intra terræ vifcera imprâgnatæe, fcaturiunt, ac per illius fuperficiem fefe diffundunt, in progreffu autem forte ad mufcum allidunt, non poteft non earundem ex parte motus hinc reddi languidior, infimul præcipitationi anfa fuppeditari, ut fubinde aliquid affigatur \& adhærefcat poris atque ramulis mufci de materia prafata margaceo-lapidea, cujus aggregatio fic continuata fenfim evadit in cruftam lapidofam, magis ac magis obrigefcentem. Ipfe vero mufcus arcto hoc materiæ tophacea amplexu compreffus, \& aëris liberiori commercio orbatus, paulatim emarcefcit, \& in pulverem pro modulo quantitatis fua redigitur; qua ratio eft, cur hujusmodi petrificatus 


\section{米( s0.) 粶}

mufcus, fi frangatur, intus. in fingulis ramulis foramine fit præditus, quod probe annotavit D. Foh. Dan. Geyerus (a): cum interim tophacea illa crufta ad figuram mufci, quem inveftiebat, conformetur, nunc quidem accuratius, nunc rudius, prout materia ejus, extiterit vel fubtilior vel craflior, ipfaq; concretio tenerior vel fpiffior fuerit.

Paria cum mufco fata fubire coguntur plante alie, ip $\int_{a}$. rumg partes, coliculi, radices, \&c. fì à topbaceis aquis diutius alluuntur. Quin etiam arborum folia \& vamenta confimilem experiuntur rortunam, quando immerfa jacent iisdem aquis, ut tandem crufta tartareo-lapidea obducantur; quæ illorum figuram ac typum retinet, pofteaquam ipfa folia aut ramenta intus corruptione jam perierunt. Nos geminum tale: fpecimen oftendere poffumus, FOLIA nempe QVERCVS \& FAGI dicto modo PETRIFICATA, aut potius, quæ involuta topho, fuam figuram in eo expreffam (abqedrudt) reliquerunt. Hujus tophi, ex innumeris foliorum laudatorum (facile diAtinguendorum) ftratis conflati, ampliffima moles confpicitur eo. dem quo mufcus petrificatus loco, prope Şagenhaujen : Exiguum vero illius fragmentum Tab. I. Fig. 43. delineandum curavi. Neque alia ratione, quam per incruffationem declaratam lapidefcere mufcum \& quisquilias plantarum, animadver. tere mihi hactenus, licuit; tametfi non dubitem, quin alibi alio quoque modo, fcilicet per infinuationem fucci lapidefcent is in poros as intimiora vegetabilium, eadem penitus durefcant in lapides, id quod confirmat fane curiofa, fi quidem vera eft, Athanaf. Kirchert (b) relatio: Prope Ronolanum, Senenjis territoriz oppidum, duos fontes calidos obfervari, quorum aqua per canales ad molares rotas vertendas ducitur. In bisce canalibus.cyperum, juncos, ranunculum, fimilesg, herbas tanta adolefcere facunditate, zit quotannis eas, ne aqua motum interturbarent, extirpare oporte-

ret:

(a) Ephem. Germ. A. N. C. Dec. II. Ann.V. obf, 2320. (b) Mundi fubterran. Lib.V. cap.III. S.7. 


\section{然( 51. ) 夥}

ret; extirpatas vero projectasg, in vicinum locum berbas omnes, in lapidem conver.jas, non fine admiratione Jpectari, \&rc. Cujus quidem phænomeni caufam non aliam citatus Autor, ipfeque aisrom rns, agnofcit, quam quod cum iftiusmodi a guis fuccus lapidens, five Biritess petrificus intime commixtus jit, quem pro alimento attrahebant plantæ; ut contra, que non perfecte, fed confufa quadam ratione cum petrifico fucco vel piritu commixte funt aqua, iftam heterogeneam materiam nequeant altius in plantas infinuare, fed eas cortice quodam lapideo tantum externe induant.

Sed magis genuina eft transmutatio lignorum in lapides, quæ hinc LITHOXYLA vocantur. Horum ultra duodecim varietates, in Territorio Norimbergenfi locisque vicinis deprehenfas, monitrare poffum, tametfi non æque clare liceat ex omnibus cognofcere, qualia peciatim ligna fuerint. Quercinum, in lapidem duratum, quod vulgo DRYITES audit, valde ponderofum, coloris ferruginei, é foffa Oppidana Altdorff. erutum, cujus etiam 1. c. meminit beatus D. Maur. Hoffmannus. Aliud, quercino perquam fimile, fed coloris cinerei, ex medio praegrandis \& quadrati faxi, non procul d monte Renfsenberg / defumtum habeo hujusque perzicrilam quandam feorfim admiror, eodem plane modo, gro lignum aliquando flet, undulatam. Rurfus aliud, prope urbem Neumateft effoffum, à priori tamen, quoad colorem ac fibrarum difpofitionem haud parum differens, ita ut dubitem, an Dryites, \& non potius ELATITES feu abiegnum fit, cui fane proximius accedit quam illi. Hoc vero utrique eft commune, quod paffim in fuperficie adhæreat, \& rimis aut fiffuris innatus fit fluor candidus, ex parte pellucidus. In quodam Neagorenfi Litboxyli frufto apparet evidentiffime rami, de trunco abrupti, veftigium. Elegans quoque reperi fpecimen in pago Şsffen : Saxo nimirum grifeo atque duro, tres uncias longo ac totidem fere lato, transverfim \& firmiter infidet 


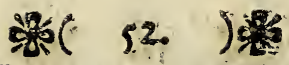

LIGNOSE RADICIS petrificata portio, fervata nihilominus. adeo figura naturali, ut trachearum \& utriculorum cavernofa compages ad oculum omnino pateat. Lithoxylon porro egregium, albicans, in monte Sultzbergo inveni, prioribus quodammodo folidius, \& quod faginum album (weiß SBúchen) fuiffe videatur, quale alias Lithographi Græcanico vocabu. Io PHEGITEM nuncupant. Alteram ipfius fpeciem, vide-

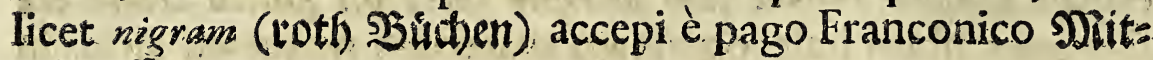
telourfi.

Cæterum omnes hactenus indicatæ $L$ ithoxyli differentic molles funt ac friabiles magis, fi comparentur ad alias, in hac pariter regione detectas. Eft in platea coriariorum, Norimbergæ, in ædibus llluftr. Fürerorum Familiæe propriis confpiciendus arboris PYRI, ut exiftimatur, TRVNCVS, olim quidem procerior, nunc autem, poft creberrimas decufliones, duorum circiter pedúm altitudine fupra terram eminens; quem non ibidem procreatum, fed alibi jam petrificatum, hic aliquando fuiffe infertum, abfentia radicum arguit. Color ipfí ex fufco nigricans, interfperfis candidi ac vere cryftallini fluoris ductibus: Durities vero tanta, ut non folum chalybis allifu frequentes eliciat fintillas, fed etiam polini exarte queat, \& f calpturam, jafpidis inftar, optime ferat, ut frepius figilla inde concinnata viderim. $\mathrm{Ab}$ hoc Lithoxylo parum abludit, quod, Lonerftadii in Franconia deprehen. fum, obtinui procurante Domino Leonbardo Conrad', Viro inwer Officiales Eleemofynarios Norimberg. præclare merito; cujus etiam liberalitati debeo alia ligni petrificati pulchra fpecimina, nempe 2uercinum (ut conjicio) itidem duriflimum, ex pago 2roelidorff/ nec non. ABIEGNVM RV-

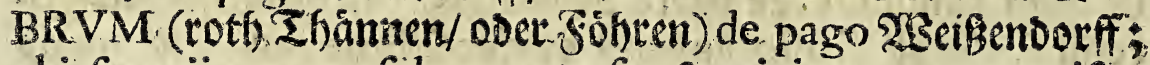
ubi fesquijugerum fỳlvæ, ante fex \& triginta annos excifæe, \& in arvum mutata, confimilibus abiegnis caudicibus, ac fegmentis in: lapides conven is, refertum effe narratur. 


\section{\%( 53.) )}

Taceo plures Litboxyli Norici huc trahendas varizetates, alia forfan occafione proponendas: Lignum autem foffle hituminofum, infra, loco magis congrúo defcribetur. Interim, fi fas eft rimari lignorum in lapides mutatorum originem, ipfa moleculis falinis \& faxeo-calcariis, mediante aqueo vehiculo in poros ligni fe infinuantibus, ibique, poft excuffas ( $q u a$ ligno propriæ erant) falino-fulphureas volatiles particulas, pedem figentibus, folet attribui; nec fane citra rationem, quam tamen prudentioribus ponderandam committo. $\mathrm{C}$ terum omnia Litboxyla fub univerfali diluvio, aut ftatim poft illud, formata effe, ut nonnulli autumant, experientiæ minus eft confentaneum; fiquidem bodienums \& quotannis ligna quadam lapidefere compluribus fide dignorum fcriptorum teftimoniis perhibetur, ita ut nec artificialis petrificatio lignorum fuis careat affertoribus, quos inter ad unum provocare jam lubet fob. Kentmannum (c): Ex alno (ait) artificiofe fit lapis boc modo i imponitur lignum, quante velis magnitudinis, in labra illa ampla anea, in quibus lupulus coquitur, ad faciendam cerevifarm; cumgs percoctus abunde lupulus eft, eximitur item lignum, es aren vel glarea in ipfis cellaris obruitur per triennium; inde cum exemptum fuerit, duratum in lapidem apparet, è quo potiffimum cotes funt, quibus ad ferramente acuenda menfariz utuntur. Sit fides penes autorem: Erit faltem, ut quis hujus afferti veritatem ipfemet experiatur, major fpes, quam habere potuit Scholaficus ille; qui, cum audiviffet, corvum ultra ducentos annos vivere, ut periculum faceret, corvum emit \& aluit.

Ego à vegetabilibus petrificat is ad ANIMALIA me confero. Horum autem, fi excipiam tefused peculiaribus tradenda capitibus, vix aliqua apud nos remanebit meffis. VNICORNV quidem FOSSILE ( quod nomen jam omne genus alteratorum in terra offum defignare folet) Noricum noftrum olim fuppeditabat, inprimis e Veldenfi crypta; inde

$$
\text { G } 3
$$

enim

(c) Nomenclat. rerum foffil. pag. 39 . 


\section{果( 54. )}

enim Cap. Hofmannus, prout iple $(d)$ teftatur, offa habuit lapi: dea, magna \& parva, variarum figurarum ferioris, dentium, \&c. iusdem cum ebore vel unicornu foffili fubftantie, ejusdem q 'ffectus. Confentit Dn. Senfried antea laudatus: (Ftlid)er Drten fin: Det man audh / in folaber Soble / eine bejondere 2(rt unbefnnd: ter Sfiete Rnod)en/ ivelabe die Sano-seute in mandherlen Rrandbeiten gebraud)en/ uno jederiveilen glüfliche Curen baburd vertidten. Quin etiam propius Altdorffio, in memorata fepius profunda valle feu crypta Grünfpergenfi, talia offa quondam reperta affirmat Autor Nymphe Noridos (e):

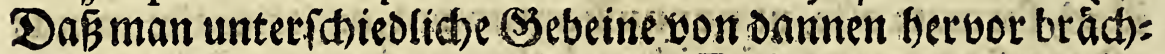

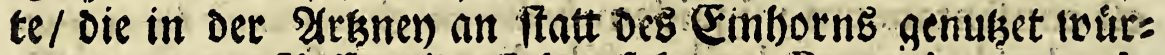
ben/und Dem Sifft twiderftefen folten. Remotius vero, in confiniis Territorii Norimbergenfis, feptentrionem verfus, ad oppidum Bambergenfe.2Boocnffein/ fimiliter offa, magnig dentes, Vnicornu fojfetis jpecimina, ante paucos annos depromta, Fob. Fac. Diax / feplafiarius Norimbergenfis $(f)$ narrat.

An autem hodie alicubi circa nos fodiatur, nequeo as feverare; fiquidem nihil adhuc fum confecutus, præter unicum dentem plane filiceum, longum \& acutuim, è monte Sulk: butg (cum ejus quædam portio, juffu lluftriff. Comites, pro horto complanaretur) erutum, nec tamen facile dignofcendum cujus animalis dens ille fuerit. Hoc interea cum optimis plerisque recentioribus Philofophis ac Medicis periuafum exploratumque habeo, cuncta illa, five cornua, five dentes, five offa foffilia, \& ratione fubftantiæ, ut apparent, vel petrificata vel calcinata, haud quaquam ex lufiu naturæe producta, fed ipforum varii generis animalium, terra margacea obrutorum, partes \& reliquias, diverfimode alteratas effe. Modum vero quo hæc eveniant, juxta cum aliis ad earundem rerum hifto

(d) Paralipom. Officinal. cap. XXV. Rammer/p.92.

(e) pag. 178. (f) Material- 


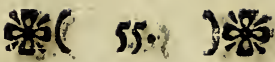

hiftoriam pertinentibus momentis, dexterrime declaravit Clariff. D. Fob. Samuel Carl, Öringenfis, Amicus nofter \& in Academ. Fridericiana quondam commilito æeftumatiflimus. edito Lapide Lydio Pbiloofophico-pprotechnico, ad offium fofflilium docimafiam, analytice demonfrandam, adbibito; quod fane friptum, eruditum pariter ac curiofum, non poteft non attento Lectori \& de hac materia folicito fatisfacere:

Cæeterum ad petrificata ex animalibus referri debent ICHTHYOSPONDYLI, aut $p$ if Gizm majorum vertebra; quarum ingens varietas occurrit alibi, maxime in Anglia; fiquidem Nobil. Luidius (g) diverfas fpecies longa enumerat ferie. Apud nos vero funt rariores, ut vix quatuor bucusgs invenerim Jpecimina. Primum fiftit Tab.VI. Fig.32. ipfumque fatis elegans: due funt vertebre, olim conjunctæ, \& etiamnum, licet divulfre, adeo congrienters, ut alterius apophyfis, aut proceffus conicus, exacte repleat alterius cavitatem feu acetabulium. Quin \& Jariquerevor (quas in fuis Tyrolenfibus quoque pondyloli-

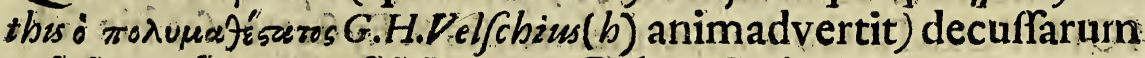
origines clare confpiciuntur Color eft nigricans, tam extra, quam intus; ubi tamen puncta aut foraminula variegata poros feu alveolos medullares adumbrant: Secundum exemplar, Fig. 33 Tiab. eadidepictum, prioribus icbthyofpondylis multo eft compreflius five humilius, colore ferrugineum, utrimque leviter concavim, fed informe, ita ut haberi poflit pro Luidiz (num: 1624.) Latrunculo obfipo : Feu alveolo oblique inclinato.n. Videtur autem; ut obiter hoc tangam, folertiflimus ifte Lithographis latrinoulz vocabulo refpicere ad figuram, qua nonnullä petrificate vertebra gaudent, calculo feu orbiculo aleatorio (cinen 5 trettipiel-ftein) fimilem; cum latrunculus proprie ad Scachicum lufum pertineat, \& faftigiatæ magis fit formæ. Tertius, quem poffideo, icbthyopondylus, æri non-

dum

(g) 1.c. p. 83. \& fequ. (b) Ephem. Germ. A. N.C. Dec. I. Ann. I. obf. $15 \%$. 


\section{柲( 56.) 夥}

dum incifus, reliquis eft grandior; altitudo enim uncialis, in ambitu vero feptem prope uncias colligit. Utrinque pariter oftendit cavitatem, fed alteram ampliorem, cum quadam deformitate: Cortex autem, fufci coloris, cervinum quodammodo cornu refert, ficut Livids num. 1607. 2uartum denique /pecimen, quoad colorem \&-materiam primo parum diffimile, mollius tamen eft, nativæque $i c b t h y o f$ ond $d y l i$ texturæ \& gravitati propinquius, nulla vero apophyfi, ut Num. Io praditum: Erat enim, cum offenderem, utrinque planum, fed unio mox latere cavitatem aperiente, pofteaquam infidens alterius cujusdain $p_{p}^{j}$ indlyli apex fuit excuffus. Longe vaftiorem illis omnibus ichthyogondylum affervat laudatus fupra Dn. Im Hoffurs, alia forfan occafione prolixius defcribendum: Meos interea partim in fabuleto, partim quodam ri-

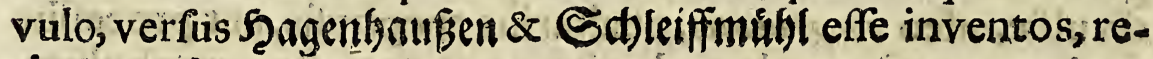
ticere nolo.

Minime abfurdum foret, fi lichtbyomorphos lapides, aut ICTHYOLITHOS Pappenheimenfes \& Eyftettenfes hic fubjungerem, quia diftincz a pifcium pecies, præfertim quoad fceleton \& offeam fubftantiam, non tam piktæ, (ut in dendrite imagines vegetabilium) quam elatius aut profundius inharentes is lapidibus fae viftuntur, at ideo pra pifcibus vere pecrificatis putari queant. Sed enimvero cum nondum fufficientibus ad hanctractationem experimentis inftrußtumime fentiam, in aliud tempus eandem différo; uti nec de $V \cdot n$ cornu, vel offum \& Ichthyopondylorum fofflium origine, mentem meam in præfenti vacat explicare, nif quod tribus quaft verbis infinuem, me ifta pleraq; pro univerfalis Diluviz reliquits habere. Facile tamen crediderim, fequentibus etiam feculis quædam offa animalium, hinc inde, variis cafibus terræ idoneæ mandata, conceffo fufficienti temporis fpatio, cæterisq; paribus, fimilem quadantenus diluvianis illis alterationem ac immutationem fubiiffe.

CAPVT 


\section{慗( $5 \%$. ) \\ CAPVT VII. \\ DE PETRIFICATIS TESTACEIS, SPECIATIM VNIVALVIBVS.}

Uandoquidem non plane rudibus \& indortis feribere conttitui, quid intelligam per TEST ACEA vix opus erit ut declarem. Notum enim eft abunde, generali hoc vocabulo venire Animalia exanguta, fubfrantiam intus babentis carnofam, foris duram \& firmam, que \& flexu frangi, \& ictur rumpi poteft : ficuti charactere's hofce, jam pridem frijtoteles (a) teftaceorum generi adjudicavit. Ipfa vero exterior dura portio, qua in univerfum Tefta, Germ. Schneden- tund SDitchel-

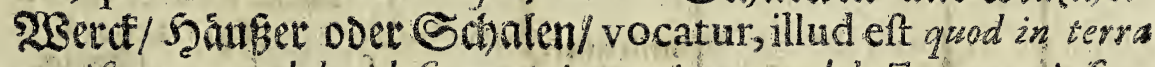
petrificatum, vel lapidofa materia vemixtum, obduczums aut infar¿tum frequentiflime deprehenditur; carnofa enim animalium eorum fubftantia fimul durata in lapidem rarifime cernitur. Quamvis autem fape nullum amplius fuperfit tefte. veftigium, ejus tamen ad formam \& modulum efficti lapides, quatenus hanc figuram foli tefte acceptam referunt, pro teftaceis fofflibus æque merito valere poternnt.

Divifionem eorum quod attinet, Capite $V$. jam edocui, redire ipfam ad duas Claffes generales, Univalvium nempe \& Bivalvium; quia vero utraque rurfus late admodum patet, confultum erit, ut fingula feparatim tractentur. Quare VNIVALVIVM feu ex unica quadam \& continua tefta conftantium primo difributionem fequenti adornabo Tabula, quam tamen non nifi in Noricos ejus generis lapides, imo ne hos quidem omnes, fed mihi faltem hactenus perfpectos quadrare ultro fateor, \& ipfemet præfagio futurum, ut accedentes novæ fpecies hanc Tabulam extendendi \& corrigendi neceflitatem fint impofituræ.

H

TAi. III.

(a) Lib. IV. de Hiftor. animal. Cap. I. 


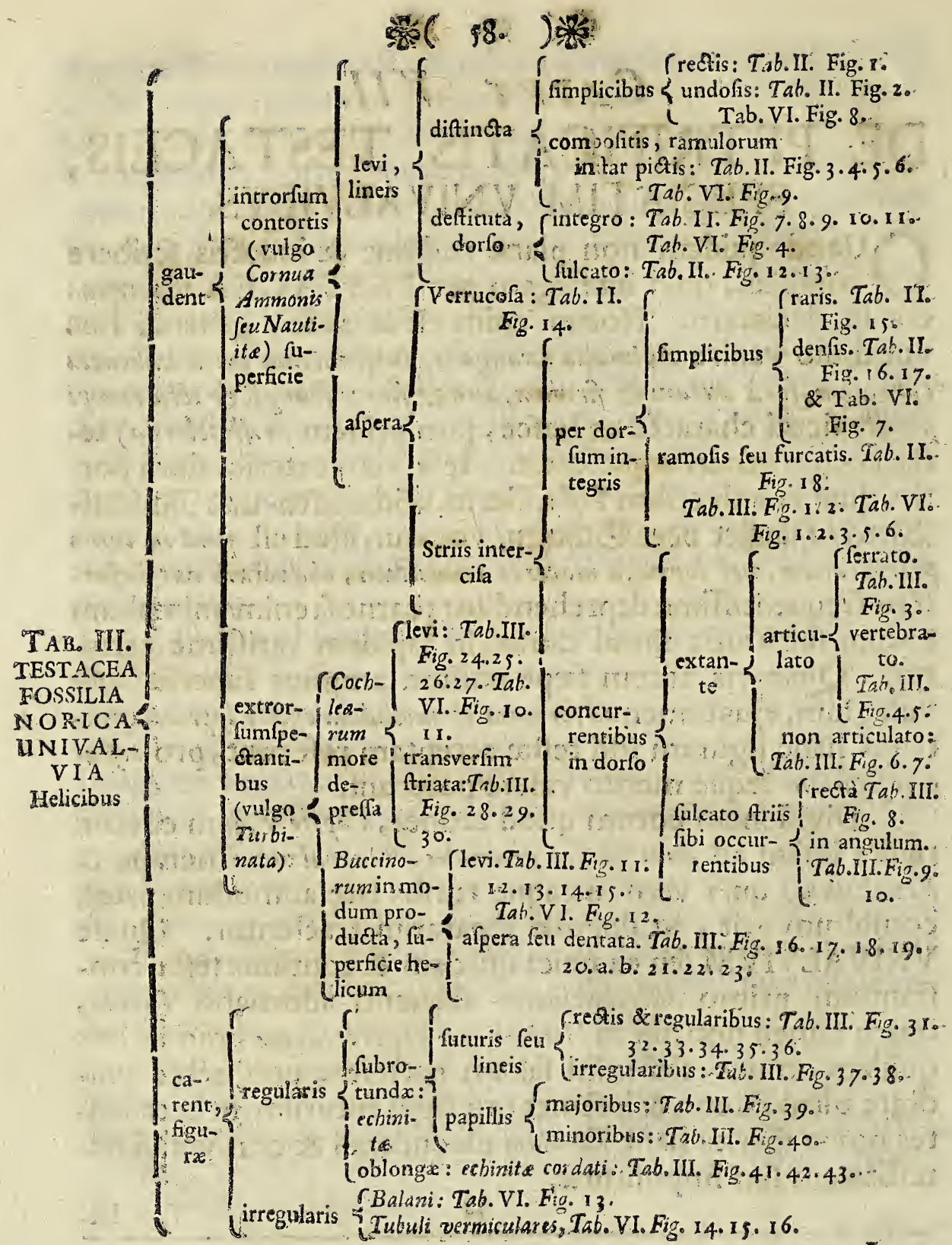




\section{粼( 59. ) 影}

Inter Vnivalvia regionis noftre foffilia, que volut is aut bes licibus gaudent, agmen ducit CORNV AMMONIS, ita nuncupatum lapidis figurati genus, quia fpiras in fe convolutas \& intortas habet ad inftar cornu arietini, qualibus armatum fovem Ammonem fuum Gentiles finxerunt; quam traditionem, \& quicquid eft my thologiae, diligenter evolvit Clariff. Foh. Reiskius (b) . Ut vero cornuum intorum conformitas cum teftaceis foffilibus homonymis elucefcat, fovis Ammonis cornuti imaginem, nummo aneo expreffam, hic lubet inferere: Cufusille eft, Mytilencorum do Pergamenorum concordia, JubPratore Valer. Ariftomacbo, ceu alterius lateris infcriptio (Efculapium ftantem \&. Cybelen cum currito capite fedentem includens ) indicat: Delineatum ac defcriptum dedit Vir Rei numaria, præfertim veteris, peritiffimus, And.Morellus (c). Subjungo, majoris illuftrationis caufa, nummum alium, Moyjs cornuti, quem infignis ille Polyhiftor Thom. Bartbolinus (d) exhibuit, ratus, eundem nummum in opprobrium Chritianorum a Judais factum, quos eo nomine male habere, Steuchus autore eft, quod cum cornibus Moy/en Chriftiani depingant. \&C.
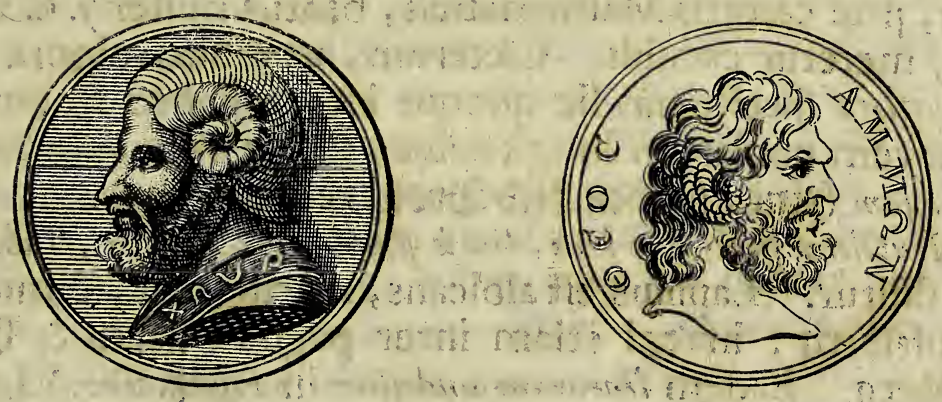

$\mathrm{H} 2$

Cornus

(b) Exercic hilor Phyf. de Cornu Hammonis, Cap. Il. (c) Specim. rei numar. antiqu. p. 240. (d) Obf. nov. de Unicornu Cap. III. 


\section{楼( 60.) )}

Cornu Ammonis Synonymon, recentioribus ufitatum, eft NAVTILITES, quoniam inter cunta Teftacea vel Conchylia. hodie decantata, nullum exiftit, cujus figuræ propius accedant Ammonis cornua, quam Nautilo, fic vocatæ tefta, navicuì lam reprefentanti eminentem, puppe in fe ipfam reflexa. Quæcunque igitur teftace fofflia talem obtinent volutæ conditionem, ut centrum nullo in lateve promizeat, fed depreflius aut faltem æquale fit helicibus reliquis, ea omnia, non obftante difpari volutarum numero, magnitudine, \&c. Nautilite vel Ammonis cornus dici folent. Quam ampla vero ipforum fit varietas, è tabulis noftris quodammodo poteft perfpici, licet muito plures extent differentiæ, ab aliis jam traditæ, \& $\vec{a}$ nobis quioque hic terrarum forlan in pofterum detegendæ. Interin depictarum secierum fynopticæ recenfioni me accingo.

Nautili vulgationis fouram, fi quis alius, accurate exprimit lapis (Tab.II. Fig. I.) dicendus Natutilites fupes ficie levi, lio neis fimplicilis rectis. Maximam partem tefta fua pertenui vefticitum, è faxo pragrandi, prope Altdorffium, verfus \&en= Benberg/ excuffi. Sunt antem ejus volutæ ita comparatæ, ut cum circulo nihil commune habeant, de quo firarum genere, pra cateris Mathematicis, beatus nofter $\mathcal{F}$. C. Sturmins (e) merecur confuli. Caterum, ut multo minora hujus Nintil 3 ic fpecimina, fic quoque ingens habeo fragmentum, noverm unciarum longitudine, figura vero dimidiatam panis mafam (einer friben 20 b 5300 ) reprafentans.

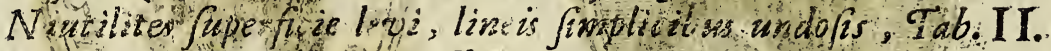
Fig. 2. fiditur. Lapillus eft albicans, marmoreus, è monte Sulinfelfery inven etiam inter pagos Yieden \& Eif̈ momegseg. Gaden limearum undofis in Fig.8. Tab. VI. apparec, juxtaque alis ordo criparzms linearum, veftigia prodens articulationis, de qua paulo poft: Sed curiofior in hoclapide eft:

(e) Mather. Juvenil. Tom, I, D. 22,6. 


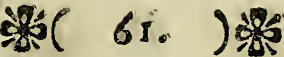

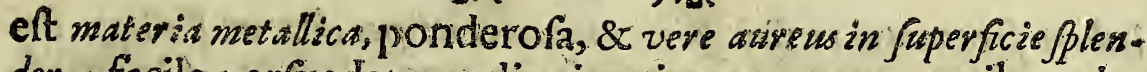
dor, facile perfuadens, reliquis etiam non renuentibus circumftantiis, ut pro GENVINO VETERVM HAMMONIS CORNV putaretur, cujus ita meminit $(f)$ Plinins: Hammo nis corrat inter facratiffimas Ethiopie gemmas, aureo colore, arietio ni cornu effigiem reddens, scc. E lutifodina Altdorfienfi de promtum accepi.

Tib. II. Fig. 3. Nautilites eft exiguus, fuperficie levi, lineis compofitis ramulorum inftar pictus, plane ut Dendrites, Cap. V. memoratus: Hoc autem modo exornata, diverfæ magnitudinis cornua Amimonis, è latomia Hersbruccenfi habeo.

Sed non tam luperficiarie pictas, quam profundius in. fculptas \& calatas ejusmodi lineas oftendunt Nautilite, Tab. II. Fig. 4. 5. 6. propofiti. Primum communicavit Dn. ImHoffius; Tertium prope : Sindelfeto inveni, elegantiflimis fane ornament is foliaceis ( ( $m$ ub-iverff) ftipatum; Fig.s. vero majoris eft fragmentum, in quo tamen ramuloram occurfus $\&$ mutuos amplexus haud fatis accurate expreffic Chalcographus. Tab. VI. Fig. g. huc quoque pertinentem fiftit lapidem, ramofis pariter lineis ornatum, quem ubi nactus fim, non recordor. Cæterum hæ linearum quafi cælatarum ramificatio. nes nil aliud funt, quam externa veftigia articulationum in ip $\rho_{i s}$ Cornibus Ammonis, quod exploracifimum habeo, \& jam dudum $O l$. IVormio $(g)$ nec non Mart. Liflero (b) perfpectum fuit, nuper etiam D. Scheucbzeri (i) avtopfia confirmatum: Internam articulorum dictorum faciem declarare volui $\tau_{a b}$.VI. Fig.25. \& 26. fed neque hæ omni carent vitio. Functos adbuc fibi pluses articulos in Nautilite, mulcum detrita dorfi fitperficie, Fig. 27. contemplandos offert. Apprime autem talismodi articalationes Cornisum Ammonis evincunt ärtams eorum eognationem cum veris Nautilis. Horum enim proprium eft,

$$
\mathrm{H}_{3} \text { babe- }
$$

(f) Hift. Nat. Lib. XXXVII. cap. 10. ( $g$ ) In Muiéo p. 86. (b) Hi ftor.animal. Angl.p.207. (i) Epift. de Dendrite g. 65 . 


\section{然( 62. ) 影}

babere frequentes in fus $\beta$ iris concamerationes, ita ut $P h i l i p p . B o=$ nannus (l) triginta numeraverit in uno Nautilo. Quemadmodum vero Cornua Ammonis ab invicem difcrepant aliis momentis, fic articulorum conformatione differunt. Hoc etiam notavi, quo profundius abrafo eft. Juperficies, eo magis inelegantes ac rudes emergere articulationes, quoniam fubtilifimæ illarum ramificationes, ad fuperficiem helicum protenfæ, hac detrita fimul pereunt.

An cunctæ Nautilitarum fpecies laudata gaudeant articulatione, dubito; certe enim in quibusdam nondum potui cognofcere. Neque tamen id mirum, quando diverfa, non petrificata conchylia reperiuntur, quibus, ut eadem externa cum Cornibus Ammonis volutarum difpofitio, ita concamerationis interne defectus communis eft. Exemplum præbent Tab.VI. Fig. 28. \& 29. depictæ cocbler, quarum hæc terreftris, in montibus fub mufco nidulari folet, illa paffim in aquis Aagnantibus, per Germaniam quoque occurrit, vocata Lifiero $(m)$ Cocblea pulla, ex utraque parte circa umbilicum cava: Ambæ vero probant, non folum confimiles hodienum Cornubus Ammonis dari cocbleas, fed etiam baud univerfalem efJe buic generi articulationem, aut inteftinam concamerationem.

Nautilitas, fuperficie levi, lineis deftituta, dorfo integro, fequentes poffideo : Exacte talem, Tab. II. Fig. 7. de monte (Sc)lipfelberg. Sed Fig. 8. videtur effe fpecimen minus Nautilite, Fig. 1. exhibiti; fiquidem attentius infpectum lineolas transverfales rectas numerofiffimas oculis objicit, aft ubi cortex vel tefta deelt, \& ipfe omnino defunt. Fig.9.\& 10. unum idemque Cornu Ammonis, prope SSindellecio repertum, fifunt, in altero, circa umbilicum, latere cavum, altero fere planum, rarioribus apud nos lapillis accenfendum, cujus exemplar aliud, interiori helice orbatum, Fig.II. cernere licet. Superficie pariter levi, lineis deftituta, dorfo integro dotatus eft

(l) Rccreat. Ment. \& Ocul. p.89. (m) I. c. p. 143. 


\section{然( 63. ) 㬓}

Nautilites Tab. VI. Fig. 4. Fed non fine gibbofa in medio belicks: deformitate, inventus inter Miteden \& CiBmanns betg.

Sulcato autem dorro, levis ac lineis deftitute Juperficiei Naus tilites, Fig. 12. \& i3 exprimitur. In utroque, duriflimo \& perquam tenui lapide, tam majori (quod fragmentum eft) quam minori, integro, duplex obfervatur fulcus, alicubi tamen imperfectior: E monte Sd)lipfelberg/ ni fallor, depromfi.

Aspera fuperficie preditorum Ammonis Cornuum, primam differentiam nuncupo Verruco am, cujus fpecimen comparet Tab. II. Fig. 14. Per omnem enim volutæ ambitum gemina tuberculorum aut verrucurum feries eminet. Non infrequens eft inter lapides calcarios montis Mauritiani: Habeo vero etiam durioris fubftantiæ \& diverfæ magnitudinis, è vicina quadam latomia.

A lineis eminentia \& amplitudine diftingui ftrias, notiflimum eft : Harum vero in cornibus Ammonis admodum variat conditio, ficut è Tabula, huic Capiti inferta, patefcit. Integris, fou continuis per dorfum friis, iisdemgs fimplicibues os raris, infrudtus eft Nautilites, Tab. If. Fig. 1 9. fplendentis plerunque, adinftar filicis, fuperficiei; fed è fluore molliori albido, magnam partem compofitus, paffim in arvis Altdorffinis obvius. Denfis ex adverfo, ipfisg, fimplicibus \& continuis per dor/um frizs gaudent fpecies, Tab. II. Fig. 16. \& 17. nec non Tab. VI. Fig 7. propofitæ, quarum primam \& alceram Dn. Im$H$ frim depingendas indulfit, tertiam attulit Amicus Grævenberga. Craffjfimas omnium habent belices, \& umbilicums viving vald profundum. Nequeo autem diffiteri, in fingulis iftis exemplaribus, frias per dorfum quidem \& bonam helicum transverfim partem integras ac fimplices apparere, fed tamen ex una interdum oquafi vadice duas aut tres fimsnl orivi. Quantum ad materiam, primum è faxo conftat grifeo, fecundum eft pyritofo-ferrugineum, cui à latere jungitur aliud pufillum, 


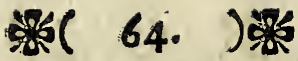

lum, internam faciem perpulchre cellulatam vel articulatam eximie oftendens; tertium è pyrite æneo, folido, penitus conflatum.

Striis vero evidentius ramojis aut furcatis, per dorfum nihilominus integris, confpicua funt Ammonis Cornua, Tab. II. Fig. 18. Tab.III. Fig.1.\&2 2. quæ rurfus ita differunt, ut primum fit mediocris craffitiei; alterum inter cuncta, quæ pollideo, in proportione tenuiffimum; tertium fat is crafjum, foliaceis orna. mentis, vel articulationum veftigis undiy, diftinctum: Hoc vero, ut \& primum, folent, pra aliis omnibus, majoris imo maximi effe moduli, \& à dimidio ad unum vel fesqui pedem in diametro colligere: Extant hinc inde in agris montofis \& lapidofis, præfertim vero latomiis. Ad illa pertinent, quæ fequuntur, Tab. VI. depicta, Viz. Fig. x. insequali compreffione helicis monftrofe oblongatum: Fig.2. cum portione matricis fux, Fig. 3. cortice vel armatura martiali anthracina veltitum, \& fucceffivas arcuum efformationes aliquot extraordinarie amplis interfitiis arguens: Fig. s. circa umbilicum conchite quodam bivalvi, firmiter accreto, contectum : Fig. 6. impuri ftalagmi$t i s$, quoad fingulas extremi arcus frias, tuberculis incruffatum; ex lapidicina Herspruccenfi.

Alius commatis funt Nautilite, quorum transverfales frice dorfum non trajiciunt, fed in medio ipfines, ab utroque latere concurrentes definunt. Horum autem plures pariter funt differentie. Quidam habent dor/um, feu potius/pinam dorfi extantem, hanc vero vel articulatam, vel non articulatam; illam iterum aut ferratam, aut vertebratam. Spina ejusmodi ferrata, feu acute dentata preditum Cornu Ammonis parvum, Tab. III. Fig. 3. exprimit, quod unicum hactenus, in monte Soblipfelberg repertum, tam propter indigitatum characterem, quam propter figuram variorem oblongam aftimo.

Obinfioribus autem tuberculis concatenatain aut vertebra. tam Jpinam gerit quod Tab. III. Fig.4. repræfentatur. Miranda ipfius 


\section{桶( 65.$)$}

ipfius fabrica : ftria fingulæ, admodum eminentes, antequam ad pinam oblique pertingant, in acsutam affurgunt apephysen, vel apicens, verfus interiora re flexum. Hæc fpecies, frequentius quam alia quavis, apud nos armatura anea fuperbiens deprehenditur, in luto coruleo, quod è cellis ervi antea dictum eft: Quin \& fapius pyrite obruta, aut largiter obduCia cernitur, ut probe jam notavitfob. Baubinus (n). Varia eft magnitudinis, variæque materiæ, fiquidem in lutifodina Altdorff. occurrunt fpecimina, ex indurato faltem luto conftantia, præfertim vero matrices fuforie, qualem Fig. 5. Tab. ead. firtit, cujus tamen pulchritudinem haud affecutus eft fculptor.

Spina non articselata gaudent Tab. III. Fig. 6.\& 7. delineati Nautilita. Prior undofas, \& verfus dorfum ramofas obtinet Arias; copiofe, grandioris etiam moduli, extat in arvis poft Collegium noftrum, prope $\mathfrak{L e n B e n b e t g}$. Alter fimplicibus magisgrar rectis, ad fpinam tamen autrorfum quodammodo inflexis ornatur ftriis; quem non amplius memini unde acceperim.

Dorfam fulcatum, \& pina extante deftitutum gerunt cornua Ammonis, Tab. III. Fig. 8. \%. 10. eo tamen cum difcrimine, ut prioris frice ex utroque latere ad dor $/ 2$ fulcum recta fibi occurrant, fingulæque in tuberculum quoddam eminens terminentur; alterius vero, nec non tertii obliquns friarum occurfus ad fulcum minus amplum obtuffores efformet angulos. Trigam hanc è monte Heimburgenfi habeo.

Alias infuper Nautilitarum noftratium differentias in proclivi effet recenfere, quia vero ferius accepi, quam ut fculpi potuiffent imagines, defcriptio quoque proroganda erit. Imo nec enumeratarum fpecierum hiftoriam abfolvere $f e f t$ nanti licuit, ut potius omittere multa fuerim coactus. Quædam vero è figuris diligenter confideratis colligi \& fuppleri

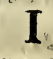

queunt,

(n) De Balneo Boll. Lib. IV. p. 15.16 .17 . 


\section{6. $)$}

queunt, e. g. numerus orbium aut pirarum, earumg vel convenientia cum circulo, vel ab eodem difcrepantia boc. De numero fane volutarum in cornibus Ammonis dubium eft pronunciare, quoniam ipfarum principium, aut unus alterque arcus fæpiufcule deficit.

Cæterum, ne pro naturæilufibus, fed veris conchyliorum teftis, earumg, partim ectypis habeam Cornua Ammonis, pluribus omnino rationibus inducor, quas longum foret omnes in præfenti exponere: Sequentium vero præfertim apud me: valet autoritas. 1) Quia certus \& conftions eft charact ir, non folum totius generis, fed \& fingularum pecierum, ita ut fi unius fpeciei vel mille reperiantur individua, nullum ifto charactere penitus careat. z) Quia non tantum prafentia tefta, verum \& conveniens ipfius color, in pluribus ejusdem fpeciei individuis monftrari poteft, tametfi illam intus modo hæc modo ifta repleverit materia. 3). Structura interna artificium: Quo refero memoratas jam fupra articulationes, \& inprimis cavitates in aliquibus fpeciminibus interne confpiciendas, quæ; uti Cocblearum \& Nautilorum naturam manifefte: produnt, ita furpicionem, de alio naturæ lufu, haud parum minuunt. Quis non miretur elegantiflimos con/pectus interne, ut loquuntur Architecti, orthographice (Ital. Profilo) Cor nusum Ammonis, Tab. VI. Fig. 21. 22.24. quibus belicum facies interior concava palam \& clarifime ante oculos ponitur? Utque feorfim è Fig. 22. luculentior emergeret demonftratio, Fig. 23: fiftit alteram, licet in ambitu parum diminutam volutarum feriem, quá alteri exastiflime quadrat. Obtinui nobilia hæc fpecimina ex monte Sultzbergo, quibuscum conferri meretur in Tab. II. Fig. 14. indigitatus jam fupra Nautie lites exiguus, majori affixus; cellul is compluarion ditcretus. 4) Denique accedit, quod perinde ut Tefiacea cuncta, pro ratione gradüum ætatis fuæe, diver $f$ modiuli, à minimo ad maximum usg, inveniantur etiam: Nautilite, fic, ut in nonnullis fpeciebus 


\section{楼( 67.$)$ 楼}

$a b$ ovulo quafi liceat gradatim afcendere, per plures individuorum magnitudines, ad fummam. Certe enim HAMMITES, faltem ille qui granis majufculis \& rotundis, ovula pifciums referentibus componitur, indeque Tiogenftein appellatur, pro iisdem, maxime teftaceorum agnofcere, cum D. Scheucbzero (o) haud vereor. Talem ovulorsm fubluteorum congeriem, in maffa lapidea friabili, Tab. VI. Fig. 31. contemplandam offert, frequenter obviam in Scemburg \& Sulfberg. At longe notabilius fpeciem Fig. 30. exhibet, ex ovulis, \& quæ ab iisdem modo prodiiffe videntur, minutiffimis Conchylizs, Nautilitis ac Turbinibus mixtim conflatum, cujus ego venuftatem deprædicare fatis nequeo, præfertim ob fimilitudinem cum vulgarium cocblearum ovulis, indegs nuper exclufis fotibus; de quibus Ant. Felicü Abbatis Marfliliz perdocta, ad Illuftr. Societat. Nat. Curiof.Præfidem, Dn. D. Lucam Schreckium, Cognatum \& Fautorem meum jugiter venerandum, fcripta extat epifola $(p)$.

Dictæ igitur rationes, aliis (nunc tacendis) conjunctæ, mihi quidem facile perfuadent, ut memoratam, de Nautilitarum non minus quam reliquorum fofflium teffaceorum ortu, hypothefin amplecterer. Hac vero ftante, porro non erit arduum occafionem, qua teftacea ifta è loco natali fuo, nimirum oceano, in terram continentem tanta copia perverint, referre ad univerfale diluvium. Quæ quidem opinio tam firmiter infita eft animo meo, ut quotquot intueor teftacea è marinis foffilia, totidem catholici illius cataclysmi monumenta videre me arbitrer, aureis velut infcripta literis : MEMOR. UNIVERSAL. DILUVII ! Hæc antiquiflima omnium maximæ, poft conditum hoc univerfum, vicifitudinis documenta, quæ comprobant, equor aliquando terre dominatum fuifJe, \& fuper illam quaquaverfum intumuiffe. Pro-

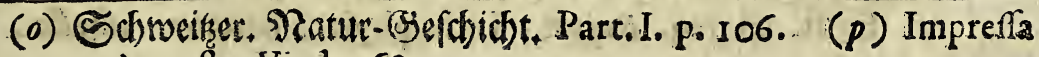
Augufte Vind. $1684^{\circ}$ 
fecto non erubefcit Clariff. Scbeuchzerus (q) affeverare, horum intuitu mortales de veritate inundationis terra univerfalis, ultra vires naturæ, ex jufto Dei judicio quondam faStæ, convinci, ff vel maxime nulla ejus fieret in S. Scriptusra mentio. Huc digiturn intenderunt plures pii gravesque Theofophi, \& argumentum inde, pro confutandis Atheis haud frivolum defumere fategerunt. Sed videor mihi audire quosdam obloquentes; triumphum cani ante victoriam, \& nimis libere adftrui hanc bypothefin, quæ magnis adhuc laboret difficultatibus. Novi equidem diverfos diverfa contra eandem moviffe dubia; novi vero etiam, pleraque jam discuffa dexteritate fagaciffirnorum inter Anglos virorum, $7 . h . R a j i(r)$ $\&$ Fob Woodw srdi (s). Qux autem recentius ab ingeniofo $E$ duardo Luidio ( $t$ ) prolatæ funt, inftantias, juxta cum aliis (fi quæ funt) momentofis argumentis, adverfus laudatam hypothefin excogitatis, dilectiflimus Frater meus, Fah. Guh. Baierus, Mathem. \& Phyf. Prof. Publ. \& Univerfit. noftra h. t. Rector Magnificus, amore veritatis, meoque hortatu invitatus, evertere, \& ab iisdem diluvianam teftaceorum fosm filium originem vindicare decenti cum modeftia conabitur, fi Detus vitam largitus fuerit, nemoque alius hoc negotium præoccupaverit.

Ego munc ad evolvendas Teftaceorum univalvium fo/fis lium clafes reliquas pedem profero. Harum autem proxima eft TVRBINATORVM, feu belicibues ex amplione ba ficio in apicem tenuem faftigiatis gaudentium: Cujusmodi lapides iterum divido in longos \& brever, utrosque rurfus in lever, quoad faperficiem, \&t a peros. Prioris generis, nimirum elon-

(q) I. a. c. ag. 89. (r) Discurfi, milcell. de dufiolut. \& mutat. Mundi, ex Angl. in German. linguam iranslat. Hamburgi 1698. p. 14: \& fequ. (s) Tentam. circa Hift nat. relluris: (t) Epift. ad fok. Rajwm, Lithophylac. Britann. adjestiz P. 1:28. 
elongatis eximie anfractibus donatos, appellare licebit BVC CINITAS, fiquidem talitis figuræ teftacea Buccinorum nomine apud fcriptores hift. natur. venire folent. Quibusdam eorum, è noftratibus foflilibus, fuperficies eft levir, ficuti Tab.III. Fig.11. 12.13.14.15. \& Tab.VI. Fig.12. indicant, omnino diverfis in fpeciebus, quas tamen figillatim jam defcribere fuperfedeo, quia differentix ex ipfis imaginibus fatis elucefcunt. Alii vero buccinitarum, gerunt juperficiem exaßpe. ratam, five ftrits, five tuberculis \& punctis, five omnibus fimul. Exempla fuggerit eadem Tab.III. Fig. 16.17. 18. 19. 20. a.b. 21. 22. 23. æque facile dignofenda, in quibus momentis $a b$ invicem abludant. Cæterum colleiti funt hi lapides, par-

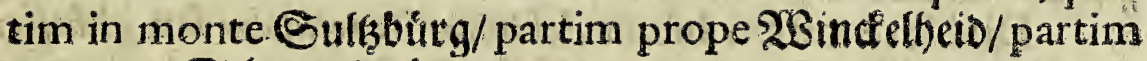
ex amne Edtwartgnd).

A buccimit is quodammodo differant illi, qui COCHLITE nuncupari merentur, ideo, quod mare Cocblearum amplis brevisgafint ventris, ac turbine potius in fe reducto quam longins emiffo conffent. Talium, \& primo quidem fuperficie levi gaudentium variæ fpecies fiftuntur Tab. III. Fig. 24.29. 26. 27. \& Tab.VI. Fig.10. \& 1 : Quamvis, ut verum fatear, nonnulla fiura conoidéa, planigg pirasum lateritus, propinquiores TRO. CHIS quiam cochleis exiftant. Seorfim vero Fig. 2\%. plane ad NERITAS pertinet, quiorum proprium eft, habere piras paucas \& umbonem five mucronem parum aut nibil eminentem. Vix aufim ftatuere omnes, quos levibus accenfui, tales femper \& à natura fuife, quia nunc plerique teftzs cavent, quæ olim forfan afperæ fuerunt. Sed revera \& adhuc affera Juperficie præditi funt cocblitc, Tab. II. Fig. 28.2\%:30. depicti; quorum penvltimus, ad 2 sinfelffeid repe tus, poft fimplicem circuitum, transverfim aliquoties fulcatum, raro fpertaculo definit in apicem valde obtufum.

Sequantur ECHINIT $\$$, fer fofflies Echini, qua claftis eft univaluium teffaccorum, heliczbus carentium, figura ut piuvi$I_{3}$ 


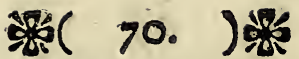

mum fubrotundle. Echini nomen ipfis competit, quia dum vivit ac integrum eft animal, numerofos è fua fuperficie quaquaverfum, ad Echini quadrupedis anialogiam, fpargit radios, five pinas, pro diverfa fpecie plus minus acutas. Non defunt equidem, qui marinos Ecbinos ad Cruftacea relegant animalia, mihi vero Avifrotelis \& aliorum gravium Virorum fufficit autoritas, ut teftaceis annumerem, præfertim quod chavaiteres ipforum, in principio hujus capitis traditos, clare fatis præ fe ferant. Cæterum uti Nobil. Luidius (u) inter fexcentos foffles Echinos, eorumque fragmenta, nullum fetis aut fpinis fuis inftructum vidit, fic quoque nos non nifi aculeis ppoliatos exhibere poffumus.

Dividere autem lubuit Echinitas in rotundos feu globofos, \& oblongos; illos iterum in papillofos, \& futuris aut fulcis lineisve ornatos. Tales funt vel regulares vel irregulares. Regularium fpecimina cernuntur in Tab.III. Fig. 31.32. 33. 35.36. quæ tamen in eo congruunt, quod è fummo vertice quinque geminati- linearum (futuris fape fimilium) ordines ad bafin æquali fere intervallo fefe diffundant. Nonnulli horum lapidum verticem habent umbilicatsim, in quibusdam vero, (e.g. Fig.33.) tuberculum eminet. Oblongus quodammodo eft Ecbinites Fig. 35. non tam, ut opinor, ex naturali difpofitione, quam violenta olim facta comprefirone, fiquidem plures poffideo ita contritos, ut appareat, materiam, qua replevit internam tefte cavitatem, \& poftea in durum evafic lapidem, quondam extitiffe liquidam aut mollem, dum ipfa cedere potuit impetui teftam confringenti. Qui Fig.34. depingitur, ad antecedentes quidem videtur pertinere, tametfi vix aliquibus rectarum linearum umbris gaudeat; eft vero omnibus anguftior \& altior. Latus inferius, five bafin Echinite, faxo inhærentis, Fig.35. refert. Plerosque enarratorum deprehendi in arvis circa pagum Rieidbelshoff / unum etiam (Fig. 33.) in lapidi-

cina

(u) l. c. pag. 44. 


\section{然( 7 r. )}

cina Herfpruccenfi. Sunt autem cuncta ex eorum Echinitarum cenfu, quos Luidius, p. 46. appofite nuncupat fibulares, propter formam glomerulo veftiario (einen Sinopf) accedentem.

Irregulares lineas, aut inequales fulcos obtinuerunt Fig. 37. \&2 38. delineati, non quidem integri, fed quoad inferiorem tantum partem confpicui, nec fine fufpicione multum corruptæ: naturalis formæ:

Papillares Echinitas voco, qui licet non deftituantur lineis in fua fuperficie, majorem tamen ejus partem eminentics orbicularibus feu papillaribus repletam gerunt, quas alii non inepte dicunt acetabsola; funt enim nihil aliud, quam veftigia, quibus olim aculei', velut inarticulati heferunt. Duplex horum Echinitarum fpecimen, Tab. III. Fig. 39. \& 40. communicavic Generof. Dn. Im Hoffius; fed utrumque fragmentum, quin apo. grapbum faltem eft ipfius teftæ, in duriflimo filice impreffum. Differunt magnit udine tantum acetabulorum, ut facile pro eadem haberi poffint fpecie: Quod fi tamen diverfas pronunciare decet, priori refpondebunt, apud Luidium (num.910.) Echinite laticlaviz maximi fragmenta; alteri vero, Ećniñites ejusdem (num. gr6.) orbiculatus laticlavins medius: Solent alias hi papillares, aut foutellut Echinite appellari OMBRIE. \& BRONTIÆ, de quibus, aliisque nominibus, Gesnerum, Bootium, Wormium, \&c. legere juvabit.

Oblong i denique funt ECHINIT 1 , qui CORDATI cognominantur, propten cordis aligisam in forma fimilitudinem, ceu ex Fig. 41.42.43. Tab. HI. patefcit. Virumy latus ejusd m lapidis defignant duæe priơres. Figuræ; tertia majufculum fiftit, \& ipfum quinis, in duplici levie, futuris, velut a u punctis notatum, quod omnibus, etiam minoribus commune effe credo, tametfi non in fingulis (detritæ fuperficiei culpa) obfervetur. hisdem in locis, queis cateros echinitas, inveni.

Teftion 


\section{紫( 72. ) 㩆}

Teftace is snivalvibus quidam Antores adjiciunt BALANOS ac TVBVLOS VERMICVLARES. Quoniam vero inconftans corum eft figura, ficuti Phil. Bonannus $(x)$ edocet, itleo reliquis univalvibus magis regularibus, tanquam ano-mala quædam, per modum appendicis fubjunguntur. $B a$ lanum quidem unicum fofflem, hattenus in Norico noftro mihi vifum, exhibeo in Tab. VI. Fig. 13. è fapius laudati Dn. Im Hoffic communicatione, affixum lapidi cruftofo; neque enim unquam per fe fubfifunt Balani, fed more parafitico rebus aliis, præfertim conchyliis, nolentibus volentibus, teftaceam domunculam fuam inædificant.

Tubulos autem vermiculares, Tab. VI. Fig. Is. \& 16. fat luculentos propofui; quamvis plura infuper fpecimina, tam craffiora quam tenuiora, teftis \& lapidibus infidentia, diverfimode circumflexa, è montibus Heimburgenfi \& Sultzbergenfi pecita, poflideam. Aft qui Fig. 14. exprimitur rectus fere $\mathcal{f}$ phunculus, nifi me omnia fallunt, ENTALII majoris eft fragmentum, repertum in monte Calvariæ Neagorenfi.

\section{CAPVT VIII. \\ DE BIVALVIBVS TESTACEIS FOSSILIBVS.}

8 Numeratis Univalvibus teftaceis fofflibus Noricis, progre1 dior nunc ad recenfenda pariter BIVALVIA, five quorum teftaceus cortex ordinarie duabus, faltem contiguis, partibus componitur. Idem vero, quod ante circa Vnivalvia factum, \& nunc faciam, allaturus nimirum promifue fpecimina, tam ca in quibus teftæ adhuc præe entes funt, quam in quibus illæ deficiunt, dummodo refidui lapides ad modulum \& formam deperditarum teftarum, queis continebantur, fint rite effigia-

(x) 1.c. pag. 92. 


\section{然( 73.) 粰}

effigiati. Cæterum ne in eorum tractatione ordo conveniens defiderari queat, fpecies æri incifas omnes fequenti ratione difponam.

$$
\begin{aligned}
& \begin{array}{l}
\text { TAB. IV. } \\
\text { TESTACEA } \\
\text { FOSSILIA } \\
\text { NOR. BI- } \\
\text { VALVIA }
\end{array} \\
& \text { funt. } \\
& \text { Teftis inter } \\
& \text { ce } \\
& \text { inxqualibus }
\end{aligned}
$$

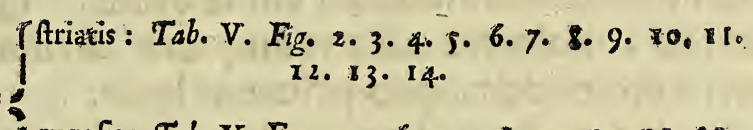

$$
\begin{aligned}
& \text { Irugofis: Tab. V. Fig. 15.16.17.18.19.20.21. } 22 . \\
& \text { ( } 23.24 .25 .26 .27 .28 .29 .30 \text {. }
\end{aligned}
$$

Primariam Bivalvium differentiam defumere confueverunt oftracographi ab equalitate \& inequalitate valvarum; aquales dicendo, quarum una alterius tam figuræe externæ, quam cavitati internæ refpondet. Eandem divifionem fosfilibus noftris bivalvibus accommodare licebit, ipfaque porro diftinguere in friata, \& non friata. Illorum quadam fricis transver falibus parallelis notantur, quedam ex uno puncto, valvarum fcilicet vertice, deorfum prodeuntibus. Prioris generis exempla non pauca fuppeditat Tab.IV. quæ ftriktim, \& quoad fieri poteft breviffime indicabo. Fig. I. videtur effe Conchites maximus Lifteri (a) margine lato, \& ad alteram ejus partem finu amplo donatus, nifi quod nofter evidentibus magis \& femicircularibus ftriis transverfim infigniatur; qua vero per longitudinem infculpræ funt lineæ, faltem vitia funt \& fisfuræ leves, neutiquam ita confpicuæ, ut chalcographus expreflit. Caterum tefice tenuitas of minus profunda cavitas, cum reliquis circumitantiis fat recte fe habent: Inveni ad pagum SSinctelfeito. Huic Conchite, licet non magnitudine, $\mathrm{K}$

atta-

(a) Hiftor. animal. Angl. p. 233. 


\section{\%( 74. ) 澡}

attamen forma ac teneritate perquam fimilis eft Tab. VI. Fig. 19. delineatus, in cujus fuperficie nativi tefte colores, rubellus, albicans \& fubflavus mixtim egregie adhuc comparent. Nollem vero contradicere, fi quis eundem ad Tellinas referret ac TELLINITEM vocaret.

Tab. I V. Fig. 2. Concbites eft valvis ab invicem ample di. dictis, ex altera cardinis parte diffuscoribus, altera intiorfum quafi retractis \& incurvatis. Prater frias transverfales, etiam nonnullas in poftica præertim parte, recta per longitudinem ductas obtinuit, fed valde exiles. Quo ipfum referam, hæreo, maloque alis relinquere divinandum nomen; reperi vero eodem, quo priorem loco.

Fìg. 3. duplici confpectu, in- \& externo, fiftit mytilum vulgarem marinum, cujus minora fpecimina Fig. 4. repræfentat, fingula transverfalibus diftincta frius, an dicam rugis? fed prius arridet. Frequenter occurrit hic MYTILITES in arvis Altdorffinis meridionalibus, inter cornua Ammonis maffæ lapideæ inclufus; nondum tamen offendi bijugem, feu: cohærentibus valvis. Cognatum MY T IL I T I facio, qui Tab.VI. Fig. 20. proponitur, in monte fupra pagum Kieden deprehenfus.

Tab.IV. Fig. s. \& 6. idem eft, diverfo duntaxat in fitur. fpecimen mytili (ut opinor) minoris fuvia i icis: Hujus teftulæ: nonnunquam intus referta funt galena, feu materia ex atro fplendente metallica. In rivo quodam vicino reperitur.

Sed vulgari mufulo fuviatili (oer gemeinen farben- odet Dinblet-Diufobel) ut ovum ovo fimilis eft Fig. in. depictus: canchites, qui proinde jure fuo audiet MVSCVLITES vulgaris: Hunc bijugem quoque remper inveni circa 2 Sindelfeis/. rarius in Seimburg. Affines quodammodo mufculiti arbitror Tab. VI. Fig. 17. \& I8. exhibitos conchitas, infolito plane modo friatos: Patet equidem diverfos effe; fed quia fragmen. ta faltem funt, exactius de iisdem judicium ferre nequeo. 


\section{然( $7 \%$ ) 獎}

Tab.IV. Fig 7.8.3. funt Conchit e exiles, fpecie vir differentes, nifi quod ulcimus compreffior fit ac tenerius friatus: Ambitu gaudent ferrato, \& pertinere ad TELLINITAS videntur: ex eodem rivo, quo ante dicti mytilite minores.

Fio. 10. Slitariz eft teftula, aut potius apographum ejus in limofo-ferrugineo lapide Altdorff. lutifodinæ : Ex utraque verticis parte æquaiter diffunditur, transverfalibus aliquot ftriis, \&z und prafertim majori exaratum: Quo autem nomine debeat infigniri, jam non lubet decernere.

Fig. 12. \& 13. puto me ftitiffe SOLENITEM; ita enim cenfui nuncupandum lapidem, forma oblonga \& friarum obliquo trazu teftam solmis pifcis (quem Itali \& alii oftredrum loco habent in deliciis ) repræfentantem, in duplici fpecimine, reperto ad pagum 2 Binctelbcio.

Fig. I4. exprimit infidentem lapidi tefulam exiguam, vel ad mytulos vel magis ad PHOLADES fpectantem; de monte Riedenfi, verfus (tiBmannsberg.

Qui autem ex sno puncto, nempe valvarum vertice, recta prodeuntibus gardent friis Conchite regulaves, hoc loco memorandi, uno verbo \& Mart. Lifteri vocabulo, funt PECTVNCVLITÆ, quorum paradigmata quædam in Tab. IV. continentur. Fig.15. defignare debet p ctunculitem aliquem ex majufculis noftratibus, qui tamen haud accurate fculptus eft, nil minus quam laudatum ordinem ftriarum oftendens. Exhujusmodi alias conchites innumerabilibus, parvis \& minimis, elegantiffime ftriatis, pragrandia lapidum frufta fere pe itus conflata paffim circa Altdorffium extant, belemnitæ fotorem, fi franguntur, fpirantia.

Fig. 16. \& 7 . funt plures pectunculite in faxo arenofo ferrugineo, cujus bina hæe fragmenta, mutwo teftularum \& matricum amplexu eleganter fibi refpondent: Copiofe in via ad pagum 2 Beifínbrinn. Fig. 18. tenerioris, nec adeo cavi, per medium quafi zona diftineti pectunculite (ut conjicio) 


\section{然( 76. )}

exemplar, fed quod infaufto nuper cafu mihi periit. Fig.19. internum eft latus concavum pectunculite, nitidiflime ftriati in lapide concbitem anomium (de quo poftea) replente: ad pagum Ret(hel:̧boff.

Striis autem deftituti Concbite bivalves regulares, vel levem habent fuperficiem, vel rugofam. Illius fpecimen præbet Tab.IV. Fig. 20. \& 21. duplici confpectu BVCARDITES, ob figuram fic dictus lapis, quem fufius defcribit Ferrandus Imperatus (b), ipfam vero Concham, addita effigie, Phil. Bonannus (c). Alios Bucarditas, fcil. reticulatum, coftatum, \&c. Lifteous (d) Mufeum Metall. Aldrovandi (e) Rarithecium Gottorpiense ( $f$ ) exhibent. Nofter ille tantum videtur effe nucleus five materia quondam inclufa teftæ, quæ jam evanuit. Minus exemplar ejusdem Fig. 22. refert, nullis transverfalibus ftriis, ut quidem fculptor finxit, donatum : Ex monte Heimburgenfi utrumque habeo. Caterum hic bucardites à nonnullis appellatur HYSTERAPETRA \& HYSTEROLITHVS, de quo vid. Agricola, Boötius, \& alii.

Poft leves Conclitas bivalves regulares, confiderandi ve: niunt rugof vel inæqualibus in fuperficie fulcis, lineis aut finibus exafperati. Talem proponit Fig. 23. (quæ, per errorem, 33. fignata eft ) valde ienerum, parum concavum, coloris cor. $n e i$, in lapide nigricante aliquoties repertum, in rivulo prope Sagenl)auben; quem dubito quo nomine fit indigitandus, faltem æqualium effe valvarum, mihi perfuadeo.

Fig. 24. exiguum tefte repræfentat apograpbum, veluti fquamofum, aut aliquot rugarum feriebus afperum, quod prope. Xinctelfeio inveni.

Fig. 25. Concham fiftit, interno latere, quodammodo finuofam vel rugofam, amplitudine confpicuarm, quam non vereor pro genwina CONCHA MARGARITIFERA feu Matre Perlas.

(b) Hift. Natur. Lib. XXIV. cap. 26. (c) I.c. pag. I 10. (d) 1. c. 235. \& feq. (e) pag, 480 - $(f)$ ab Ad, Oleario edit. Tab. XXII. 


\section{㐘( 77.$)$ 夥}

Perlarum venditare, fiquidem nec forma eft aliena, $\beta$ Plendor vero in omnibus tefte lamellis, perinde ut confffentia vix à naturali difcrepans. Hanc ferme integram, \& fragmenta non pauca, deprehendi in monteHeimburgenfi.

Rugofa quoque eft (nifif frriata magis, vel imbricata) Cons$c h a$, Tab.V. Fig. I. depicta, teftis ambabus, adhuc connexis, æqualibus, quæ ratio eft, cur huic claffi eandem inferam, tametfi /peciem OSTRACITA, aut offrei fojflis, alias inæqualium valvarum, reputem: $E$ lapidicina Herfpruccenfi.

Alterum genus teffaccorum fofflizum, bivalvium, compleCtitur illa, qua ivalvas gerunt incquales, aut quarum una alteriquoad magnitudinem,formam externam, cavitatem, \&cc. diffimilis eft: Tales Conche vocantur etiam anomia. Foffles vero, quot quidem, apud nos extantes, mihi hactenus innotuerunt, commode dividuntur in friatas \& rugofas. Conchitæe ftriati hoc loco audiunt, quicung, à vertice per longitudinem teffarum excurrentibus donantur ffrizis, propter quas, fiquidem elatiores funt, ad inftar pectinis radiorum, PECTINITE nuncupari confueverunt: Seorfim hoc nomen, ex Lifferz \& aliorum fententia, iis competit, quibus ex utroque verticis latere exeunt apophyfes vel aures, \& altera teffarum cava, altera plana eft; ad quae momenta in conchitarum hujus generis difpofitione potiffimum eft refpiciendum. Plane autem tefla, mediccris cujusdam pectinite fragmentum, Fig. 2. $\tau_{a} b: \mathrm{V}$. refert, multo elegantins ftriatum, quam fculptura oftendit. Fig. 4. eft gibbora pecizinita teffa, amphyotis, aut binis auricularibus apophyfibus, etfi non integris confpicua:

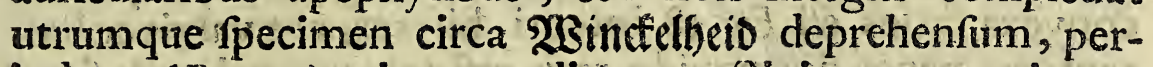
inde ut (Fig. 14.) minorum aliquot pectinitarum portiones, affabre ftriatz, lapidi cruftofo infixx. At vero Fig.3. internam concavam reprefentat partem pragyandis Pectinite, cujus margo \& aures fracturam videntur perpeffe, tunc temporis, quo immerfas fuit materiæ, olim forte molli ac liquidæ, 
nunc faxex: ipfum, nobilioribus annumerandum fpeciminibus, è cella quadam Altdorff. effoflum accepi.

Qui vero Conchita friati quidem more fectinitaram, fed son auriti funt, nec inequalium valvarum, PECTVNCVLITAS antea nominavimus. Horum tamen plures dantur, irregiulares dicendi, ob teftarum inter fe diffimilitudinem; crijusmodi funt omnes, in $T_{a b}$. V. à Fig.s. usque ad 13 . inclufive, delineati, quibus figuris in univerfum /ex differentie defignantur. Fig. 7. \& \&. unius peciunculite latus utrumque exprimunt, ficut etiam Fig.9. \& 10. Ab his proximum par, nempe Fig. 11. \& 12. Fubtiliffime friatam fintit TEREBRATVLAM, aliquibus ita dietam pectunculita fpeciem, quod tefta alterius apex aut roftrum perforatum cernitur. Reliqua ifiegure fingula, nimirum 5. 6. \& 13. Fngulares indicant differentias, quibus decentia cognomina, vel ex aliorum ingenio, vel meo imponere, jam non audeo, cuilibet id negotii liberum permittens: Hoc tamen non diflimulo, Fig. \%. \& 10. pariter ac 33. effe exempla Conche anomie friate tejn் $\beta_{\beta}$ Fab. Columna(s) aut Pectunculite anomii tril bi, Lifteri (h).

Supereft vugoforum, inequalibus vulvis preditorumCnnchitarum clafjes, in quam conjicio cunctos, qui non è vertice regulariter prodeuntibus ftriis, fed tantum tran,sverralibus rue is \& irrogularibus lineis aut fulcis exafperantur. Hujus indolis præcipue eft Conchites anominur rugofus, roftro fubtereti er infigriter adunco donatus Lifteri (i) ab ipfo accurate fatis defcriptus. Valvarum ejus natural m combinationem ac fitum Tab.rojtr.V. oftendit Fig. 17. \& in minori fpecimine Fig. 19. cujüs poftica convexa facies eft Fig. 18. Integri, bifores, aut valvis cohærentibus, penes nos oppido rari, etfi fol tar $æ$ valvæ \& frag menta illarum copiofe jaceant circa stsincterheib \& Aften: tham / fape etiam triplo majoris moduli, quam hic deline.

antur.

(g) Trat. de Purfura cap. XV. (b) Lib. fap. cito pag 249. (i) ibid. p. 238 , 


\section{然( 79. )}

antur. Utriusque (licet diverforum individuorum) tefte: inferioris, quax admodum craffa \& concava, Fig. 15. ac JuperioFis, quæ tenerior \& planior inftar operculi, Fig. 16. confpectum internum exhibere ftudui; ubi notandum inprimis venit mufculi aut tendinis utrings vefigium, peramplum \& profunde quafi infculptum, perpetur in omnibus individuis, eodem loco, præfentia : Ut propterea mirari fubeat, nonnullos hunc concbitam inferuife univalvium catalogo, quod etiam feciffe videtur Celeberr. D. D. Foh. de Muralto (I) Nautilum lapideum ipfum appellans, fine dubio alterius teftæe vel operculi, tanquam infrequentioris, ignoratione ad illam opinionem feductus. Meliori ratione Clar. Luidio $(m)$ Concbites hic, intuitu roftri adunci (quod tamen in noftris exemplaribus depitis obtufum eft) GRYPHITES dicitur ; quod nomen æque bene quadrat in Concbitam, Fig. $20 . \&$ 21. propofitum, itidem rugofum, cujus valvarum altera prominulo \& ádmodum adunco, altera (qua convexitate non cedit priori) obtufo magis rofiello eft inftructa.

Cæeteræ in Tab.V. Figurc omnes, à 22. usque ad 30 . defignant varias differentias Conche rarioris anomie vertice roftrato Fab. Columne (n) quibus cunctis hoc eft commune, ut præter transverfalem rugofitatem, teftæ fupereminentis apex five roftrum foramine donatum, aut pertufum appareat, unde Luim dius $(0)$ his in genere nomen TEREBRATVLF attribuit。 Vulgaris maxime inter hos conchitas Fig. 23. exhibitus, modicæe latitudinis, nec finuatus: Fig. 24. Fubteres, omnium longiffimus \& anguftiffimus: Fig. 25. latifimus: Fig. 25. \& 27. triangular is fere, propter alterius teftæ dorfum anguftum vel acuminatum, alterius vero planam fuperficiem: Fig. 28. \& 29. Snuofo aut lacunofo margine praditus, major ac minor: Fig. 22. fimbriatus merito dicendus, licet hoc nomine nondum, quod fciam

(l) Ephemer. A. N. C. Dec. III. Ann. V. \& VI. p. 44. (m) I. . . pag. 99. (n) l. c. Cap.XII. (o) l. c. pag. 40. 


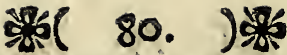

ab ullo defcriptus. Figura 30. denique id confirmat, quod Excell. D. Scheuchzerus ( $p$ ) notavit : In hisce, nimirum, conchitis anomiis aliquando confpici maculas (ut fane multis in fpeciminibus monftrare poffum) albidas, que microfcopio fubjecte funt circelli tres, quatuor, quing, fex concentrici, affabre veiuti circino è centro medio exfculpti, \&c. Solent vero laudatæ differentic (quamvis una præ altera copiofius) inveniri mixtim cum recenfitis antea pectunculitis, inter arva montana \& lapidof Palatinatus fuperioris, nec non quibusdam latomiis.

\section{CAPVT IX. \\ DE SALINIS ET SVLPHVREIS FOSSILIBVS NORICIS.}

NOn adeo amplus concretorum hujusmodi apparatus 1 nobis eft: Qualiscunque demum fuerit, toc Capite explicabitur. E SALIVM clafe memorandum ptimo venit NITRVM; haud equidem antiquitus fic appellatum Salis $g^{e-}$ nus, quod magis alcalicum of fmecticum, indegs à moderno diverfum, pluribus argumentis edoceri poteft; verum id, cui hoc \& Salis petre nomen hodie imponitur. Ipfius copia paffim à ruricolis coqui folet, è terra pingui, fub ovilibus, equilibus, fimetis, vetuftorum ædificiorum ruderibus, \&c. defosfa; quam explorandi, praparandi \& coquendi (pro nitro) artificium dexterrime tradidit Lazar. Erckerus $(a):$ Virtutes

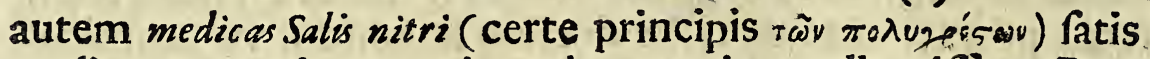
prolixe \& omnium optime decantavit excellentiflima Profefforum Med. Halenfium biga, D. D. Erider. Hoffmannus (b) $\&$

(p) Specim. lithograph. Helvet. pag. 25.

(A) Aul. Subterr. Lib. V. fere integro. Ann. 1694. habita.

(b) Difput. de Nitro 
\& D. D. Georg. Erngf. Stablims (c). Neque vero diffimulare poffum, me jam à plufculis annis fcribendæ Nitri biftorie, poft Clarckium \& quoslibet alios, cepiffe confilium, quod ne nunc quidem ex animo dimifi, commoda, oùv $\Theta \varepsilon \tilde{,}$, occafione executurtis.

Speciem Nitri, quin ipfum Aphronitrum, multi reputant falfedinem è faxis calcaries, \& hinc conftructis parietibus ac muris, præfertim antiquis, inftar lanuginis efflore/centem. Talis apud nos ubique deprehenditur, inprimis è laquearibus carcerum fubterraneorum Norimbergæ, fed fiiviarum forma excrefcens. Hujus autem Salis vel NITRI CALCARII difcrepantiam à vulgari, \& peculiarem in Cryftallos concreti figuram, perfpicue oftendit eruditiflimus Mart. Lifferus (d).

Seorfin etiam VITRIOLI mentionem facere liceret, quod ex Pyrite, in Norico noftro hinc inde obvio educi arte poteft, imo \& fponte folet efflorefcere, martialis naturæ: Verum de hoc, ipfoque PYRITE, \& LIGNO FOSSILI BITVMINOSO, noftratibus, tanquam præcipuis in Capite præfenti exponendis concretis faliso-fulpboreis, adeo dixer.soiss jam dudum egit Andr. 1, ibavius (e) ut temperare mihi nequeam, quo minus integrum iftum locum, etfi valde prolixum, lectu tamen dignifimum huc transferam. Ita autem ille. Quam Doldius Altorfo Noricorum mifit non procul ab oppido à medicina fudiofis effofjam terram, partim prope accedit ad Colonienfem fiffilem, nimirum fiffili ßpecie, forma carbonum, fuccedine, \& lignéa putredine fracturaque; partim integrior folidiorg, eft, mujorib. quoque portionibus adeo referens ligneum ex popuilo Lybica vel tremula, aut betula vel fago, carbonem, ut primo ajpectu plane perfuadere imperito pofjis lignum fuiffe, atque etiam vix oculis tuis credas, $\{$ aliter percipere rem velint. Ebenum fosfile foret \& ad gagatas pertineret, nijs putredo roperveniffet; quin

$$
L \text { funt }
$$

(c) Obferv. Chim. Phyf.Med. Ann. 1698. M. Mart. (d) Tract. de Font. Med. Angl. Cap. I. (e) Singular. Part. III. Lib. Vill. cap. 8. p.1034. \& fequ. 


\section{\%( 82. )}

funt quedam parizicule integritate fui non alio referenda. Neque tamen ad lithanthracas commiones ob peciem diverfam, differen. temg naturam, vel oculorum judicio, revocare queas, quamquam carboni ligneo, ut diximus quam proxime accedai. Relinquimus ei fedem in medio Eben: foffilis feu gagatæ \& lithanthracum, cumg puiredo corruperit majore ex parte, quin o fucci terrei of lapide $i$ fere fint admifti, ampelitidi, licet non optime not a fubjiciendarn judicavimu. Carbo eft aridus ox exucciss, fibris in longum pora rectis cum fluxu fubftantie, \&u proceffu ligni tremule, vel betule. Ab extremitate fradta $f$ in picias (nota tamen, non efje eandem plane faciem omnium mafjularum) affulatim concreviffe videtur integrior; corruptior vero affulas occultat : alius etiam fiffles divifasque exbibet, omnino ac fi. lignum piceum vel faginum divifffes in laminas, quas dicas quoque plane inde effe, \& fub terra corrofas infectasgs induiffe nigrorem of fragilitatem. Sunt quadam portiones longe 4. vel fex aut plures digitos, fed non fimper continue. Sispe enim in medio fifura transver fa interrumpit continuitatem, quadi vulnere facto. In agua fi maceres, lenie/cunt, ut digitis divellere. finderey of flectere queas, fed non omnes. Integriores atxum babent colorem; corruptiores fujcum, aut etiam brunum, ut lignum tofum; media particula medio je babent modo. Que corrols funt penitus, coherentibus tamen adbuc partibus of aliquam foliditatem exbiben: tibus, fi frangas, nibil diverfum à fubftantia fibrarum, feciondiums longum inpectarum, niff fitum ductumg faltem alium exhibent, fed solor \& frubftantic ratio eft eadem, nifi inaqualiter fint putrefacte. Alix in fractura nigerrimum, valdeque plendens bitumen funt, ut poliriGagate more pofje tibi perfuadeas, nifi exilitas, \& putredo obfiaret. Et bac nota deprebenfa, oculi fe fallos primo alpectu fuijfe difcunt. Nullus enim carbo, nec lignum tale quid refert, nec eft in fracturis. Inter portiones in fodina intercurrit plerumg marga cinerea, vel alba, aut etiam argilla, \& ochra bituminea. Qwo circa videas alluviones hujusmodi aliquibus adherere, \& albo, vel flavo aut rubroillas colore inficere. Aliquibus immiftus PYRITES 


\section{然( 83.) 颗}

of $t$, qui ibidem invenitur, \& adeo quidem interdum coaluit, ut es: utrog facco una fit facta maffa: alias 5 altem foris adherens, aut lacuna cuniculog facicto fefe infinuans. Pyrites is plendet, coloremgrs ex citrino albicantem feu argenteum refert, ut is fuem inflopetorum ignitabulis geffant vulgo. Miruim dictu; carbones quosdams in decurf fu fibrarum in longum, nodos reprafentare tanquam initia ramorum, aut furculorum, quafi inde aliquando ramuli enati fuifent, aut faltem prodire contendiffent. Inveniuntur \& particula jam in Ocbram mutate intus, quiburs foris adherent adbuc fquama nigra plendentes. Earum una peciem habet ferri rubigine confunti, \& tamen adbuc coharentis. Aqua pulversis bujus terre. macerati, guftu fubdulcisis fit, cum abfer foria aliqua acredine in fine. Coagulum e jus eft inffar falis chalcanthini, initio. Jubdulce, poffeses. valde acre, ut atramentum agnof Cass. Pulvis in catino vel cocbleari ferreo in ignem illatus non fagrat, nec facile nigrorem perdit, etziamfi diu exxcanduerit. Carbones integri folidique nondum. exefi putredine, inardefcunt, etiam ad ærnulationem optimi lithanthracis Cycnæi. Flawnma enim inde ef luculenta, cum fu. mo nigro inffar picis, odore mitione quam Gagate, bituminofo tamen. Sulphur in aliquibus deprebendas, nimirum quibus accubuit, aut immiffus. eft pyrites, qui ex Julphure \&s lapideis fuccis concrevit. Niger color in ardentibus pertinax eft. Didimus quassdim particulas inter ardendum bullientes, ut Gagates humidior, vel bitzamen Jpeciale. Bullam reliquit deflagratio leviffimam innatantems aque ó, nigram. Portiones brune o ligni putridi faciem babentes non Jlendentes in frasturis, deuruntur \& candefount ut pruna absque eiaculata flamima, \& fatim ut in aqua tabefount, deterunturg, levi tacitu digitorum, ita in igni dilabuntur. Hac autem peregimus inter prunas ligneass. Num foli quoque iffi carbones fint arfuri, reliquimzos in copia ante folles fabris experiundum, \& nos $\{$ p prius admot is ligneis inflammentur integriores, non diffitemur fabri flammain prebieturos poffea, eamque eo commodiorem, quia Jizititus adeo graves nor exhalant, ut narrant de Darri- 


\section{类( 84.) 犊}

bus. Diuturniore igni \& follibus, $f i$ exerceas, tandem in cineres rediguntur,fed diverficolores. Quadam enim portiones tot $x$ funt ruffe, foris, int us nigre: quedam foris citrina lanugine \&o alba funt cinct $e$ : alice foris candide, intus atre, quod nigrities valde fit refractaria, ut folet in bituminibus. Et licet insineratus fit carbos tamen interdum conftat corpulentia portionibus, quas fi iterum admota flamma incendas, ignem concipere, fo aliquousque glifcere, candereg videas. Neque enim facile exhauritur feminarium bituminis, ut non mirum fit Ethra cineres in craterem relapfos, denuo inflammari. Cinis in aquam precipitatus, uti fo nigre adbuc particule prius ignibus candefact $\alpha_{*} j a m g$ non amplius calide, frident, \& bullas multas à fundo remittunt. Crudi carbonis uncia, poft combuftionem prabuit reliquias trium drachmarum. Plerumg cinis peruftus in fummo albet, in imo niger permanet, nifi crebro a fundo regeras \&o vertas. Tentavimus deftillationem defcenforiam; fed nibil aliud confecuti fumus, quam copiam fpirituum alborum odore Gagat a ardent is, \& guttas: ruffas fpiffasque, que aquam premijforiam infecerant, ut oleret: aquam fuccini allium halitibus repræfentantem. Ille gutte abibant in liquamen pingue tenax craffum, of partim innabant: aque, partivn ad fundum concefervant, partim vitri adbarebant loteribus pertiznaci]/ime, uti fit etiam in deftillatione Gagate. Paus. cum oleum prodit, nec fumt ibus dignum. Rectius id petitur ex $G$ agate oleofiore. Hæc hiftoria, quam vere fecundum experientiam, fenfum \& rationem ponimus, convincit iftum carbonem bitumen effe, æmulum Gagatæ in fua integritate, vel Ebeni foffilis, quod Gagata fpecies eft; fed quia majore ex. parte corruptus eft, viciniorg, terre, ampelitidi accenferi poj]e, potij].mum nigri bitusninis of fimilitudinis, quam cum piceis carbonibus vel betulaceis, aut bujusmodi babet, pene exactam, nomine. Si in pulverem redigitur, accipit oleum pariter terre Colonienfi, \& melioribus particulis etiam citius. Vt judicandum fit, quanquam in oleo coctione non abeat in glutinofum fpiffamentum, tamer miftuo 


\section{身( 85.) 然}

miffura poffe pro unguine vitium effe. Et facile deteritur in pulverem nigrum vel fufcum, quaque partes in fractura plendent bituminis fudaici fulgore, ex etiam nobiliores funt Colonienfi terra. Unde pictores Norici non opus haberent Colonia afcijcere materiam, fed legerent in vicinia, fi refcifcerent, uti to fabri ferrariz. Illa ipla materia inferviret etiam chirurgis ad tumores molliendos, glutinandag, vulnera, \& anginas difcutiendas, aliag, multa, qua analogice ex fuperioribus bituminum hiftoriis quis facile poteft colligere, fi fit induftrius.

Scholæ ejusdem Autoris.] Doldiam libenter appellavimus iftam terram, à primo monftratore ejus, Leonhardo Doldio apud Norimbergicos medico eximio. Prius innotuiffe poteft aliis; fed quia neglecta, celebratorem Doldium expectavit, ab boc nominanda fuit. Nos eam variis argument is defcripiam exhibemus. Vulgo videtur ligneus carbo effe aut fegmentum fabrile quodolim ibi ex materia fabrili relictum terrag tectum tandem nigrum evaferit or putridum. Sed falli boc judicium liquido oftendimus. Quedam portiones exacte referunt corticem fagi cum parte aliqua ligni, $\sqrt{2}$ oculos confulere velis fine detritione \& fractura, aliisque examinibus. Cum franguntur plendidi/fimi nigerrimig. a phalti nitor in confpectum prodit, \& priorem vultum redarguit. Pyrites alias igniarius $e x$ codem loco sruitur. Sed qui carbonibus fociatus eft plerumg mollior exiftit \& friari poteft. Exculpfimus ex nonnullis etiam Galenæ nitidifimæ portiunculas. Unde colligere eft, locum iftum non carere metallo, \& quantum externo afpectu judicare licet, plumbi argentique ferax videtur effe. It $a$ o Cycnea Agricola friptum reliquit: In monte carbonum perfoffa terra carbones molles apparere, poftea faxa crafja, inde carbones duros fub quibus Cadimiam bituminofam, pyriten aluminofum, of as purum. Nec metallo foachimico defunt bituminofe minere. Viderent ergo quorum id intereft, ne quis Thefaurus in agro Norico circa Altorfium, ubi eft carbonum iftorum area, latitaret. Aqua in qua infugi fteterant fapore dulcz infecta erat, L 3

fequen- 


\section{楼( 86.) 桸}

Fequente aftrictione cum acrimonia. Humore omni paulatim abfumto in vitri fundo albe quafi fquamule apparebant circa concretionem quandam ramo fam in medio exbibentem pulchre plante imaginem albis ramis diftinctam, quale quid folet exiftere in vitrioli coagulo interdum, ficubi non eft quantitas magna. Non eft purum atramentum, fed fale nitrofo multo remiftum. Sapit initio quiddam dulce, poftea valde acriter linguam mordet. In aëre facile lique cit. Aquam Galla non inficit nigrore ob falem copiofiorem qui obftat nigritiei, vel quia debilior eft vena chalcanthi quams ut denfari crafse queat citra additamentum ferri, aut aris; fed alumini vicinior eft. In igne non fluit, nec crepat, aut bullit, fed perarefcit, cum aliquantulo rubore tanquam colcotaris feu vitrioli uffi nota. Tunc fapor non eft tam fubtilis \& penetrans quains prius: Fed potius. Falfus \& terreus, ßpiritibus nimirum fubtilibus ignis vi deperditis. Tactu afper pulvis eft, \& $f$ poft reverberationem (ut loquuntur Chymici i) in aquam dejicias, fundum petit, nec totus refolvitur ut ante, fed pars major irrefoluta manet, tanquams cals gisedam faxea, in quam fal etiam abire poteft \& lapidefcere. Ex cinere aquis infufo item fal elicitur fed candidior. Initio eft fubjpiceus. Si torreas inter prunas in catino, vel ferreococbleavi, primum fubaduftus \& bumidus apparet, \& adharet trulle firmiter, quin of in veficas attollit laminas fua acrimonia. Tandem evadit niveus, inftar aluminis uffi. Sapor fal fus terreusq o minus acris non tofto. Afper tactu. Alumen putes; fed boc combuftum, $f$ digitis teras, mollius eft, \& natat aliquantijper in aqua antequam refolvatur. Guftus quoque utrumg difcernit. Defcenforia detillatio experimenti caufa inflituta quinque duravit horas, dato igni per gradus ita ut diu fatis valente flamma carbo fit peruftus, neque tamen potuerit exbaurivi. Defcenderunt fpiritus fumei, olentes incenfum Gagaten, \& conceptaculum totum implentes, candidog colore, quafi falis, inficientes, quin \& in aquam præmifforiam fese infinuantes. Poft refrigerationem evanuit albedo. Oleum exivit paucum ut dictum eft. Carbo deftillatione peracta niger 


\section{犊( 87 ) 夥}

exemtus eft of inflammatilis ex parte; partim autem etiam exhau. ftus, levis, fifulorus of quafi bullis inflatus, plane ut in gagate confuevit fieri. Aqua pramifforia fubalbida, faporis abominandi fuit exbibentis fimul aliquid chalcantbine dulcedinis of acrimonia fed modica. Liquamen oleofum fat olet graviter, \& diu inquinatas manus tenet. Carbo reverberatus inter deftillandum, aqua perfufus fridit fumigavitg. Cum tam tarde \& difficulter procedere deftillatio de (cenforia, noluimus operam perdere afcenforia, uti nec inclinatoria. Satis item apparet bujus bituminis natura ex dictis. Quoniam autem nonnulli pnigitin (a loco ita nuncupatam) quoque inter terras bituminofas babent: (Nam cretam nigram Belga di. cuntur appellare lithanthracem Aquisgranen fem; Encelius fidivat: Ee Sectoen interpretatur ampelitin; Seidelius pnigitin) perpendenda funt autorum de illa verba. Diofc. ait dictam pnigitin colore quodammodo fimilem effe Eredriadi (quam vel albam admodum pofuit, vel cineream, que per aramenta tracta lineam referat violaceam) grandioribus tantum glebis, refrigerantem manus admotas, tactu lingue adeo glutinofam ut pinflis hereat, \& aliqui viendant pro Eretriade, ofc. Hac ipfa \& Plinius babet lib.3s.c.16. Galenus facultates pnigitidis \& cimolia exequat; colore diffimilem facit, ut-

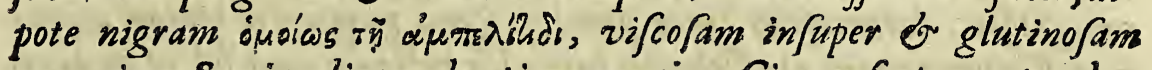
non minus Samia, aliquando etiam magis. Circumfertur autem lapidis atramentarii titulo terra quædam nigra glebis fat magnis interdum cujus ufus non in atramento fcriptorio tantum, fed \& pingendo fcribendog pro creta, nifi quod atrum colorem prabeat. Facile vadi of deteri poteft plane ut creta. Alicubi venulis candidis \& allaviecula diffinguitur, quafi argenti vivi adhereret of rimis receptus effet halitus. Sed nihil potuimus hydrargyri notabilis elicere. Suftinuit ignem illa albedo, \& in elutione per alveolum forma oblongarum particularum micam argenteam retulit : crudo apectu etiam Galenam aut bismuthum. Per fe olet griddam molle \& ingratum cum naufea. Ad candelam reddit odorem aque in qua ies eft extinctum, feu infufus ftetit litbantbrax uftus. Nons 


\section{然( 88. ) 楼}

quidem flagrat, fed ignitur tamenut pruna, \& in albam calcem mutatur. In ferreo cocbleari, inter prunas ufta tale quid Jjirat quale ex luto \& lithantbrace miffura. Deinde excandeccit reddita pauca flamma fagrante inter prunas, à quibus $\{$ vemoveas mox reftinguitur. Integre particule inde funt allba ut os uffum vel argilla candida. Pulvis vero etiam diuturniore flamma, in fummo faltem cinereum accipit colorem. Tandem vero item evadit candidus, idque magis $\&$ citius 5 v varus fit. Aliquando portiones etiam ruborem induunt. Itaque conjicere licet aliquidbituminis argillam albam infeciffe, \&o nigro tinxijfe. Sapor cineris, terreus, calidus ficcus \& nonnibil fubdulcis eft. Ampliori igni poteft totus erubefcere, absg magna fubfantie jactura. Color enim \& - piritatis tinctura evanefcunt. Cinè terræx Altorfinæ feu carbonis ampelitici Doldiani tenerior fit; fed tamen vehementia flammarum etiann declinat ad ruborem quesn tandem plane quoque induere poteft. In cifula Kentmanni eft picea quedam medulla faxorum Pirnenfum. Hec qualis fit nondum potuimus indagare. Videbit medicus iffius loci num inter bitumina veferri debeat, \& cui generi accenferi. Cum de Gagate f cripfimus, produximus Liparen Plinii ó Liparaum Theophraffi. Sunt in illo figna Gagata, quia niger J cribitur, lavis, JpifJus, interceptus inter pumices (aut pumico os lapides, quos. marillas nuncupant ex Et threis incendies reliquas, qua folent in ag ris Siculis refolvi \& effe loco lataminis feu marg.e.) Nefcio an fimile fit quid in ifta medulla, ut pro Liparcoo lapide \&s Jecie Gagate haberi queat. Medulla tamen cum dicitur, quafi marga nigra bituminea, ad daffem ampelitidisis terre vevocanda foret, innuitur.

Hucusque folertifimi Libavii, de noftro Ligno folfili bitumino o, tum Pyrite, \& hinc eliciendo Sale Vitriolico, accurata veraciflimaque narratio; cui quod addam vix habeo, nifi locum, quo ifta inveniuntur: Hic autem eft profunda, fæpius nominata fpelunca (die $\mathcal{T}$ eufflg-gruben) non procul à pago (Sirůniperg / ubi media inter faxa arenofa occurrunt vene guafa parfa, vagag Arata dictorum carbonum, aut lignorum fojs- 


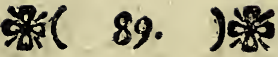

lium, cum pyrite frequenter commixtorum. Nec dubi um eft, quin \& alibi circa nos corundem concretorum vens lateant: Certe enim terre bituminofa, fuperiori plane fimilis, con/picuas portiones depromfi è rivulo verfus Saganghußen/ leucæ minimum intervallo à Ortưnfperg. Quid, quod ubivis obvii funt lapides cruftof, in cinereo nigricantes, bitumineum fatorem, fi durius fricantur vel conteruntur, exbalantes.

Cæterum in eo ægre adfipulor Libavio, quod cuncta noftratis ligni foffilis bituminof fpecimina meræ mineralis fint profapiæ : Licet enim hoc concefferim de rudioribus $\&$ informibus, de fingulis tamen, præfertim iis, quæ ligni vegetabilis naturam, quoad tractus fibrarum, pectines (Die Sahbe) corticem, nodos \& ramorum veftigia, \&c. nimium exacte referunt, concedere neutiquam poffum. Sane jam pridem doctiffimus Mart. Sclboockius ( $\mathrm{g}$ ) ita diftinxit: Quc fub terra inveniuntur, arborumgs loco habentur, aut illud funt quod ause diunt, arborum fcil. trunci, ramis atgue radicibus fuis inftructi, ant -faltem tale quid videntur. Et pofteaquam idem Autor operofe conatus eft oftendere, plerag ifforum fofflium lignorum nunquam vera extitife vegetablia, fic tandem $(b)$ concludit: Neque tamen, fuadentibus plurimis experimentis (ad que quams dilizgentiffme attendi) inficias ive licet, alicubi ipfas cum fuis fructibus arbores prolapfas fuiffe, \& profundo merfas. Etenim non modo trunci, fuis coherentes radicibus notantur, verum etiam trunci paviter cum folis \& fructibus ab is propendentibus, \&c. Equidem alii ( $\&$ inter hos non ultimus ingenio D. Mattb. Zachar. Pillingius (i) contendunt, lignum quodcung bituminofum à natura produci fub terra: Veruntamen fi id, quod magna confidentia fupponitur, nempe vim quandam specificam bitumini ineffe, qua ad lignorum imaginem formari po $\int 2 t$, vocetur in dubium (uti merito debet) vel negetur, tota vacillabit aut prorfus corruet hypothefis.

M

De

(g) De Tui fis, Cap.XII. p. 82. (b) 1.c.pag. 248. (i) de bitum. \& lign. folfil. bitum. cap. $8.8 \times$ \% 


\section{\%o( 90.) \%}

De Pyrite noftro exploratum hoc habeo, quod Sulphuris : haud modicum contineat, cum foenore hinc feparandum, fi modo cumulatior præfto effet minera, cujus tamen adhuc nullæ conftantes venæ comparuerunt; Namq; fruftulatim (Nieren-uno Reft-lveife) faltem jacet ille pyrites; tam loco dito, quam alibi, nimirum hic Altdorffii, pariterq; ad Oppida Reumardt \& Serfpruf $/$ per fubcoruleam iftam terram, quæ cellarum excavandarum gratia eruitur, difeminatus, variis ludens imaginibus \& figuris, quemadmodum \& Fob. Baubinus l. c. de Bollen fa pyrite fuo annotavit. Sunt mihi fruftula vivaciffimis quibusque coloribus: refplendentia: Quædam compacta \& valide dura funt, bombardis, pro fufcitando ad explofionem igne, accommoda. E quibusdam aliquandiu aëri expofitis Vitriolum martiale efflorefcit, perinde ut è celebri Haffaca martis minera, folari cognominata, quæ: nec ipfa quid aliud, quam Pyritis aut Marcbafate fpecies eft, à noftrate parum diverfa, ut facile crederem, hanc ill: poffe fubftitui. Profecto itriolum inde evocatum, \& in cryftallos viridefcentes coagulatum, eft egregium ac fubdulce. Confimilem quoque: pyritem obfervavi in lapidicina Herspruccenfi, duriflimis ingenitum faxis.

Opportunum hic effet experimenta quadam, circa Pyritem à me inftituta non vulgaria fubjungere, fed eadem, exclufus tempore; in aliam refervare cogor occafionem.Si quis interim de Pyrite plura defiderat legere, illi Petrus Maria Caneparius (l) inprimis fatisfaciet. Cxterum SAL, quod carbones \& ligna foffilia nofira, ad examen Libaviz prabuerunt, deprehenfum fuiffe ALVMINOSVM, minime decet mirari; quandoquidem aluminis genuini venas, glebarum ejusmodi lignofo-bituminearum facie, paflim, pracipue vero in Bohemia licuit confpicere.

Cappr

(I) De Atrament. Defcript. I. Cap. II. IX. X. \& fequ. 


\section{然( 9r. ) 船 \\ CAPVT $X$. \\ DE METALLIS NORICIS}

Uamvis Noricum noltrum, facunditate metallorum, Saxoo nie, Bobemia, Hungarie, aliisque hoc titulo celebratis regionibus lubenter cedat, expers tamen metalli haudquaquam eft. Præefertim FERRO abundat, \& olim forfan abundavit magis, etiam nobiliore ac duriffimo, quod CHALYBS vulgo nuncupatur. Certe Plinius (a) bonitatem ac præftantiam Ferri Narici collaudat: Et Horatius (b) Noricums enfem, tanquam maxime terribilem, commemorat; nec minus Ferri Norici durities ab Ovidio (c) indigitatur:

Durior \& ferro, quod Noricus excoquit ignis. Aft hæc loca de antigro Norizo (cujus Cap. I. mentionem feci) interpretanda videntur: Quicquid fit, modernum quoq;Noricim eodem nomine meretur extolli : Et credibile eft, hanc præ cæeteris regionem prifos Naricos, patria extorres, fibi pro fede nova felegiffe, propter Ferri copiam, quæ porro exercendis artibus avitis commode inferviret; quam fufpicionem officinarum ferrariarum veftigia per Noricum (maxime ad Pegnefi ripas) hodieque numerofa haud leviter corroborant.

Præftantia feorfim Ferri metalla, fuo jam tempore G. Agricola (d) teftatur habuiffe Noricum Č̈́danubianum (ita enim noftrum fatis recte appellat) ad fecundum lapidem ab Amberga Sulcebachum verfus. Huic confentit Valer. Cordus $(e)$ : Ferrariarum (fcribens) omnium largifsme funt Ambergi, in iis HFMATITES NIGER pulcherrimus ferrum optimum fundit. OCHRA ibidem RVBIGINOSA, quam vocant Sebererk/ / copiofe effoditur, que optimum remittit ferrum. In ìsdem ferrarizis RVBRICA DVRA, hematitis modo, ferri plendorem pre $f$ e ferens. \&c. Quin \& fequentibus temporibus hasce ferrarias,

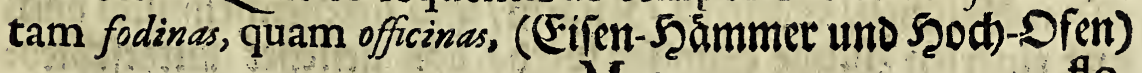
$\mathrm{M}_{2}$

(a) Hift. Nat. Lib. XXXIV cap. 14. (b) Epod. XIV. circa finem (c) Metamorphof. Lib. XIV. (d) de vet. \& nov. metall. Lib. II. cap. 15. (e) Sylv, var. obferv. p. 218. b. 


\section{嗮( 92. ) 㩆}

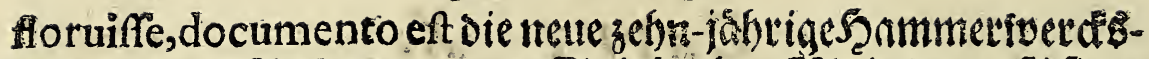

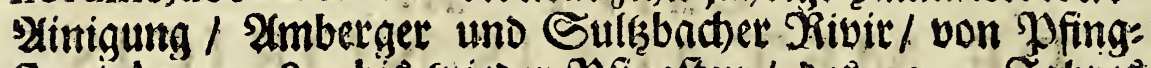

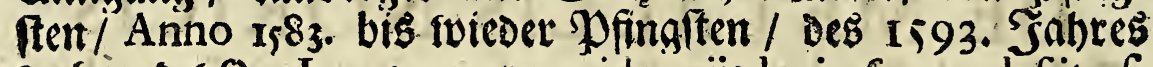
ivefireno $(f)$. Imo ne nunc quidem iis locis ferrum defiit effodi \& excoqui, venis fat laudabilibus, è quibus ipfemet hematitem Cordi nigrum, præftantem fane Ferri min eram, infuperq; aliam, quam, ob fuperficiem globofam \& f fplendentem(S) I $\mathrm{b}$ : fopf vulgo vocant Metallici, non obfcura fpecimina collegi.

Propius autem ad Altdorffium, locis variis', abundat ferrum: Inde dictum furficari licet $\mathcal{S e t r i e d e n} /$ Brandenburgico-Onoldinx ditionis pagum, de quo beatus Georg. Ca/p. Kircbmajerus, metallicæ rei peritiffimus $(g)$ hæc habet: 2It: Iernedift benm Dorff Dber-Serrieden finter \&lltoorff/ unfweit Der Megenfpurger Strafien/auf Der Şóbe im $2 \mathfrak{S}$ alo/bricht ein überaus guter und reidbhaltiger Eifenftein. Sed in ipfo quoque Norimbergenf/ Territorio frequens fatis ac dives extat

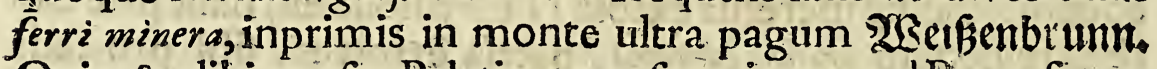
Quin \& alibi verfus Pàlatinatum fuperiorem, ad Pegnefi tra\&tum, cujus mineræ copia \& bonitate confifus, pralaudatus Dn. Kircbmajerus, Autor effe cepit Proceribus quibusdam Norimbergenfibus, ut fodiendo. \& elab́orando iffi metallo operam, fructuofam futuram, impenderent: Facilioris autem perfuafionis gratia, fumtuum \& ex adverfo redituum talem (b) inivit rationem:

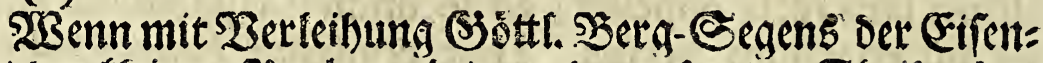
ftein / Der fleinen prob nadd/ nue Den zebenden Theeil geben

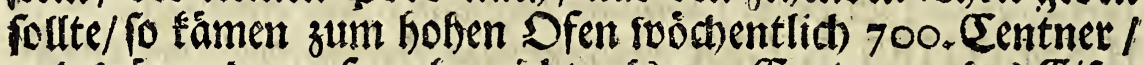
und saáren Darauf mefhe niddet als 70 . Centnet robeb Eifen zu etrangen. Der Eentner- auf Dem Szammer Daférbften rviro bezaflet à 2, fl. frútró betragen

140. fl. = = auser Das jentige/ fras am Defen/

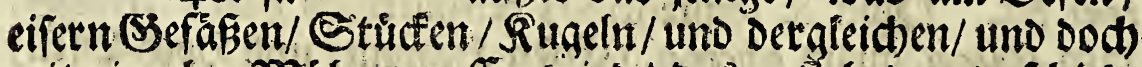

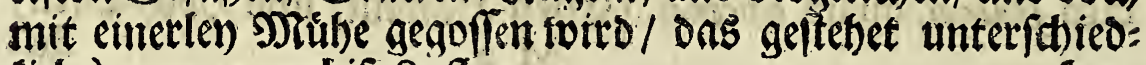
(id) à 2. 3. 5. 7. bíz 8. f.

万ृets

( $f$ ) Impreil Ambergx, 1583 , Fo $g$ ) Append. ad initucut. Mietall, p. mo 110. (b) l. c, pag. 108 . 


\section{然( 93.)}

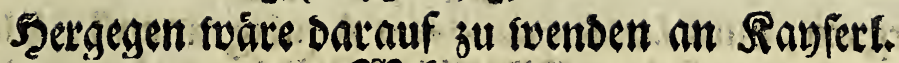
2BSebrungl

14. f1. Pro jure territoriali, an Zefenden/ratione bee

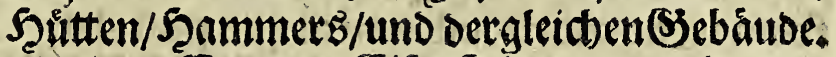
35. fl. vor 700. Eentnet Eifen/tein zu geivinnen/ uno anzufútben.

4. fi. vor 3 ulating.

42. fl. vor 21 . Suber Sohlen/ iedes a 2, fl.

21. fi, Dem Facteur, Sdbmelismeifter und 6, Sam: imer: Reuthen.

Ir. fl. Dem Siohlentráger.

I ${ }_{2}$, fl. zu Cubaltung Des Inventarii.

Thut 120. H.

Pieft 20, fi. Uberidum.

Sed duo hic inprimis ardua \& incerta Vir optimus, nofrique (cum viveret) amantiflimus, videtur fuppofuiffe, continuum fcilicet DCC. centumpond. minere, \& XXI. plauftr. carbonum in fingulas feptimanas apparatum, qui unde fuppeteret, ego quidem nequeo perfjicere. Hoc autem plane exiftimo, illuftrem Senatum Norimberg. pro decantata fapientia fua, \& paterno in cives fubditosque affectu, minus de ferri metallis in fua ditione inveniendis effe folicitum, quam de fylvis confervandis, quarum fane pernicies ac peftis, fornacum quibus ferrum excoquitur ac funditur ( $(50$ d)-Ofen) frequentia.

Cæterum non modo Pyrites nofter, verum etiam Ochra, pluresque Terra, in Cap, III. recenfita, pertinent ad Ferri mineras, tum Lifferi. (i) tum proprio meo experimento; quatenus e fingulis, poft aliqualem uftionem, promte colligit magnes Ferri moleculas, notabili quantitate.

Es five Cuprum in Norico noftro nondum, quod fciam, repertum eft; nihilominus exaliunde advecto prope Norim$\mathrm{M}_{3}$

(i) de Aqzu. Med. Angl. Exerç. I. cap. 2. 


\section{然( 94. )}

bergam, cum lapide calaminart' Aquisgranenfi, à longo jam tempore conficitur ORICHALCVM, quod mox in officinis peculiaribus in fila (Diath) ducitur, aliasve convertitur in formas, ut moris eft, emtorque poffulat. Exis autem foboles, aut affine faltem ipfi eft COERULEUM NATIVUM ('פerg-Lafur) cujus fipecimen pulcherrimum, durum ac rplendens, in lapide cinereo, CHRYSOCOLLA pariter NA-

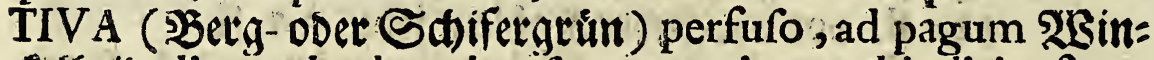
felfheib aliquando deprehenfium accepi, quod indicio foret latitantis forte ibidem metalli; ; fed quia ulterius nihil iftorum foffilium comparuit, una birundo ver inon faciet.

Neque vero Metalla nobiliora, Aurum puta \& Argentum; in Norico noltro fe prodiderunt. Quamvis enim fubinde oborta fuerit fufpicio venarum argenti, noluit tamen ex voto res fuccedere. Sic noftra memoria, in Diocefi Eyftettenfi, ad oppidum Эernariél / minera quæedam, ut ferebatur, Lune cæperat erui, fed non refpondit fumtui labor. Meliori cum fructu hodieque ARGENTVM audio fodi, ad pagum San: fee/ non procul ab Oppido DJennfelo/ ejusdem Diœcefis, cujus alia quoque loca Ferrum fuppeditare copiofum dicuntur.

In Norimbergenfi Territorio celebrant vulgo peluncam Veldenfem, tanquam pretiofioris metalli feracem, quaque propterea clanculum vifitetur ab ignotis Italis : Sed fabulam fapit traditio, nec ipfe Argus aliquid auri vel argenti in illa crypta obfervabit.

Non longe abeft Altdorffio pagus Stub/ad quem ante plufculos jam annos quæefitum fuit metallum, fruftra tamen \& fine emolumento. Paria fata habuit Grunfpergenfis fodina, olim Das Silbetlod) / in fpem comparituri argenti nuncupata, cujus tam putei (Sdad)t) quam cuniculi (Stollin) cernuntur etiam nunc veftigia. Videtur autem memoratus fupra Pyrites plendidus anfam fodiendi dediffe, nifi magis GALENA (SIant) ad quam refpexit etiam mo- 


\section{然( 95: )}

nito fuo Libavius, ipfeque illam minime fterilem judicave rim, fed copia deficit.

Quando Galencm, utpote PLVMBI NIGRI mineram nominavi, æquum cenfeo, ejusdem metalli amplifimarum quondam in Superiori Palatinatu fodinarum injicere mentionem. Has perintegrum quafi feculum viguiffe, fidem fa-

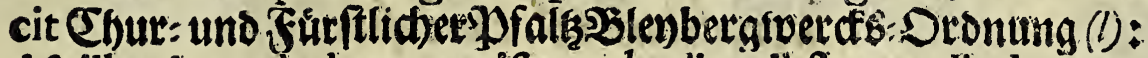
Aft ille vigor dudum remifit, ut hodie nil ferme aliud agant perpauci operarii in Oppido metallico ( $\mathfrak{B i l f e c t ~ \& ~} \mathfrak{Y S e n d e n / ~ q u a m ~ u t ~ e ̀ ~ v e t u f t i s ~ r u i n i s : ~ \& ~ c u m u l i s ~ ( a u s ~}$ Den alten (̧allen) colligant lavando metalli veliquias, \& in propinquis officinis elaborent. Minera vero dives admodum, \& neutiquam vulgaris, cujus tres præcipuas notavi differentias. Primam candidam, femique diaphanam, fuoris infiar, unde \& $\mathfrak{F} l \mathfrak{u} \tilde{E}$ appellant; ac centenarium ipfius ad LXXX.pondo Plumbi nigri fundere affirmant. Secunda eft opaca, pcabra, colore \& forma cruffofa tartaro vini rubro fimilis, quapropter to: the Sdhalen audit; ex dimidia vero parte in Plumbum liquari afferitur: Forfan hæc eft Plumbum nativum Sultzbachium, quod Georg. Fabrieius (m) rubeum pronunciavit. Tertia ex flavo viridefcens (grun SIley-Erk) ponderofa quidem, fed non tam ut priores metallo abundans. Cæeterum ex hisce mineris coctum fine dubio quondam fuit, ut copiofum, fic præftans Plumbum, illudque ipfum quod fobs Kentmaannus ( $n$ ) nominat, ¿ Palatinatu moliffimum: (SSank freidh Şlen. Ego vero mesallorum recenfionis, \& totius ORYCTOGRAPHI E NORICE, poft gratias humillimas, DEO Ter Opt. Max. pro conceffis mihi viribus per: folutas, hic facio

\section{$\mathcal{F} \perp \mathbb{N} M$.}

(b) Impreff. Amberg 1619 . in Fol. ( $m$ ) de rebus metall, cap.VII. (n) Nomencl. set. foffil. p. 84. 20. 


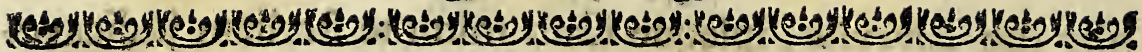

\section{SYLLABVS CAPI TVM.}

CA p. I. De Situ ES Natura Agri Norici.

GA R. II. De Aquis, prefertim medicamento fis, mineralibis $E$ curio/is.

CAP. III. De Terris, quarum fingularis ufus eft, partim apud Mechanicos, partim Medicos.

CA $\mathrm{P}$ IV. De Lapidibus ingenere, $छ$. peciatim iis qui funt amoepor, h. e. nulla certa figura conpicui.

CAr. V. De Lapidibus sumóepors, feu figura certa gaudentibus, in genere, E ppeciation talibus ex Lufun natura.

CAP. VI. De Lapidibus apuopous feu fguratis, ex quorundam Vegetabilium $\mathrm{O}^{\circ}$ Animalium transmutatione.

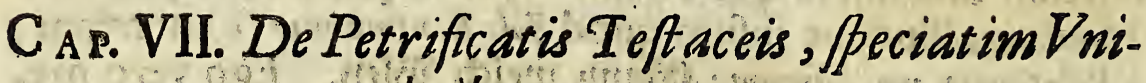
valvibus.

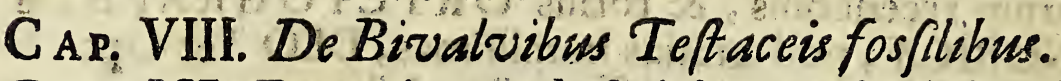
$C_{\text {A }}$. IX. De Salinis E Sulpbureis fosfilibus Noricis.

$\mathrm{C}_{\mathrm{AP}}, \mathrm{X}$. De Metallis Noricis. 


\section{Tab.I.}
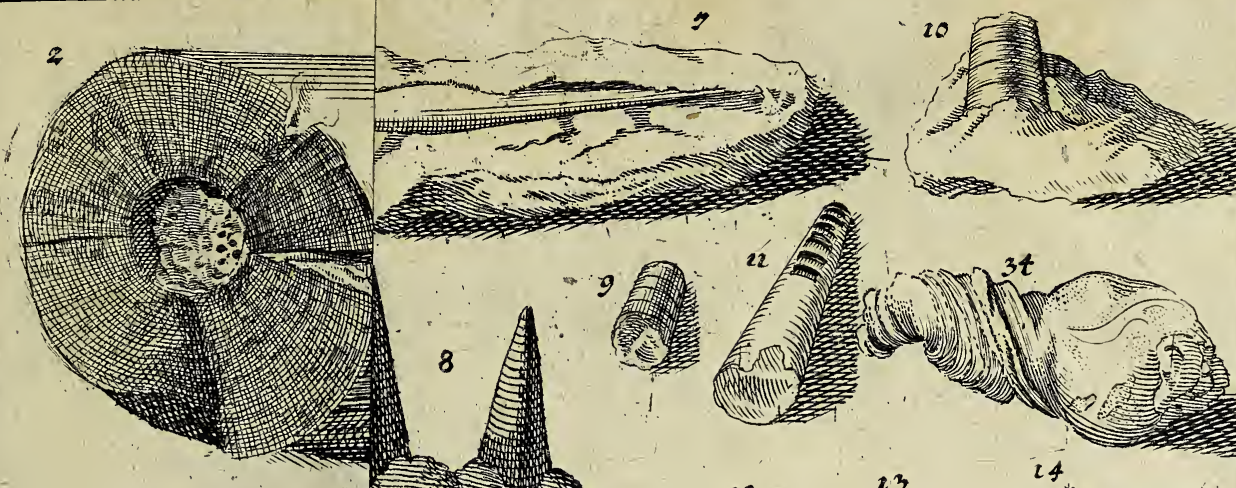

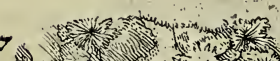

a 1 ,

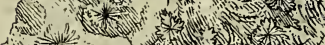

(1) $=5$, n

1)

1 5

- 5 winn
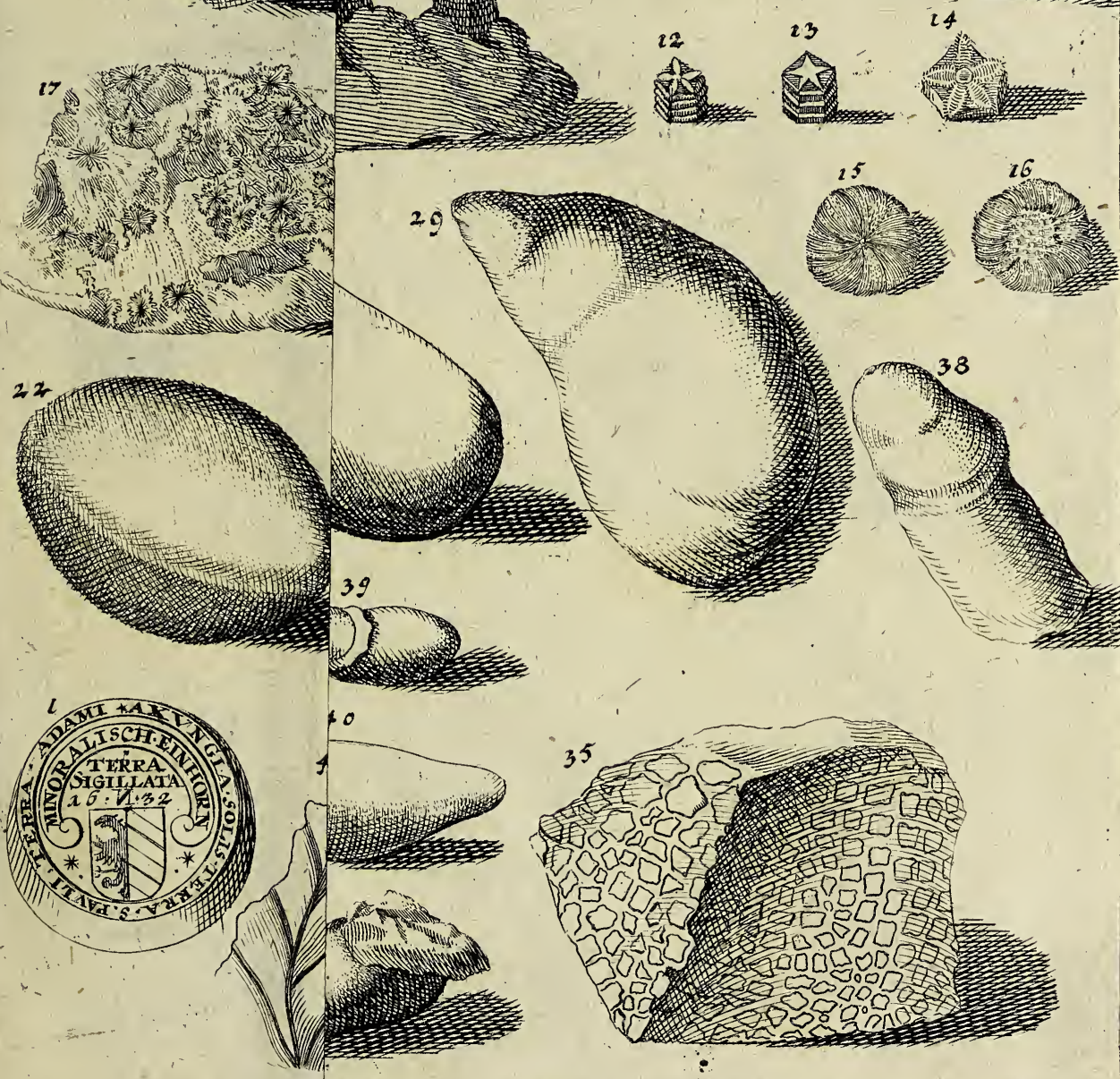




\section{Tak I}

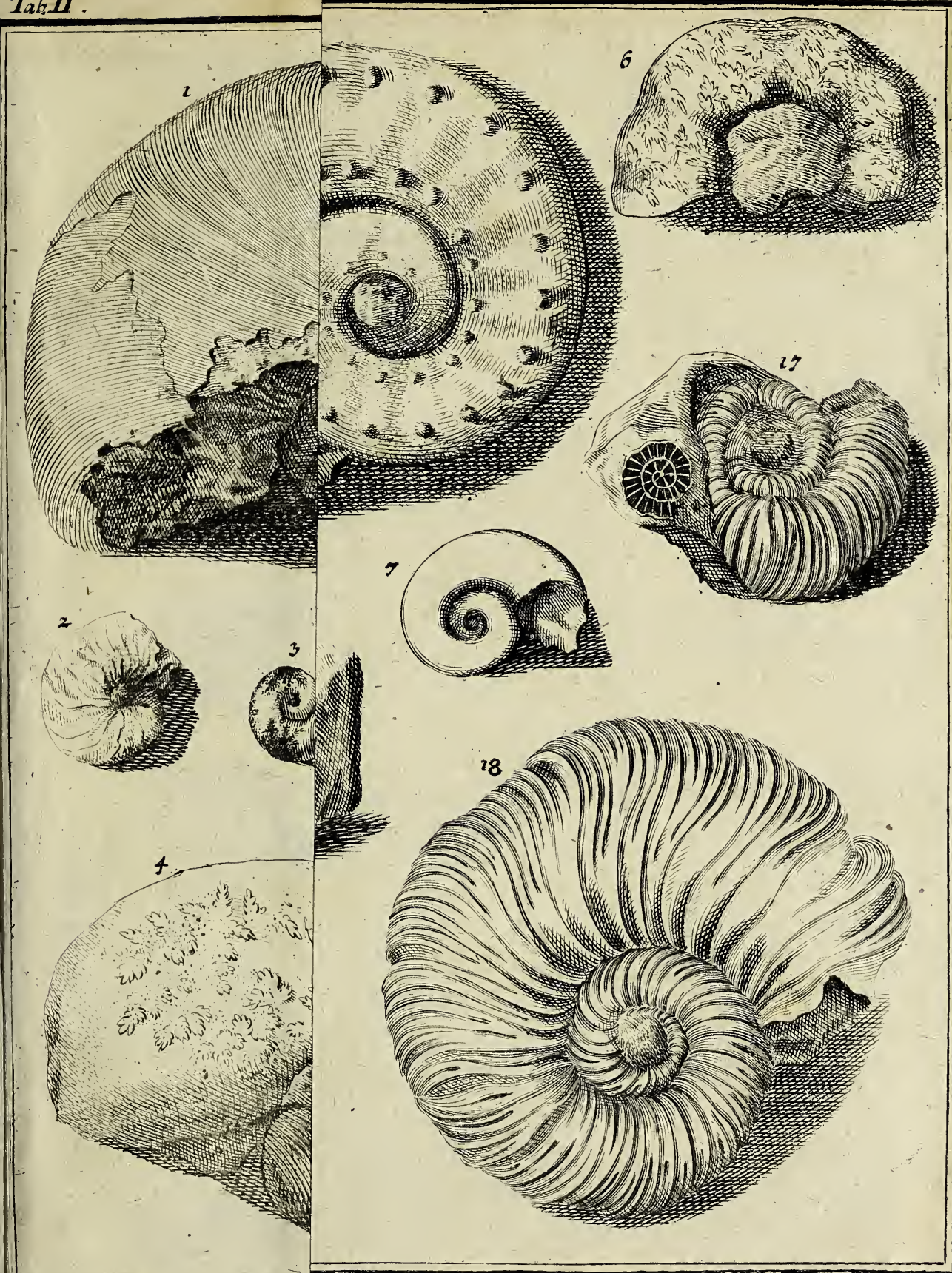






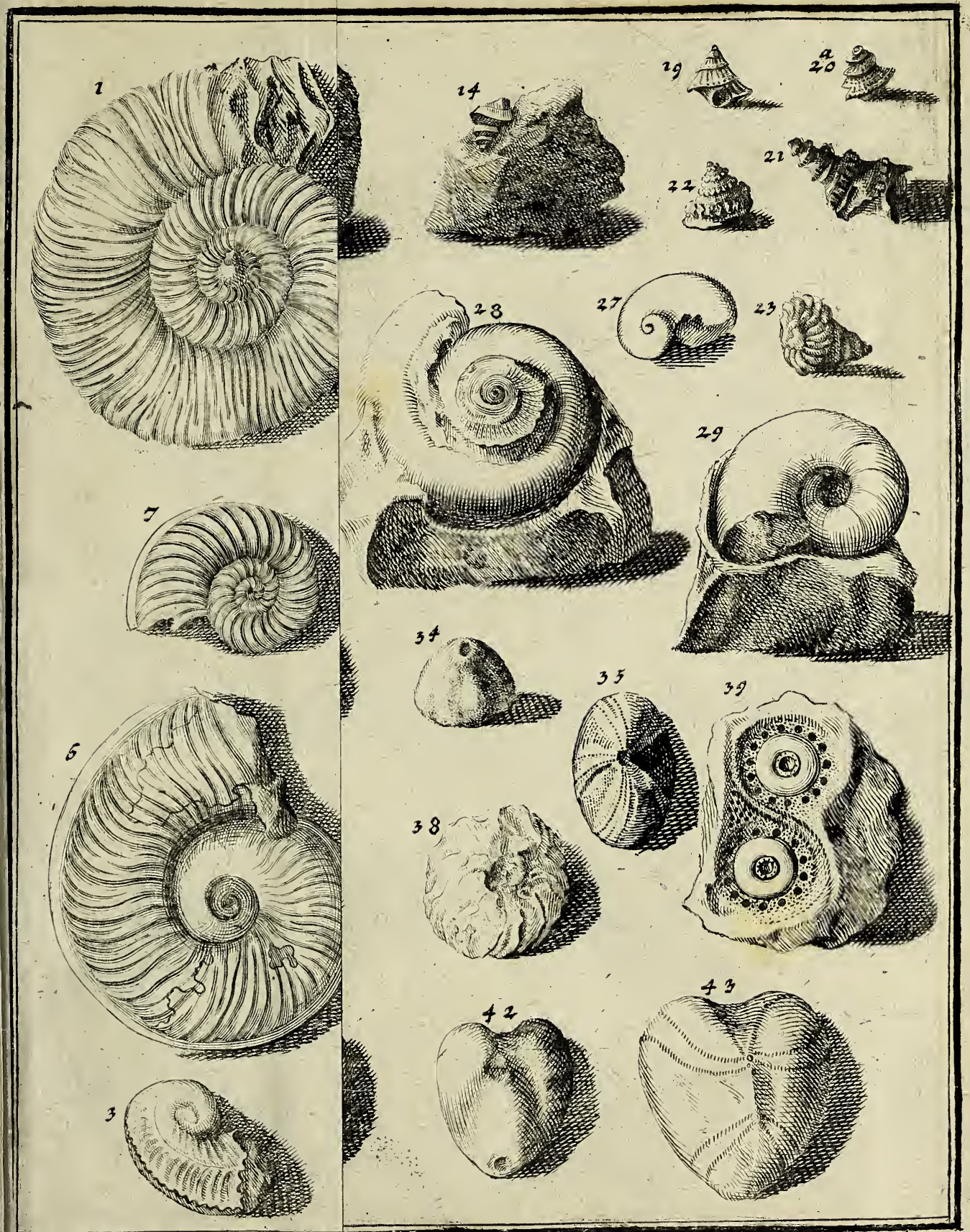





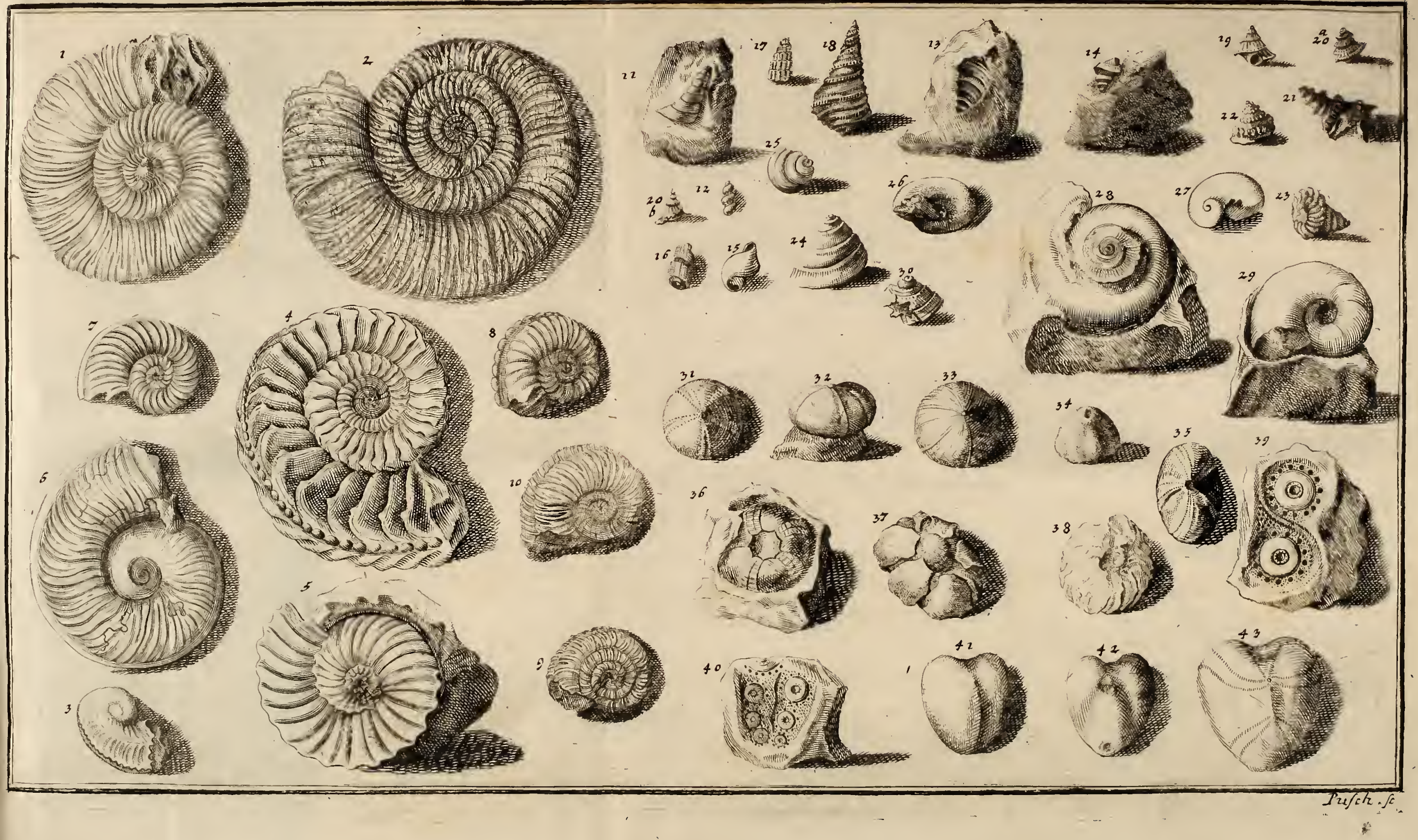





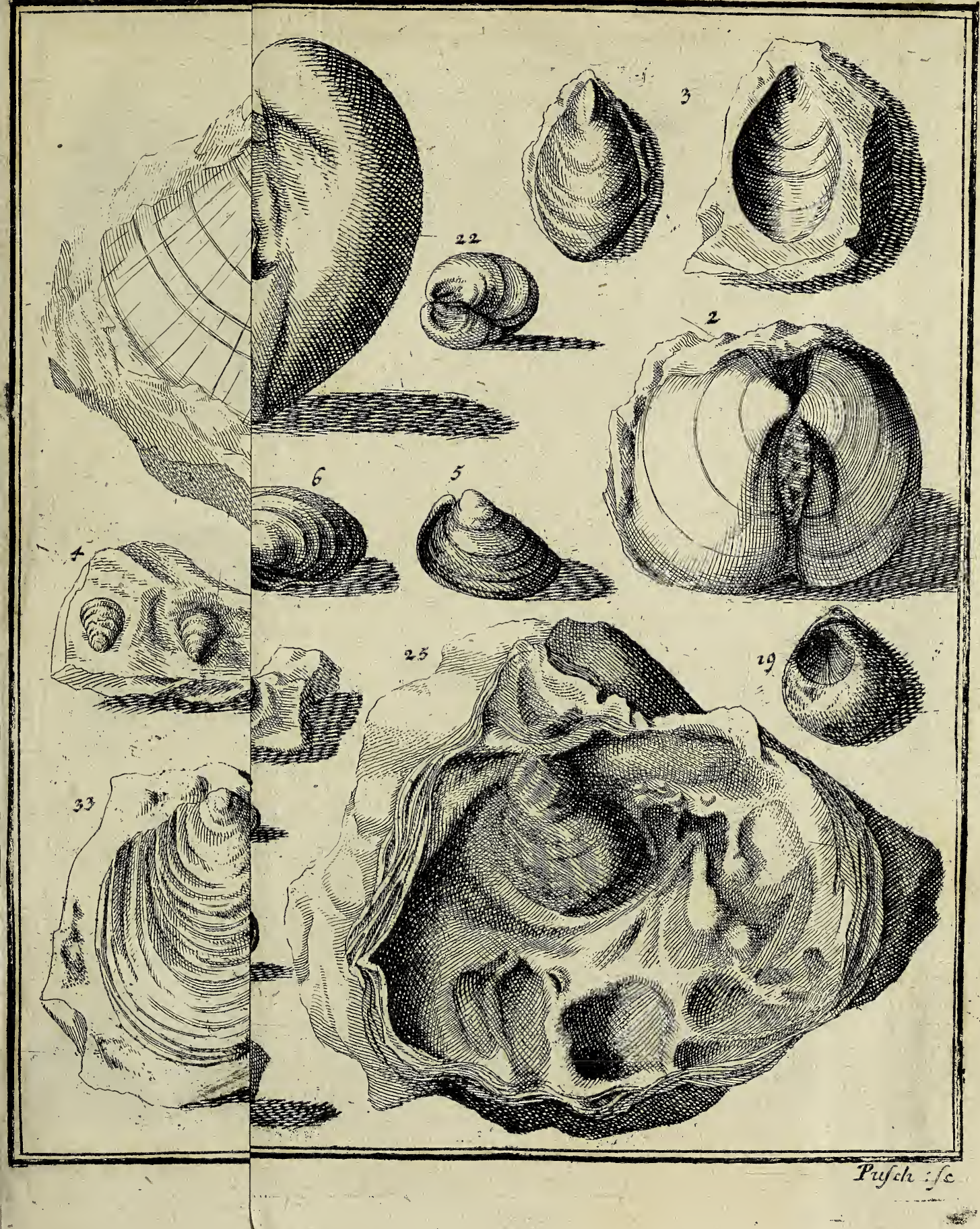




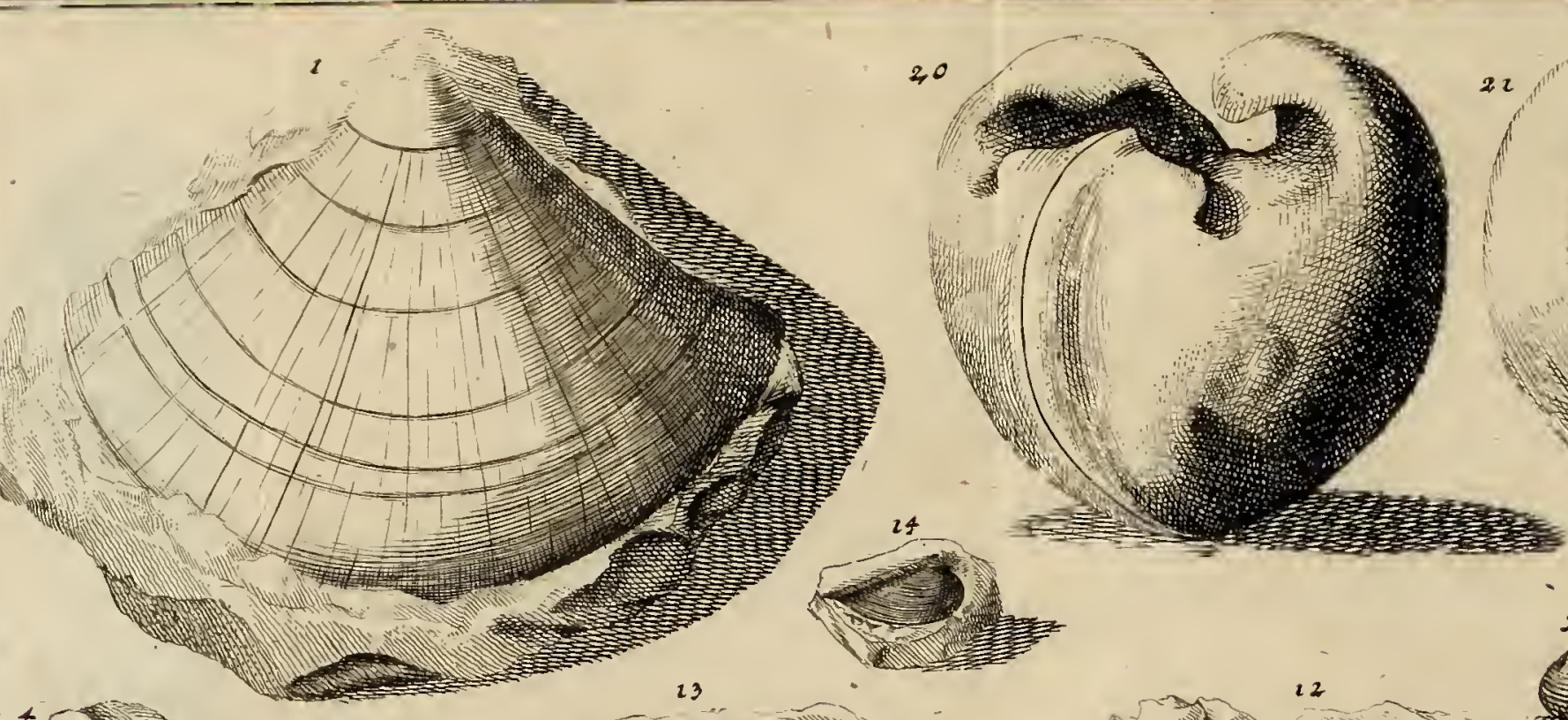

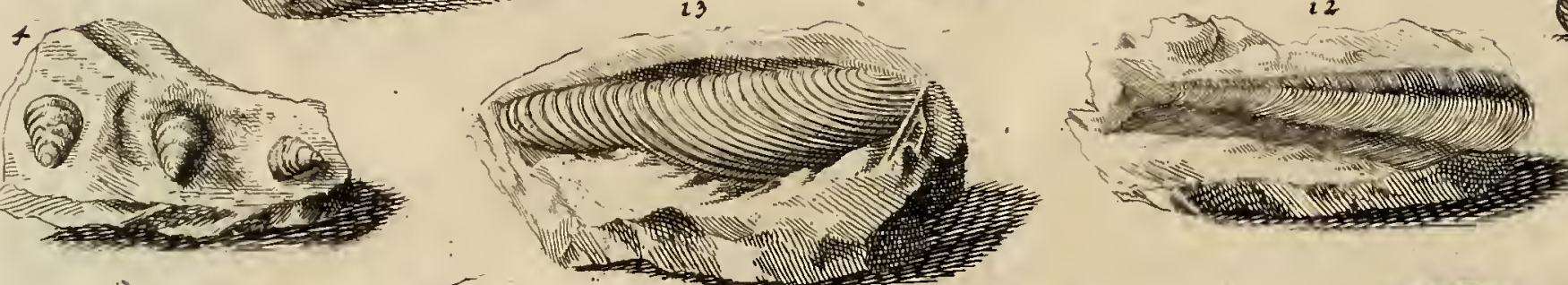

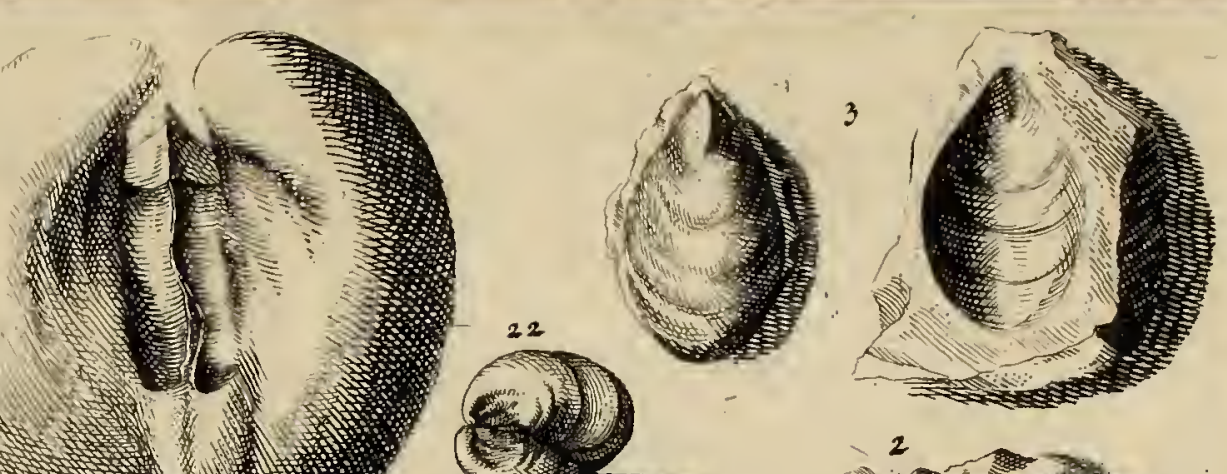

1(1)

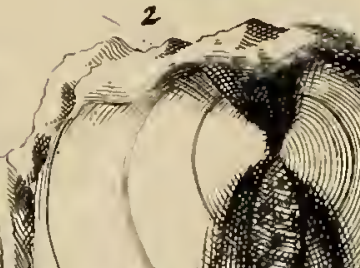

- 10 2 (n)
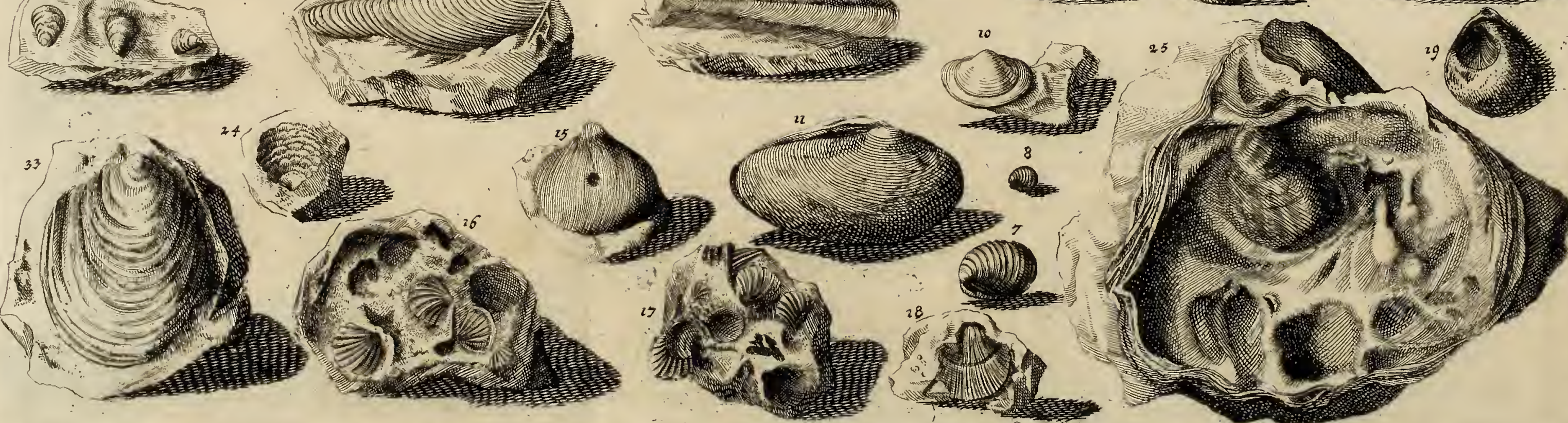


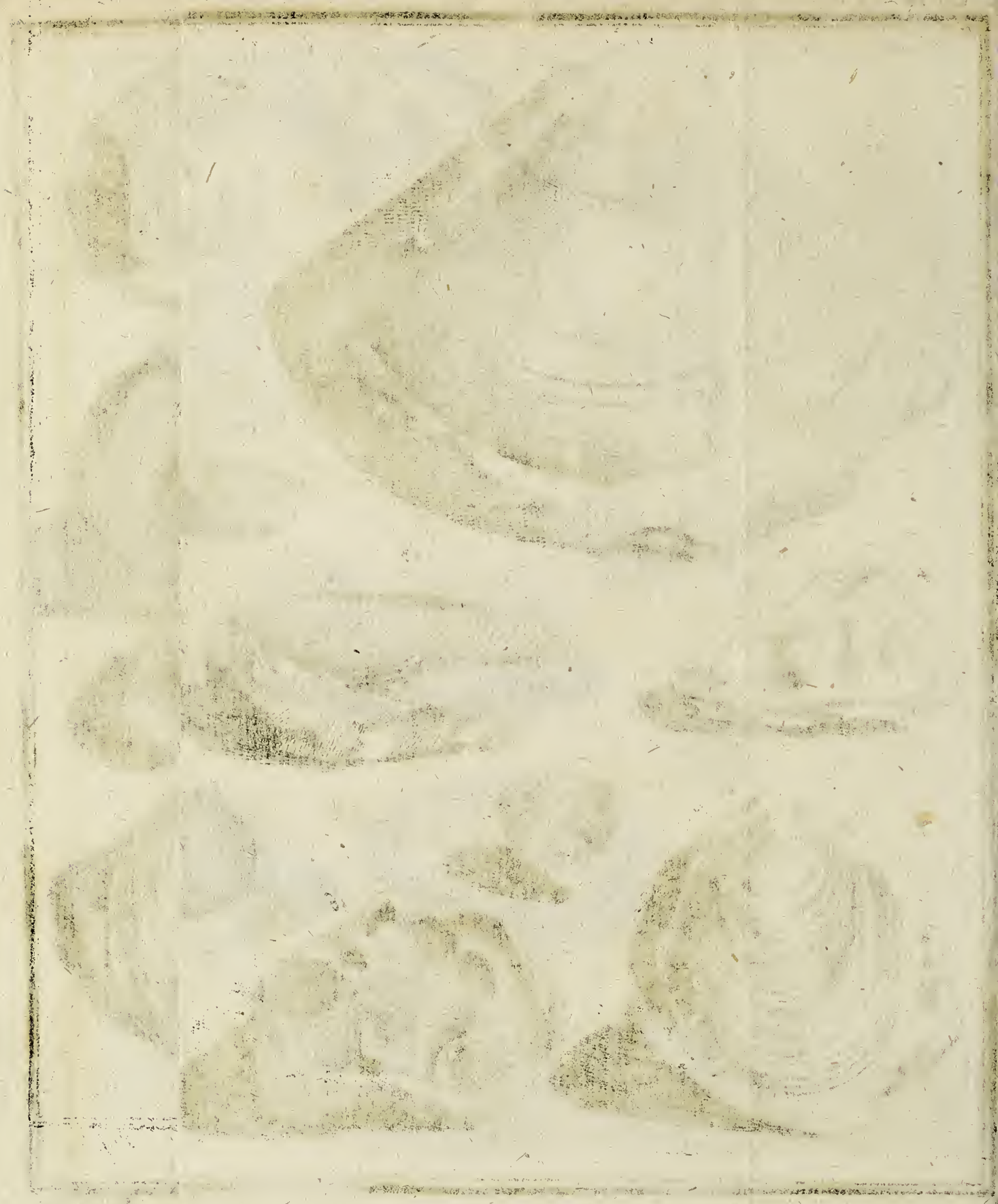



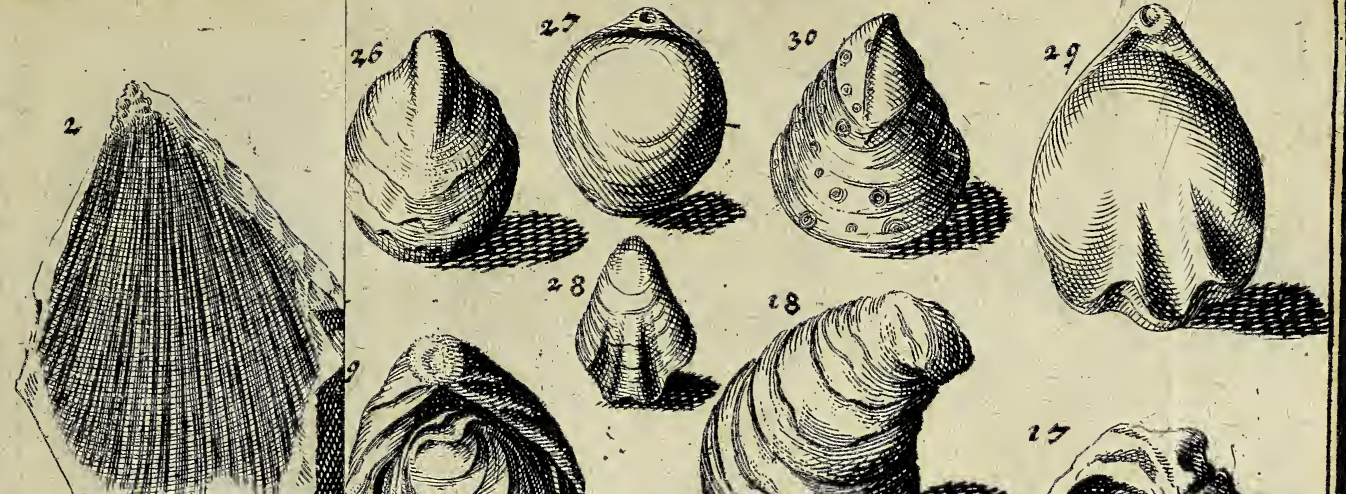

(4) 3 . 31 -
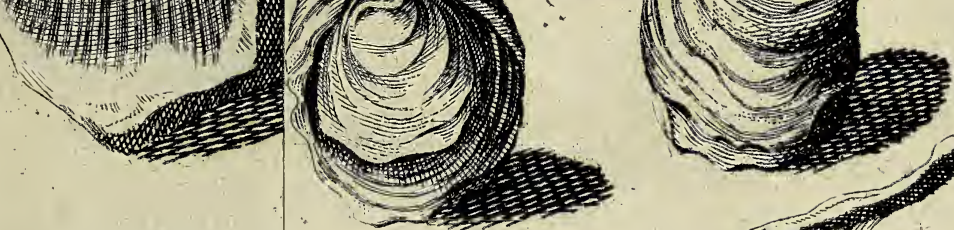

27
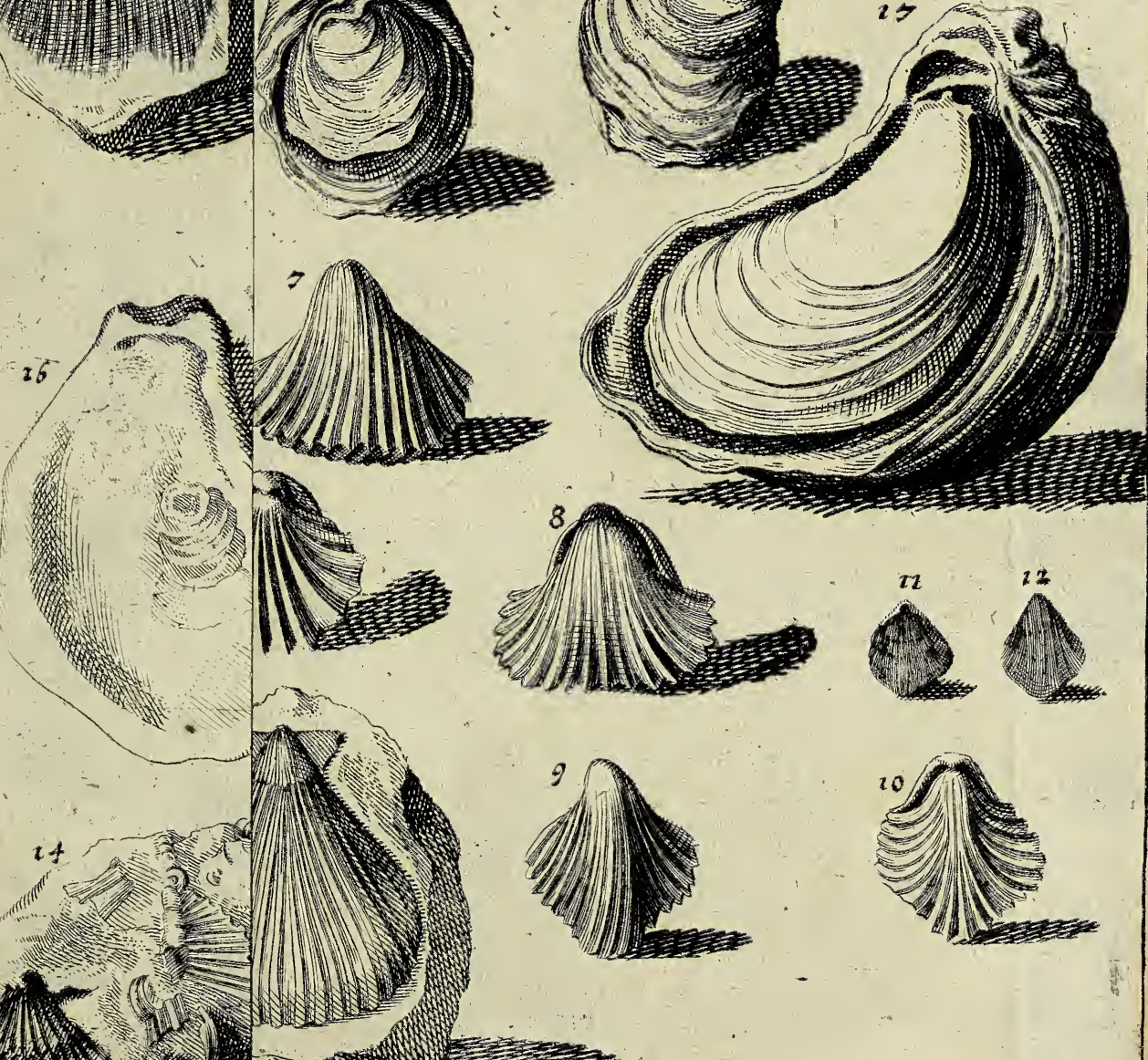

$-70 \times 10200$
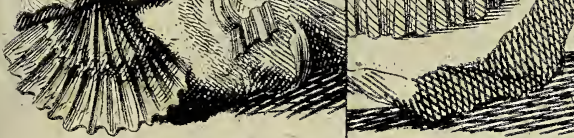




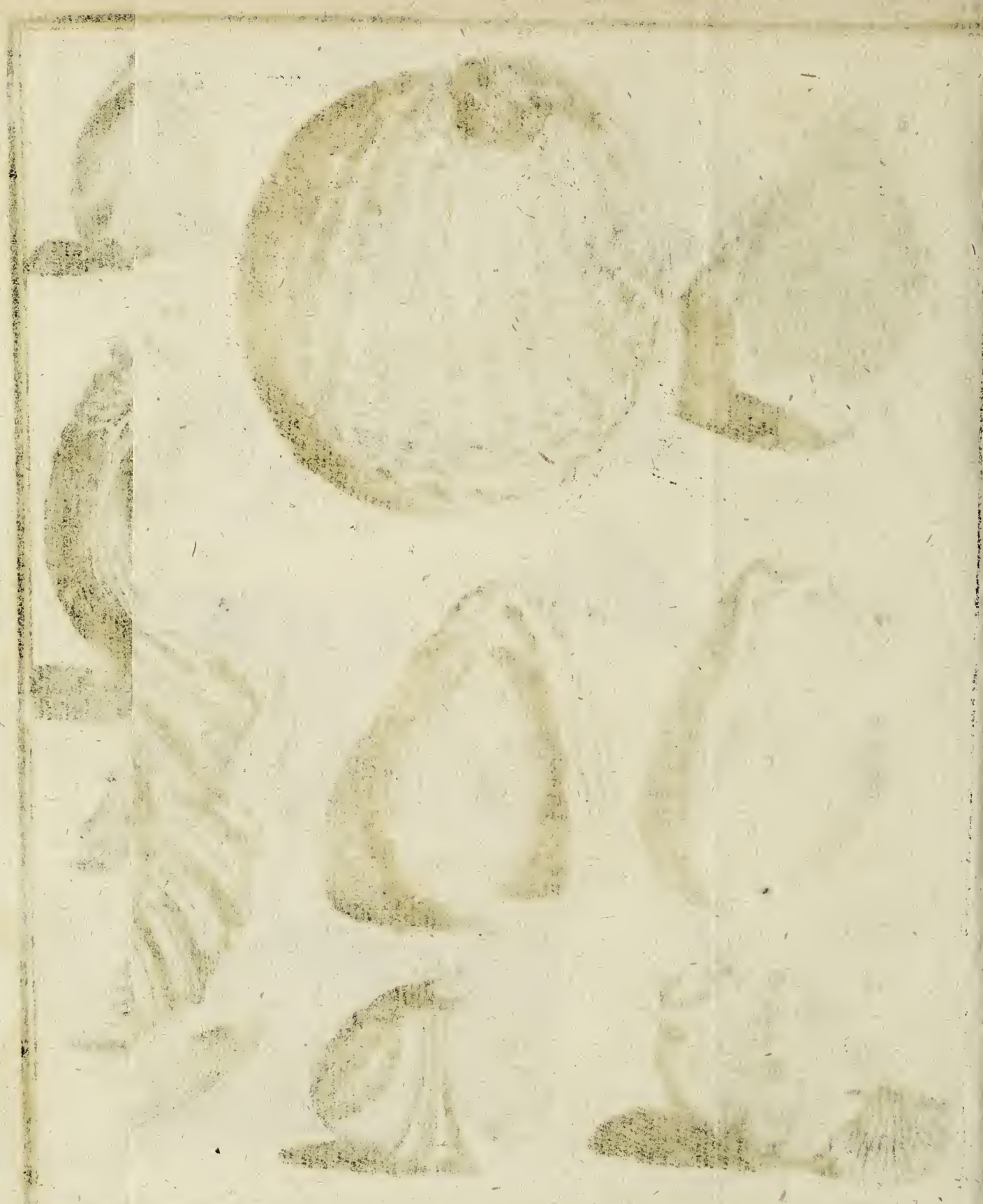

thes $4 \quad \ldots=4$ 


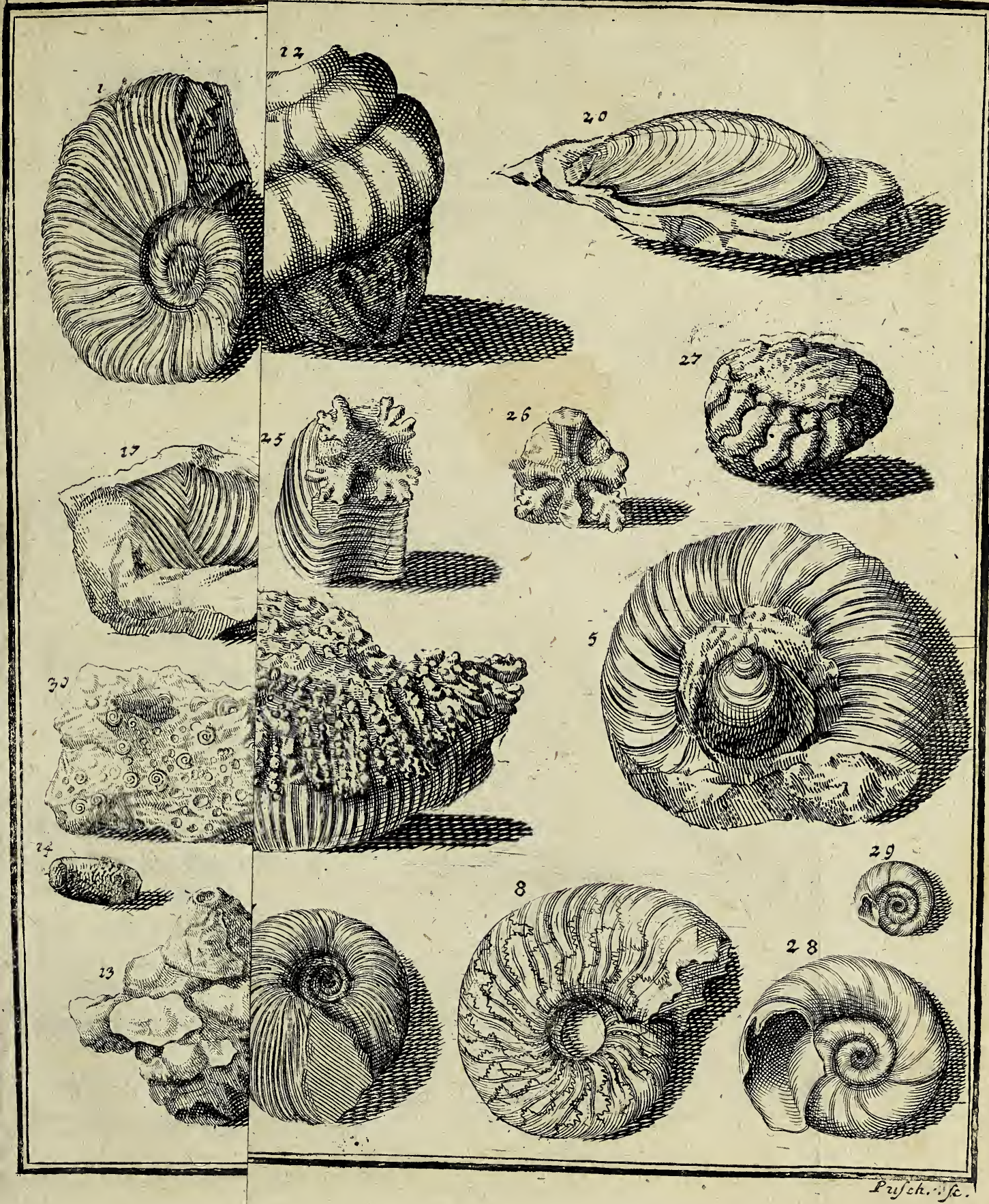





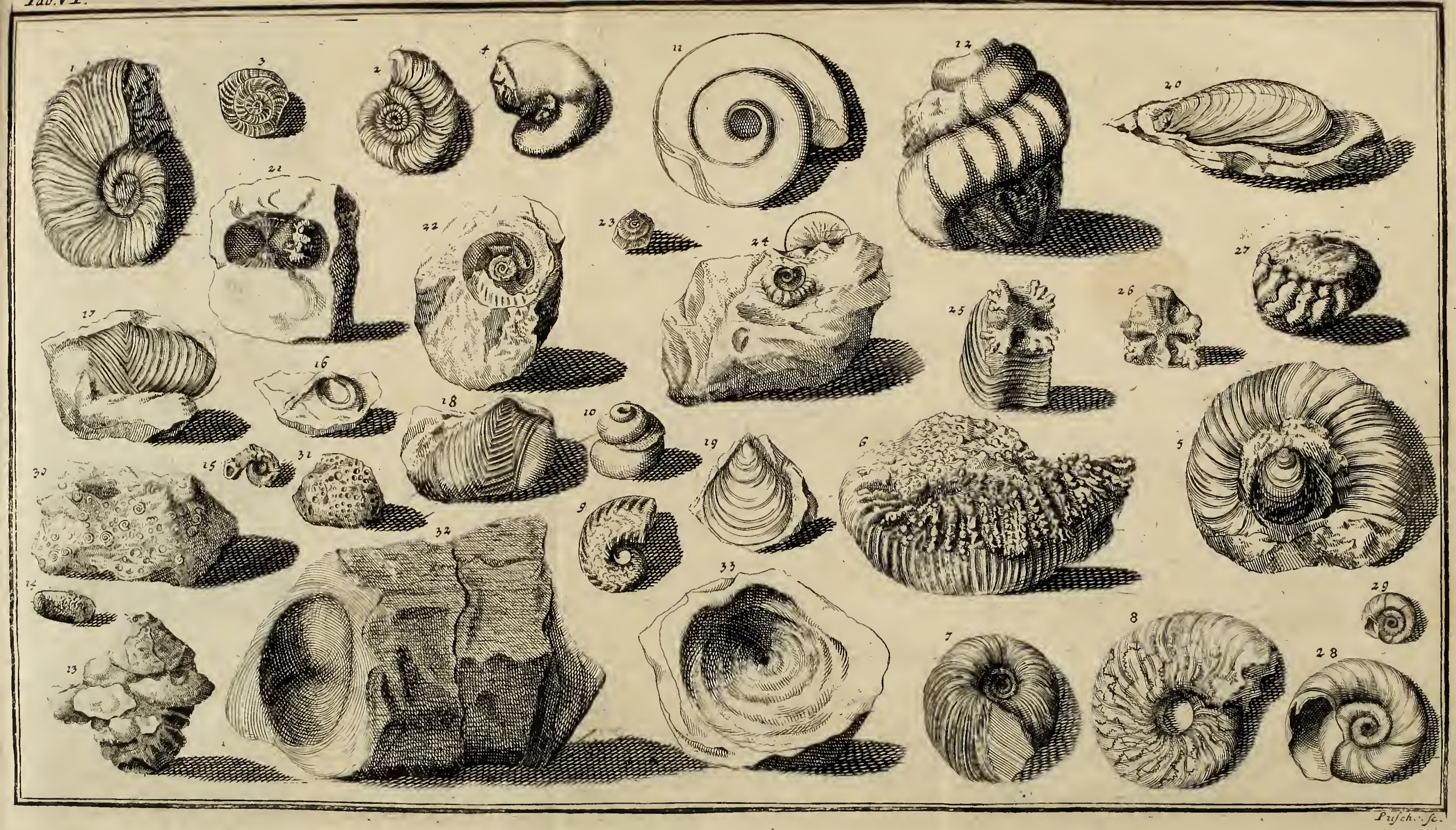




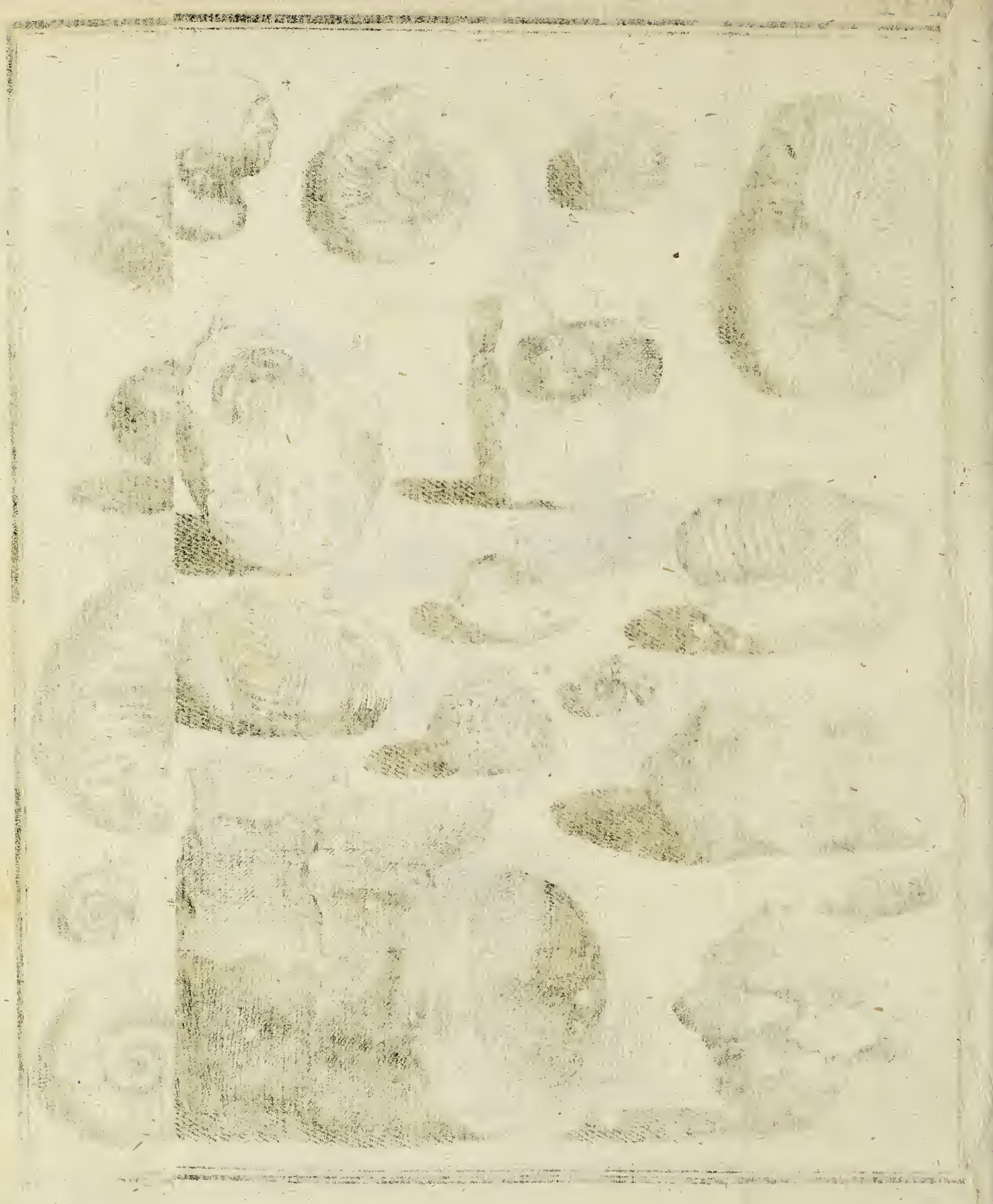




\section{将( 97. ) 然}

म46

\section{INDEX \\ Scriptorum aliorumque in hoc Opufculo nominatorum.}

A Gricola Georg.

A Aldrovandus vlyJes. Ammannus Paulus. Ariftoteles.
B.

Baierus Foh. Guil. F. Bartholinus Thomas. Bauhinus fob. Baufchius Foh. Laur. Behrens Georg. Henning. Boëtius de Boot Anjelm. Bonannus Philipp. Borrichius Olaus. Boyle Robert.

Bruno fac, Pancratius. C.

Caneparius Petrus Maria. Cardanus Hieron. Cardilucius fob. Hiskias. Carl Foh. Samuel. Cellarius Cbriffoph. Columna Fabius. Cordus Valer. Cupani Franc.

Diofcorides $P$ ed. Doldius Leonbardus.
E.

Encelius Chriftoph.

Erckerus Lazarus.

F.

Fabricius' Georgius.

Galenus.

Gefnerus Conr.

Geyerus Fob. Dar.

Grimm Herm. Nicol. H.

Hertod Foh. Ferdin.

Heffus Helias Eobanus.

Hoffmannus $C a \beta$.

- - Frider. Fil.

- - Mauritius.

Horatius.

2.

ImHoff Chriftoph. Frider.

Imperatus Ferrandus.

Jonftonus $\mathcal{F}$ h.

\section{K.}

Kentmannus Foh.

Kircherus Athanaf.

Kirchmajerus Georg. $C_{a} / \bar{p}$.

Konig Eman.

$$
\text { L. }
$$

Lachmund Frider. 
Langius Fo

- Car. Nicol.

Lehnerus Fob.

Libavius Andr.

Lifterus Martin.

Lochnerus Mich. Fridere

Luidius Eduardics.

Lydius Baltbafar.

Major Foh. Dan.

Marfilius Ant. Fel: Abbaso

Morellus Andr:

de Muralto Fob.

$O$.

Oldenburgerus Andr.

Olearius Adam.

Ovidius.

$P$.

Pillingius Matth. Zachar.

Plinius.

Rajus $\mathcal{F} 0$.

Reiskius fob.

Rhumelius Fob. Conr.

- Fob: Pharam.
Rofenbergius Fob. Carol.

S.

Scheuchzerus $\mathcal{F}_{a}$. $\mathcal{F} a c$.

Schoockius Martin.

Schrockius Lucas.

Schrœderus $70 h$.

Scriptura S.

Scultetus $70 h$.

Seidelius Bruno.

Genirled Fob Henr.

Stahlius Georg. Erneft.

Sturmius foh. brafto.

$$
\text { T. }
$$

Theophraftus.

Vegetius Flavius.

Velfchius Georg. Hieran.

Vitruvius.

\section{W.}

Wagenfeilius Chriftoph. Wagnerus Fob. Facob. Woodvvardus $F$. $h$. Wormius Olaus. W urff bainius Foh. Pard:

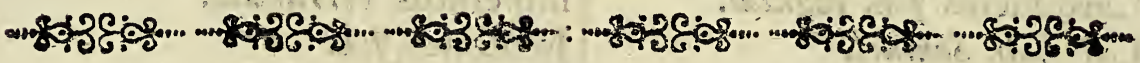

RERVM MEMORABILIVM

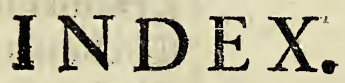

A. $\quad$ Etites.

A Biegnum lignum petrifica- Agaricus mineralis, vid. Lac LuAcidula dilutior. 51.52 nख. 


\section{整( 99. ) 䅫}

Agri Norici fitus. diverfitas. fertilitas.

Alabaftrum.

Alcyonium foffile.

Altdorffina terra bituminofa. $8 \mathrm{r}$. feq.

Alveolus lapis.

Aluminofum fal. Amethyftus occidentalis. Ammonis cornu. Amnes Norici. Auog: $D_{*}$ lapides. Ampelites terra. Amygdala lapidea. Anomii conchitx. Aphronitrum. 38 82. feq.
1 2. 3

\section{2.}

25

46 3erg = (5)tưn. Safur. Bituminofa Ligna \& carbones.
33. req.

94

94

Bivalvia teftacea folilia, eorum86.90 Bolus rubra.

72.73

28 Brontia. it 14

51) Bucardites.

2 r. feq. Calcarium fal aut nitrum. $8 \mathrm{I}$

faxum. $7 \mathrm{r}$

45 . Calceamenti fimulacrum in $12-$ 77. feq. pide.

8 I Carbo bitumineus $\&$ foffilis. $8 \mathrm{r}$. Aqux petrificantes feu lapidefcentes.

fubterranea.

Aquila lapis.

o Carpolithi Altdorffini. feq.

Io Ceraforum oficula lapidea. 45 Arenæ fpecies varix. Arenarium faxum.

32 Ceratites. 23. feq. Chalcanthina vena. $\quad 86$ 22. req. Chalybs Noricus. $9 \mathrm{I}$ Argentum Noricum. $\quad 94$ Chryfocolla nativa. 94 Argilla Norica ejusque fpecies. Cochlitax, eorumq; fpecies. 69

Afteriæ lapides. Aftroites.

Atramentarius lapis. B.

Balanus foffilis. 12. req. oim $4 \mathrm{I}$

Corruleum nativum: 94 Colonienfis terra. 85 41 Concha margaritiferafoffilis. 76 87 Conchæ anomix rugorx. $78.7 \%$ Conchitæ valvis regularibus. 73 . 72 Balneum ferinumNorimbergenfe.

\section{feq.}

Neagorenfe. 8 Conici lapides.

irrogularibus $7 \%$ feq. 


\section{秋( 100.) )}

Cordati Echinitx.

Corii antiqui fuperficiem exprimens lapis.

Cornu AmmonisEtymologia.59. Entrochus.

in nummis ex-

preffum. 59 varix fpecies. 60. feq. genuinum Plinii.

Cornuum Ammonis articuli. 6 I Atructura interna. 67

Cornu apicem referens lapis. 47 Crypta Baumanni.

Illfchvvangenfis.

Kauerheimenfis.

V.eldenfis.

Cryftallus.

\section{D.}

Dendrites.

Dens foffilis filiceusà

Dentis apri figura in lapide. 48

Diaphani lapides.

40

4.0

I. I

10

28

Diluvium univerfale caufa teftaceorum foffilium.

Ioldia terra.

Sonnerteil.

Dryites.

\section{E.}

67

85

34

$5 \mathrm{I}$
44

Ebenum foffile.
Echinitæ, feu echini folfiles, eorumq; varix fpecies。, 69. feq.

Filahbach rivus.

$F$.

eorumque di-

29.30

72

42

Faginum lignum petrificatum. 52

Ferrum Noricum.

Fibulares echinitæ.

91.92

Ficoides lapis.

Figuratorum lapidum divifio.

$7 \mathrm{r}$

46

29.30

Figurati lapides ex lufu naturæ.

$3 \mathrm{I}$

ex transmuta-

tione vegeta-

bilium \& animalium. 48 .

feq.

Fluores pellucidi \& colorati. 28 .

54 Folia arborum petrificata. 50

29
50
50 boff.

Fontium Norimberg. multitudo.

Fungites.

4. 46

G.

Gagates. 81 r. feq.

Galena Norica. $\quad 38.74 .85 .095$

8 r Geodes.

(W) laefopfi.

33

$92:$

Elatites.

Gyphites. 
Hxmatites niger.

Hammonites.

Hemisphæria lapidea.

Hyfterolithus feu hyfterapetra. 76 $I$.

Ichthyolithi Pappenheimenfes;

Eyftettenfes.

Ichthyofpondyli.

Incruftatio lapidofa.

Judaicus lapis.

Jupiter Ammon cornutus.

Lac Lunæ.

Lapidefcentes aq̧ux.

Lapis Aquilx.

Judaicus.

Lyncis.

Lapides ä"rop фoro.

$L_{0}$ cruftofi \& bituminofi.

Lapidum Noric. divifio.

Lapidicinæ Noricx.

Reber, Srr.s.

Ligna in lapides convertendi artificium.

petrificata:

Lignum foffile bituminofum.

Lufus natura quid?

Eyncis lapis

Marga faxatilis.

$$
M \text {. }
$$

Margaritifera concha forflisis 76

Marmor.

Mater perlarum foffilis.

Mathematicx figur: lapides.

Medulla faxorum.

Metalla Norica.

Minerx ferri varix.

Minera Martis Haffiaca.

56

55

50

44

59

16. feq.

32

34

eq.

s9

22

23

91

53

S!

$8 \mathrm{i}$

31

34

20

26

76.

31.

20

90. feq.

91.92
Modiolus ftellaris:

91 Moyfes cornutus.

67 Mulculites vulgaris.

42.43

59

74

32 Muftricula lapidea. 47

Mytilites feu mytuli tefta foffilis. 74 $N$.

$\&$

44 $92 /$ Plumbi nigri minera divites. 3.75 N 3

69

80

$8 \mathrm{r}$

Nummi Cornu Ammonis exprimentes.

$$
0_{0 .}
$$

59

Ochra Norica.

rubiginofa. 91

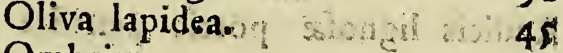

Ombrix. $\quad 7 \mathrm{I}$

Orichalcum Noricume 94

Offa foffilia.

Oftracite $\hat{s}_{\text {. }}$

53.54

77.

67

$P$.

Papilla muliebris lapide reprafentata 47

Pectinites, var, fpec.

77

Pećunculitx, var. Spec. $\quad 75.78$

Pegnefus amnis.

Penis puerilis imago in lapide. 47

$\begin{array}{ll}\text { Perficites a lapide exprefiar } & 47 \\ & \end{array}$

$\begin{array}{ll}\text { Petafunculus lapideus. } & 46 \\ & 47\end{array}$

Petrificantes aquia $\quad 9$

Phengites. $\quad 52$

Pholades. 75

Pifcium unanes in lanidibus, 56 vertebræ petrificatæ. is

Pifcina pragrandis, Der Dufsetteicf Inigio 
Prigites.

Porpites Luidii.

87 Sina ragdus occidentalis.

Porus lapis.

Prunum lapideum.

42 Sólen tes.

24 S-elzum, vid. Crypta.

Pfeud-Amethyftus.

Pfeudo-Topazius.

45 Spelunca, vid. Crypta.

28 S herre lapidex.

28 Sphragis Afteros.

Puteus falutaris Noribergx credi- tus.

Pysa lapidea.

Pyri truncus lapideus.

Pyrimachus.

Pyrites.

\section{2.}

Quercinum lignum petrificatum. $\rho^{\prime}$ $R$ ilusigention

Radicis lignofe portio petrificata.

Siogerftcin.

Rotundi lapides.

Kubrica dura, hæmatiti fimilis.' gs fabrilis.

Rugofx conch $x$ anomix foffiles. 78

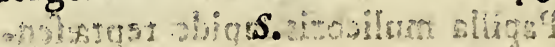
Sal aluminofum.

nitri. petrre.

Salina foffilia Norica so. feq.

Sandalio indutum pedem referens

lapis.

Saxum arenarium. 22. feq. calsarium.

Scaturigo mernorabilis.

Schifer: (Bruu.

Silices.

Siliqua piperis Indici fimilis lapis.

27

67

86. 90

86

80

47

7

24
Stagna fu terranea.

Stalact tes.

46. Stalagmites.

$\begin{array}{lll} & 2 \\ 27 & \text { Stellares lapides. } & \\ \text { Sulphurea foffilia Noric. } 80 . \text { feq. }\end{array}$

Tafconium Plinii.

Tellinites.

Terebratula.

Terra ampelites.

Colonienfis.

cruftofa \& miniata.

Doldia.

incea feu flava.

figillandd Nurica.

13

74.75

78.79

82. feq.

Vermes 72

4 Vertebre pifciuma petrificate.

94 Veriolum Noricum. 81.90

2- Unicornu folfie. 53

Topazius occidentalis. $\quad 28$

Tophus lanis. 24

Trochi foffiles. 69

Tubuli vermiculares foffiles $7 \mathbf{2}$

Turbinata foffilia. 68

$$
x \text {. }
$$

Univalvia teflácea petrificata corumque divifio.

$$
\text { F } I N \perp \text { s. }
$$

Errata quxdam corrigenda.

Pag. 6. lin. 2 s. leg. regni. p. 7 lin. penulr. leg. indigitatam. p. 8. 1.6. \& 12. leg. Neagorenf. p. 44. 1.5. \& 17. leg. Dendrit.

57.58 



